\title{
ALIA
}

\section{Antropologia di una comunità dell'entroterra siciliano}

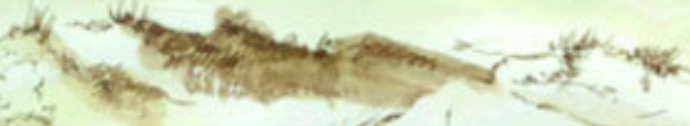

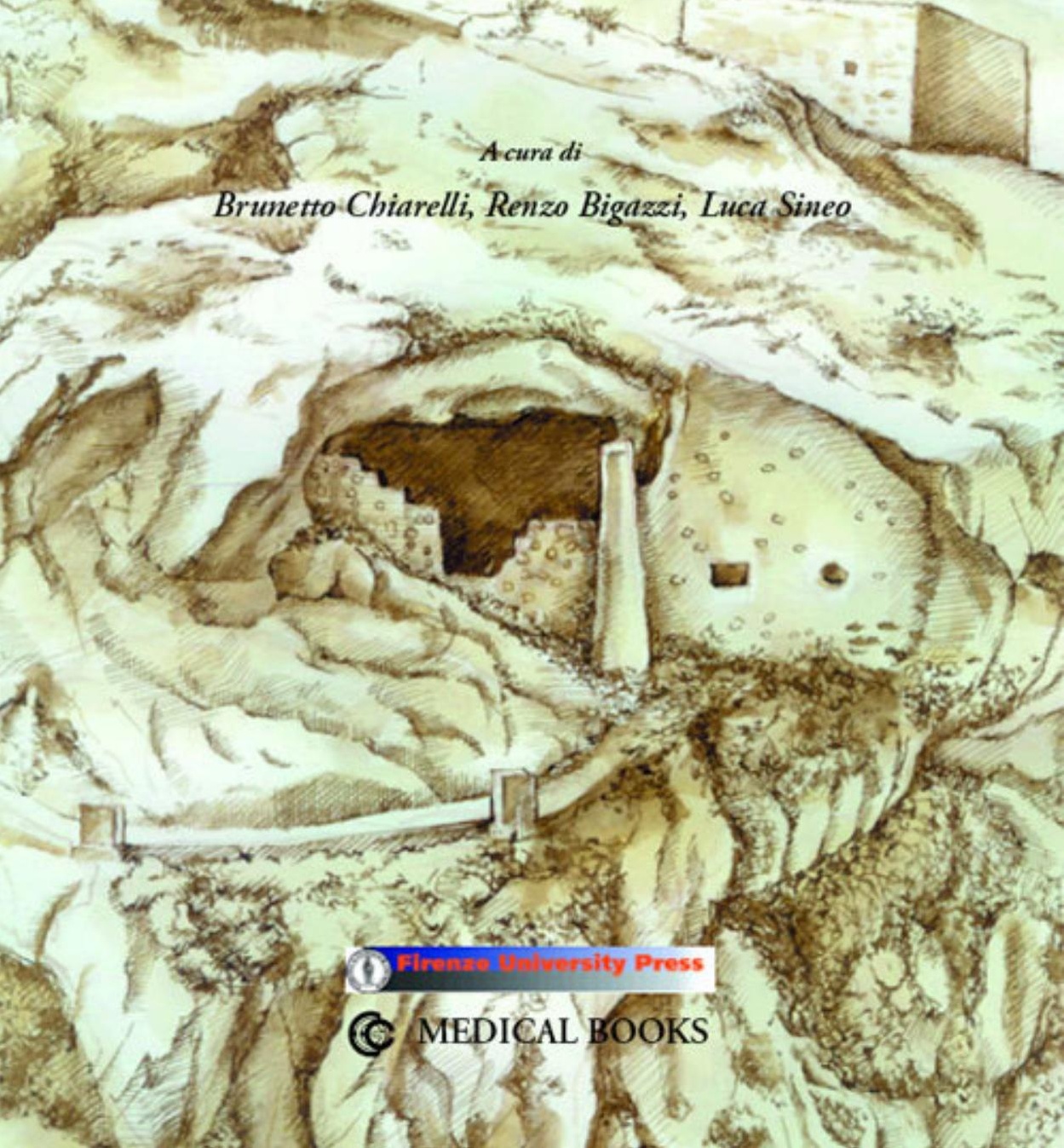




\section{ALIA}

\section{Antropologia di una comunità dell'entroterra siciliano}

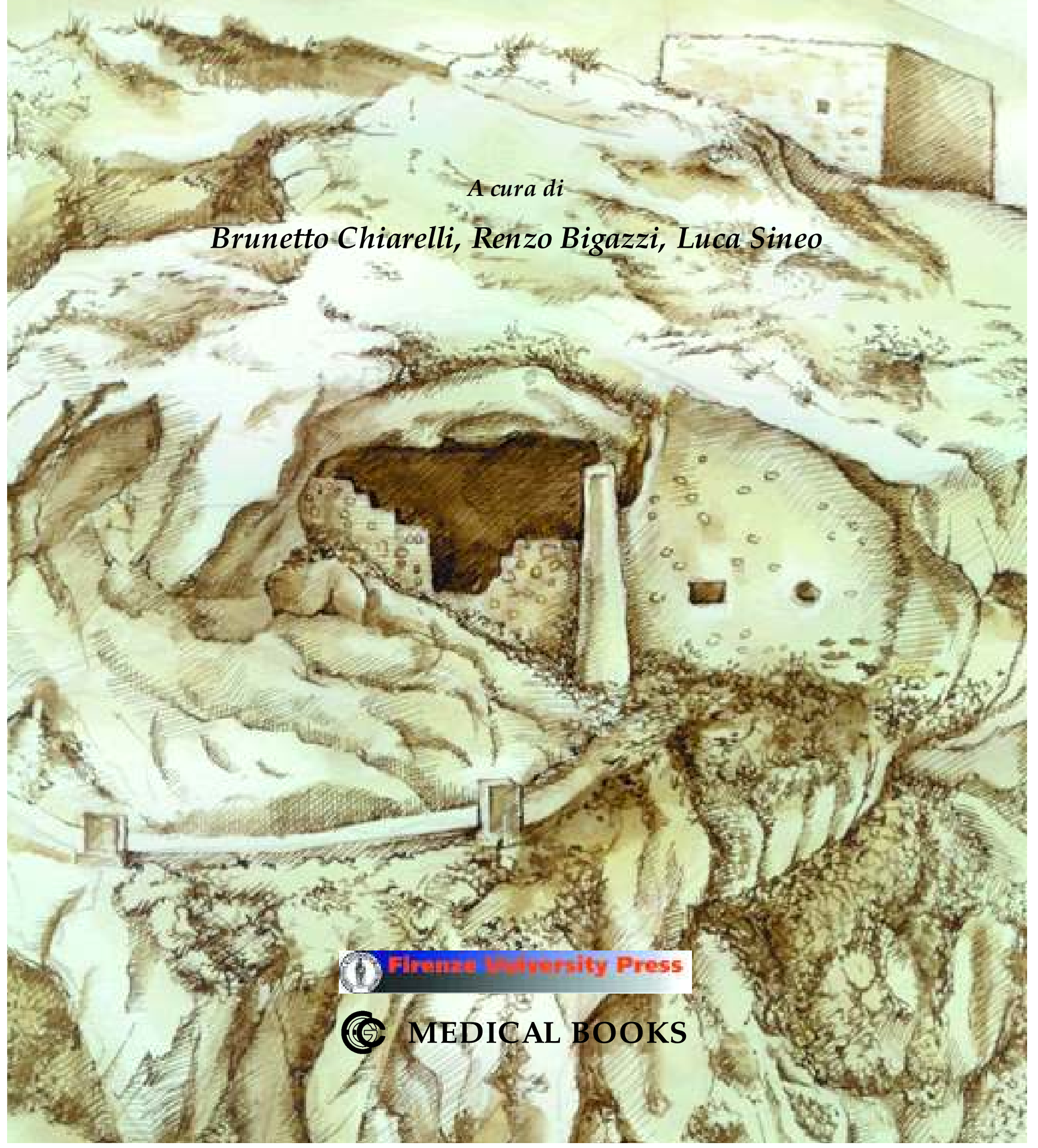





\section{ALIA \\ Antropologia di una comunità dell'entroterra siciliano}

A cura di

Brunetto Chiarelli, Renzo Bigazzi, Luca Sineo 
Alia : Antropologia di una comunità dell'entroterra siciliano / a cura di Brunetto Chiarelli, Renzo Bigazzi, Luca Sineo. - Firenze : Firenze university press ; Palermo : Medical Books, 2002. - 95 p. : ill. ; 28 cm.

ISBN 88-8453-036-9

ISBN 88-8034-034-4

573.6 (ed. 20.)

1 Antropometria - Alia 2 Alia - Biodemografia

I Titolo II Chiarelli, Brunetto

L'edizione elettronica di questa pubblicazione è disponibile su: http://epress.unifi.it

Il volume è stato pubblicato con il contributo del Comune di Alia.

Precedentemente pubblicato a stampa da Medical Books, 2002

(C) 2002 by Firenze University Press

Firenze University Press

Borgo Albizi, 28

50122 Firenze

Italy

http://e-press.unifi.it

email: e-press@unifi.it

Printed in Italy 


\section{Indice}

Presentazione, 7

Brunetto Chiarelli

Capitolo 1

Alia: storia di un paese, 11

Guccione I.

Capitolo 2

Le vittime dell'epidemia di colera del 1837: note di biologia scheletrica, 15

Bigazzi R., Crisafulli R., Lazzerini L., Tartarelli G.

Capitolo 3

Studio biodemografico della popolazione di Alia nel XIX secolo, 21

De Iasio S., Guccione I., Tulumello S., Bigazzi R.

Capitolo 4

Analisi demografica delle crisi di mortalità: l'epidemia di colera del 1837, 37

Bigazzi R., Torres Joerges X., Tulumello S., De Iasio S.

Capitolo 5

Alia: alcune considerazioni di antropologia molecolare, 43

Vona G., Ghiani M.E., Vacca L., Mameli G.E., Succa V., Calò C.M.

Capitolo 6

Studio delle immunoglobuline

e delle emoglobine nella popolazione di Alia, 51

Cerutti Giorza N., Rabino Massa E.

Capitolo 7

Il colera e la fibrosi cistica:

cosa accomuna due patologie così diverse?, 63

Sineo L.

Capitolo 8

Analisi genetica di popolazioni storiche:

il caso di epidemia colerica ad Alia, 67

Bramanti B. 
Capitolo 9

Il museo etnoantropologico di Alia, 73

Cedrini $R$.

Capitolo 10

"Le cose importanti della mia età". Un esperimento fotografico per la popolazione giovanile del territorio di Alia, 79

Chiarelli C., Tartarelli G.

Docenti dei Campi Scuola di Alia (1996-2000), 93

Eventi correlati con le ricerche antropologiche in corso ad Alia, 95 


\section{Presentazione}

Sono trascorsi più di sei anni da quando il Sindaco di Alia, Gaetano D'Andrea, si mise in contatto con il Dipartimento di Biologia di Palermo chiedendo la disponibilità di un esperto per un sopralluogo alla "grotta del Cimitero Vecchio", situata appena fuori del paese.

Nella primavera del 1995, durante i lavori di risanamento del muro che ne chiudeva l'ingresso, erano difatti tornati alla luce i resti scheletrici delle vittime dell'epidemia di colera del 1837, qui frettolosamente inumati.

Tramite il compianto professor Goffredo Cognetti fui personalmente interessato della faccenda, in quanto allora docente incaricato di Antropologia presso la Facoltà di Scienze Matematiche, Fisiche e Naturali di Palermo. Inviai pertanto un gruppo di miei giovani collaboratori dell'Istituto di Antropologia di Firenze per un primo studio: Giuseppe D'Amore, Renzo Bigazzi, Giandonato Tartarelli, Luca Lazzerini, Rachel Crisafulli e Francesca Iandelli, affiancati in seguito da Antonio Valletta, Sara Tulumello, Xaviera Torres, Iole Guccione, Angelo Piazza, Giacoma Brancato, Barbara Bramanti, Myrta Vianello.

La prima indagine portata a termine fu quella di Rachel Crisafulli, una giovane italo-americana che frequentava in quel periodo il Master di Antropologia e Archeologia per la Regione Mediterranea la quale produsse un elaborato sotto forma di tesi, ora diligentemente custodito nella Biblioteca Comunale di Alia.

Da quel momento il progetto Alia si è sviluppato senza sosta, analizzando l'evoluzione biologica della popolazione aliese mediante le metodologie di studio tipiche di differenti discipline antropologiche quali la biologia scheletrica, la genetica di popolazione, la biodemografia. Assieme a studiosi dell'Università di Firenze hanno lavorato e stanno tuttora compiendo le loro ricerche esponenti delle Università di Palermo, Parma, Cagliari, Torino e Göttingen.

Le quattro edizioni del Campo Scuola di Alia, la mostra "Antropologia ad Alia", la realizzazione del Museo Antropologico e di quello Etno-Antropologico, il riordino dell'Archivio Storico, il XII Congresso dell'Associazione Antropologica Italiana, i cicli di conferenze e un concorso fotografico, sono solo alcuni degli eventi che hanno visto Alia al centro dell'interesse antropologico nazionale ed internazionale. Momenti in cui il paese è stato felicemente "invaso" da giovani studenti ed affermati ricercatori, italiani e stranieri, in cui tra la popolazione e gli ospiti si è creato un legame umano che spero rimanga a lungo impresso nel ricordo di tutti.

A tal proposito vorrei esprimere un apprezzamento particolare e personale a Tanino D'Andrea, artefice dell'attuale trasformazione di Alia. Da piccolo centro agricolo delle Madonie con forte tendenza emigratoria negli anni del suo mandato, Alia è diventata "città giardino". Anche il viandante più distratto che transita sull'antica strada che da Palermo conduce a Catania, passando per il bivio che 
si inerpica verso Alia se ne rende conto. L'accesso alla strada è curato con piante da giardino che destano interesse anche al turista più sbadato. Cura di insiemi e di particolari che si apprezza ancor più all'interno dell'abitato, in cui il contrasto architettonico fra i palazzi residenziali pre-bellici e le costruzioni abitative postbelliche viene smorzato da angoli con giardini pubblici e piccoli monumenti. Una tendenza all'ordine e alla cura non sempre presenti in altri contesti urbani siciliani o anche nazionali. In questi anni Alia si è anche dotata di una piscina coperta e di un eliporto, attrezzature di tutto rispetto per una cittadina nelle Madonie a $70 \mathrm{~km}$ da Palermo.

La recente gestione comunale ha inoltre incentivato il turismo, con la creazione di case-albergo e l'attivazione di agriturismi, con la valorizzazione dell'artigianato (i meravigliosi ricami) e dei prodotti locali. Importante è poi l'attività culturale promossa ad Alia e l'incentivazione del turismo congressuale, il tutto corredato da un'attività editoriale di tutto rispetto, frutto anche della passata esperienza giornalistica di Tanino D'Andrea. Alcuni dei titoli pubblicati con gli auspici del Municipio di Alia sono il volume di Liborio Guccione "Giorni vissuti come fossero anni", "Gioie e lacrime: il Brigantaggio in Sicilia" di Lucio Drago Salemi, "Con la patria nel cuore" di Matteo Teresi; letture queste che permettono di addentrarsi nell'animo degli Aliesi e nella profondità dei sentimenti del popolo siciliano. Questa, unitamente a pubblicazioni sulla storia di Alia e dei suoi resti archeologici, nonché alla promozione di concorsi letterari, hanno fatto di Alia un centro di attrazione culturale di rilievo a livello regionale e internazionale. L'amministazione comunale non ha infatti trascurato gli Aliesi emigrati in paesi diversi (Stati Uniti e Nord Europa); una fitta rete di contatti lega Alia ai suoi figli migrati per necessità in terre lontane.

Nel chiudere questa presentazione voglio sottolineare la collaborazione, oltre che dell'amministrazione tutta e di Don Antonino Di Sclafani, dei signori Gioia di Fontanamurata, della contessa Stella Maurigi e dei signori Rinchiuso dell'Agriturismo Villa Dafne, che con il loro gentile sostegno hanno facilitato molte volte il nostro stare ad Alia e ai quali va la nostra gratitudine. Desidero inoltre ringraziare Daniela Carrillo per il fattivo contributo alla revisione di questo volume. Niente di questo e di altre cose antropologiche sarebbe stato possibile fare senza l'acuto, accorto e silenzioso aiuto del compianto collega Goffredo Cognetti e all'entusiasmo e alla disponibilità di Nino Cardella. Alla memoria di entrambi, con il consenso dei contributori, dedico questo volume, la cui realizzazione vuole es sere principalmente un ringraziamento a tutta la gente di Alia da parte di coloro che per più tempo hanno avuto la fortuna di lavorarvi accanto.

BRUNETTO CHIARELLI 


\author{
Dedica di B. Chiarelli \\ a Tanino D'Andrea \\ e alla popolazione di Alia
}

Un sindaco come Tanino D'Andrea, Alia avrebbe dovuto inventarlo se non fosse esistito realmente! Da piccolo centro agricolo delle Madonie con forte tendenza emi gratoria negli anni del suo mandato, Alia è divenuta "città giardino". Anche il vian dante più distratto che transita sull'antica strada che da Palermo conduce a Catania, transitando per il bivio che si inerpica verso Alia se ne rende conto. L'accesso alla stra da è curato con piante da giardino che destano interesse anche al turista in transito. Cura di insiemi e di particolari che si apprezza ancor più addentrandosi all'interno dell'abitato il cui contrasto architettonico fra i palazzi residenziali pre-bellici e le co struzioni abitative post-belliche viene smorzato da angoli con giardini pubblici e piccoli monumenti. Una tendenza all'ordine e alla cura non sempre presenti in altri contesti urbani siciliani o anche nazionali. In questi anni Alia si è anche dotata di una piscina coperta e di un eliporto, attrezzature di tutto rispetto per una cittadina a $70 \mathrm{~km}$ da Palermo.

Ma la gestione di Tanino D'Andrea non si è limitata alla valorizzazione abi tativa della città con l'incentivazione di case-albergo, dell'artigianato locale, con la valorizzazione dei prodotti locali e l'attivazione di agriturismi; importante è l'atti vità culturale e l'incentivazione del turismo congressuale, il tutto corredato da un'at tività di stimolazione editoriale di tutto rispetto, frutto anche della sua passata espe rienza giornalistica. Alcuni dei titoli pubblicati con gli auspici del Municipio di Alia sono il volume di Liborio Guccione "Giorni vissuti come fossero anni", "Gioie e lacrime: il Brigantaggio in Sicilia" di Lucio Drago Salemi, "Con la patria nel cuo re" di Matteo Teresi; letture queste che permettono di addentrarsi nell'animo degli Aliesi e nella profondità dei sentimenti del popolo siciliano. Questa, unitamente a pubblicazioni sulla storia di Alia e dei suoi resti archeologici, nonché alla promo zione di concorsi letterari, hanno fatto di Alia un centro di attrazione culturale di rilievo a livello regionale e internazionale. Tanino D'Andrea infatti non ha trascu rato gli Aliesi emigrati in paesi diversi (Stati Uniti e Nord Europa); una fitta rete di contatti lega Alia ai suoi figli migrati per necessità in terre lontane; e questo è quanto dovuto a Tanino D'Andrea. 



\title{
Capitolo 1
}

\section{ALIA: STORIA DI UN PAESE}

\author{
GuCCIONE I. \\ Laboratori di Antropologia, Dip. Biologia Animale e Genetica, \\ Università degli studi di Firenze
}

\begin{abstract}
Alia è un paese rurale di circa 4000 abitanti, situato sulle pendici occidentali delle Madonie a circa $700 \mathrm{~m}$ sul livello del mare. La sua superficie, che ha un'estensione di 45,67 Kmq, confina con i comuni di Roccapalumba, Montemaggiore, Valledolmo e Castronovo. L'insediamento viene citato sin dal 117 d.C. ma comincia ad essumere dimensioni di abitato solo alla fine del 1200. Nel 1366 il feudo divenne proprietà di Rainaldo Crispo. Tornò ad essere considerato come casale all'inizio del secolo XVI, sempre sotto il protettorato della famiglia Crispo. Solo nel 1600 , si consolidò un vero e proprio abitato.
\end{abstract}

A questo periodo si fanno risalire le origini socio-economiche del paese quando Pietro Celestri, barone e marchese di Santa Croce, figlio di Giovan Battista XIII, supremo reggente del Consiglio d'Italia a Madrid, ebbe in dote il feudo di Lalia perché sposò la "nobile donzella" Francesca Cifuentes Imbarbara. La famiglia Imbarbara, molto influente anche nel resto della Sicilia, lasciò un segno sulle terre di Lalia che, per tutta una serie di matrimoni e di discendenze, restarono sotto la loro amministrazione per parecchi anni).

Nel 1617 donna Francesca, rimasta vedova, prese l'investitura del feudo e, nel 1623, a cinque anni dalla morte del marito, ottenne il regio permesso (dal Re Filippo III) di poter fabbricare il paese che fu costruito e popolato dai marchesi di Santa Croce.

Il paese, per circa due mesi, rimase sotto la giurisdizione di baroni e marchesi che, essendo titolari del feudo in cui furono costruite le prime case, erano riconosciuti "signori" del borgo e, in quanto tali, esercitavano il loro potere sugli abitanti e sui forestieri che vi si trovassero di passaggio.

Il comune prese il nome di Feudo di Lalia, ma presto cominciò ad imporsi nell'uso corrente la denominazione di "Terra dell'Alia" per indicare in maniera specifica il centro abitato. In seguito, tale denominazione prevalse in maniera definitiva finchè rimase la forma più semplice di "Alia" $\mathrm{o}$ "Comune di Alia". La locuzione originaria ha avuto e continua ad avere maggiore resistenza nella parlata dialettale del luogo e dei centri vicini.

Lalia sicuramente non nacque sotto buoni auspici: la peste si era diffusa da Tunisi a Trapani attraverso un veliero con a bordo alcuni contagiati, si era propagata nella Val di Mazara e aveva cominciato a colpire Palermo. Nell'estate del 1624 la situazione era estremamente grave. L'epidemia si diffuse subito a Misilmeri e così via fino a raggiungere i paesi intorno al feudo di Lalia. Gradualmente la peste si esaurì e, solo nel 1627, vennero chiusi ufficialmente i lazzaretti.

Nei primi decenni, dunque, la situazione economica non fu molto florida, pur tuttavia non esistevano casi di estrema miseria. I fondatori, allo scopo di incrementare la colonizzazione, fecero di tutto per mettere gli immigrati nelle condizioni di sfamarsi e di conservare qualcosa per affrontare eventuali periodi difficili.

L'economia di Alia era prevalentemente agricola, venivano coltivati grano, mandorli e viti, ma anche cereali e legumi; estesi appezzamenti di terreni dei vari latifondi vicini venivano utilizzati a pascolo. L'allevamento portò una discreta produzione casearia malgrado non vi fossero dei veri e propri caseifici. Oltre all'allevamento dei bovini, equini ed ovini, era da tempo conosciuta, anche se in proporzioni limitate, l'apicoltura. Infatti nelle campagne si trovano molti piccoli alveari, con fiscelli preadamitici: uno splendido alveare fu impiantato, un tempo, dal cav. Guccione Gioacchino in Porcheria, una delle più belle tenute della sua vistosa proprietà terriera.

Il commercio, basato dunque sul grano e soprattutto sul formaggio, era controllato dai grossi proprietari, che ne decidevano la destinazione e $\mathrm{i}$ 
prezzi; il resto della popolazione viveva in condizioni di miseria.

La religione ebbe un ruolo fondamentale nella formazione di una prima coscienza comunitaria tra gli originari abitanti. Un aspetto che, durante $i$ secoli XVII e XVIII, risultò rilevante per la nascente vita comunale di Alia, fu che i sacerdoti, oltre al loro principale compito spirituale, svolgevano un vero e proprio servizio burocratico e sociale a favore del borgo: le registrazioni di battesimi, matrimoni, morti.

Mentre in Francia, dopo la Rivoluzione del 1789 , si assisteva allo spezzettamento delle proprietà nobiliari ed ecclesiastiche con il declino del regime feudale e all'incremento della piccola proprietà contadina, in Sicilia tutto rimaneva immutato. Le sorti della Sicilia erano sempre nelle mani dell'aristocrazia terriera, ossia dei baroni e dei marchesi, i quali possedevano immense distese di terreno e godevano di ogni tipo di privilegio.

La terra dell'Alia conobbe inoltre il tipico fenomeno dei "gabellotti" che fu comune in Sicilia a quasi tutti i paesi feudali. Negli ultimi tempi, anche i baroni del luogo preferirono la vita di città a quella monotona e disagiata dei latifondi.

Le terre vennero, quindi, affittate mediante gabelle ad imprenditori che, subaffittandole a contadini, ricavarono grossi guadagni: ai baroni davano poco e dai contadini pretendevano molto. Questi ultimi vivevano miseramente guadagnando, con grossi sacrifici, quel minimo indispensabile per sopravvivere. Naturalmente il canone era fisso e non in rapporto alla produzione dell'annata; per cui, spesso, erano costretti a chiedere dei prestiti ad usurai o agli stessi gabellotti.

Il passaggio da terra dell' Alia a comune di Alia e, cioè, da paese feudale a paese demaniale, non cambiò la situazione per la maggior parte degli aliesi.

Coloro che occupavano la posizione sociale ed economica più agiata presero il posto della nobiltà controllando l'economia del paese: era il cosiddetto ceto dei "borgesi" che rappresentava la classe media del paese; accanto a questi ultimi cominciavano ad emergere gli artigiani, che diventarono sempre più numerosi. In aumento erano anche $i$ "letterati" (Guccione E., 1991), anche se il numero rimase sempre ristretto, ai quali si possono associare i preti che appartenevano anch'essi alle classi più abbienti, così come i "galantuomini" ("notabili" ed impiegati municipali).

I contadini, che costituivano la maggioranza della popolazione nella classe sociale inferiore, era- no malnutriti e denutriti e vivevano in piccoli terreni in subaffitto.

Al di sotto di tutti esisteva un ceto senza nome che veniva chiamato "dei miserabili"; praticavano i lavori più umili, vivevano in condizioni igienico - sanitarie pessime e ciò li esponeva spesso a notevoli rischi di infezione.

Anche in questo estremo lembo d'Italia, dove non giungevano emissari rivoluzionari, per la distanza della capitale dell'isola e per le vie allora inaccessibili e pericolose, covava l'odio contro la dominazione borbonica e si cospirava segretamente per abbatterla.

"L'insurrezione della plebe, ispirata alle idee dell'89, era intesa come guerra di sterminio contro i cosidetti "galantuomini", perciò, nei piccoli comuni, come Alia, degenerò in rivolta contro le persone" (Cardinale C.L., 1995). Nel 1820 fu assalita la casa del giudice distrettuale e, con un incendio, venne distrutto quasi totalmente l'archivio comunale cancellando così una preziosa documentazione sul passato della comunità; nel 1837, Alia fu colpita dall'epidemia di "cholera morbus" (che, per la provenienza venne chiamato "colera asiatico") provocando centinaia di vittime. Da luglio a novembre si contarono più di trecento morti (Registro defunti 1837) e alcune famiglie si estinsero completamente.

Alia, come quasi tutti i comuni della Sicilia, non era in grado di affrontare adeguatamente un'epidemia di quella gravità. Non esistevano fognature, rete idrica, strade e quegli accorgimenti necessari per bloccare o ridurre le conseguenze dell'epidemia. Per l'occasione, fu utilizzata come fossa comune una grotta naturale che gli aliesi, in rispetto ai defunti, denominarono "camposanto" e che, in seguito, per distinguerlo dal cimitero in contrada "Santuzzi", lo chiamarono e continuano a chiamarlo "camposanto vecchio"; "mentre il colera imperversava tremendamente, mietendo centinaia di vittime, con la scusa di inveire contro coloro che l'ignorante plebaglia credeva autori del fatale morbo asiatico, armata questa di pietre, di randelli e di fucili, fece scempio di parecchi innocui concittadini e funzionari dello Stato" (Cardinale C.L., 1995).

I moti del 1848, scoppiati a Palermo il 12 gennaio, contagiarono molti comuni della Sicilia e anche il popolo aliese insorse bruciando le carte della polizia e della giustizia e mettendo in fuga i pochi agenti borbonici che si trovavano in paese.

"Alla vigilia del passaggio dai Borboni ai Savoia avvenuto, come è noto, dopo la discesa dei Mille*, 
con il plebiscito del 21 Ottobre 1860, tramite il quale i sudditi del Regno delle due Sicilie espressero la volontà di annessione al Regno di Vittorio Emanuele, le condizioni di Alia erano quelle di un tipico paese rurale medioevale, in cui mancavano ancora $\mathrm{i}$ necessari servizi pubblici quali le fognature, la conduttura dell'acqua potabile, strade interne accessibili, vie esterne di collegamento con le arterie principali, scuole pubbliche idonee a dare una cultura o un'istruzione professionale ai molti giovani, un collegio per le ragazze" (Guccione E., 1991). Tale situazione si protrasse per buona parte del XX secolo.

Tra gli antichi casali di Alia, riveste notevole importanza il Casale della Gurfa dove sono situate le omonime grotte. A circa $5 \mathrm{Km}$ dal centro abitato ci si trova dinanzi ad un vero e proprio monumento di architettura rupestre, le Grotte della Gurfa, nome che in arabo significa "camera sotterranea scavata nella roccia". Sia per la loro posizione strategica che per la fertilità e abbondanza di sorgenti d'acqua delle zone circostanti, sono state di grande attrattiva in tutti i tempi. Nei loro pres si si sono rinvenute monete del periodo romano, bizantino e spagnolo. Non sembrano esservici tracce di iscrizioni, né all'esterno né all'interno. I vecchi narrano che un tempo si vedevano sul frontespizio dei geroglifici indecifrabili dei quali oggi non rimane più nulla. In realtà, uno sguardo più approfondito rivela la presenza di alcuni segni illegibili, corrosi dalle piogge. Essi si trovano in corrispondenza delle aperture dall'esterno verso la scuderia e verso il tempio; al di sotto di questi segni si legge la seguente dicitura: 1767 usque 1775 e poi in un altro punto il numero 1740 , nelle quali epoche si crede siano stati costruiti il caseggiato e la chiesetta tra le cui macerie è stato trovato un fonte in marmo per l'acqua benedetta datato 1741.

"Le monete di conio romano, greco e dei tempi di Carlo V (1557) e di Filippo II (1568) entrambi "Rex Siciliae", i diversi oggetti come il piatto, l'anello, la scimitarra, il cimelio e i sepolcreti che si sono rinvenuti e che continuano a trovarsi in quei dintorni e che, a quanto pare risalgono ad epoche diverse e lontane le une dalle altre, non danno alcuna indicazione precisa sull'origine dell'antichità di tali grotte" (Cardinale C.L., 1995).

\footnotetext{
* Garibaldi, accompagnato da circa mille uomini, sbarcò a Marsala l'11 maggio 1860 con l'intento di annettere la Sicilia all'Italia. Il 2 agosto 1862 giungeva ad Alia che, esultante, lo accoglieva festosamente. Pernottò in casa di Don Matteo Guccione e infatti sulla facciata del palazzo di quest'ultimo, in ricordo di tale avvenimento, venne apposta una lapide (Cardinale C.L., 1995).
}

Lo storico castronovese L. Tirrito (1873) crede che risalgano all'epoca delle abitazioni trogloditiche e che poi, dopo il decreto di espulsione generale degli Arabi dalla Sicilia, fossero state occupate dai Saraceni, i quali ne fecero il centro del casale della Gurfa.

"Altri credono, partendo dal concetto che i trogloditi (essendo popolo primitivo e perciò mancante delle più elementari cognizioni di architettura e avendo l'abitudine di scavare i sotterranei per sfuggire agli ardori del clima) non potevano essere assolutamente capaci ed avere tempo di costruire un'abitazione come quella, che è un mirabile monumento di architettura, che le grotte in discorso rimontino a sei settecento anni prima di Cristo, quando i Raseni soggiogarono una parte dei Pelasgi e costrinsero gli altri a ritirarsi nella Trinacria, dove cercarono di nascondersi e di fortificarsi" (Cardinale C.L., 1995). Durante il Convegno di studi storico - archeologici sulle Grotte della Gurfa tenutosi nel dicembre del 1995 ad Alia, è stata comunicata la scoperta di una iscrizione fenicia su una delle loro pareti. Nonostante tutto, purtroppo, non si sa con certezza quale sia la loro origine e quale sia stata la loro funzione e, a causa degli inevitabili effetti del tempo, non è possibile riconoscere i "segni" del passato.

La presenza di numerose documentazioni, il ritrovamento in una grotta naturale di reperti ossei di oltre trecento individui, vittime dell'epidemia di colera del 1837, la presenza di un archivio di stato civile completo e di uno parrocchiale, ha dato il via ad una serie di ricerche nel campo delle Scienze Antropologiche.

Il progetto è nato nell'estate del 1996 e coinvolge le Università di Firenze, Palermo e Parma. Al primo camposcuola di Antropologia per lo studio dei reperti ossei ne hanno fatto seguito altri tre finalizzati ad uno studio di Genetica di popolazioni, Biologia Scheletrica e Biodemografia sulla popolazione aliese.

\section{Bibliografia}

AA.VV.,1995. La Gurfa e il Mediterraneo. Comune di Alia. Cardinale C.L., 1995. Alia, monografia in: Dizionario illustrato dei Comuni Siciliani a cura di F. Nicotra. Comune di Alia, Palermo.

Guccione E., 1991. Storia di Alia 1615-1860. Salvatore Sciascia, Palermo.

Tirrito L., 1873. Sulla città e comarca di Castronovo di Sicilia, ricerche storiche, topografiche, statistiche ed economiche. Tipografia Priulla, Palermo. 



\title{
LE VITTIME DELL'EPIDEMIA DI COLERA DEL 1837: NOTE DI BIOLOGIA SCHELETRICA
}

\author{
BigazZi R., CRisafulli R., LAZZERINI L., TARTARElli G. \\ Laboratori di Antropologia. Dipartimento di Biologia Animale e Genetica \\ Università degli Studi di Firenze \\ E-mail: rbigazzi@unifi.it
}

Nella primavera del 1995, in seguito ai lavori di consolidamento del muro eretto a chiusura di un riparo sotto roccia poco distante dal centro abitato di Alia - conosciuto come Camposanto Vecchio (fig. 1) - è tornata completamente alla luce un'ingente quantità di ossa umane (fig. 2).

Lo studio di documenti storico-archivistici reperiti in loco ha permesso di collegare i resti scheletrici ai defunti dell'epidemia di colera che - dopo aver investito gran parte del continente europeo a partire dal 1835 - raggiunse anche la Sicilia e, per quanto ci attiene, l'abitato di Alia nel luglio del 1837. Uno dei provvedimenti emanati dalle autorità per limitare il pericolo del contagio fu infatti di provvedere alla sepoltura dei morti - invero gettati in una sorta di fossa comune - in una zona abbastanza lontana e insieme facilmente raggiungibile dal paese.

Il lungo ricovero in un ambiente con notevoli infiltrazioni d'acqua, la frequentazione sporadica da parte di animali, l'occasionale ingresso nel corso degli anni di giovani aliesi in cerca di un "ricordo" dei propri antenati, la rimozione delle ossa da parte di personale non specializzato, ha purtroppo causato la perdita di ogni connessione anatomica.

Il materiale scheletrico, raccolto in 29 grandi sacchi, era frammisto a terra e calce - versata sui cadaveri probabilmente allo scopo di arginare il propagarsi del morbo.

Dopo un sopralluogo preliminare si è dato inizio allo studio dei reperti, che ha comportato una prima fase di ripulitura delle ossa, un parziale restauro e una successiva suddivisione delle stesse per distretti scheletrici.

\subsection{Calcolo del numero minimo di individui}

Le prime informazioni ottenute sono quelle relative alla consistenza numerica del campione, rilevata tramite il conteggio del numero minimo di individui presenti (tab. I). Per fare ciò sono stati considerati i distretti scheletrici maggiormente rappresentati - calvari, mandibole, femori e tibie.

I dati ottenuti sono peraltro concordi con il numero effettivo ricavato dal registro parrocchiale dei defunti dell'anno 1837, il quale elenca 306 morti causati dall'epidemia.

Tab. I - Calcolo del numero minimo di individui presenti nel campione

\begin{tabular}{|c|c|c|}
\hline Distretto & Classe di età & $\mathbf{N}^{\circ}$ minimo \\
\hline \multirow{3}{*}{ Calvari } & Adulti & 220 (occipitale) \\
\cline { 2 - 3 } & Bambini & 52 (frontale) \\
\cline { 2 - 3 } & Totale & 272 \\
\hline \multirow{3}{*}{ Mandibole } & Adulti & 250 \\
\cline { 2 - 3 } & Bambini & $\mathbf{2 9 6}$ \\
\cline { 2 - 3 } & Totale & $\mathbf{2 5 3}$ (lato destro) \\
\hline Femori & Adulti & $\mathbf{2 6 4}$ (lato destro) \\
\hline Tibie & Adulti & \\
\hline
\end{tabular}




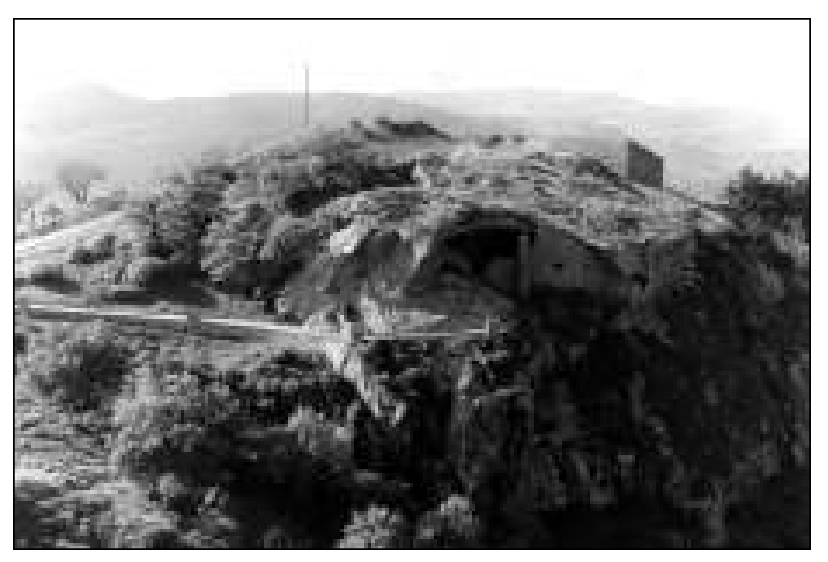

Fig. 1 - Grotta del "Camposanto Vecchio".

\subsection{Analisi morfometrica dei crani}

Uno studio a livello individuale è stato possibile soltanto attraverso l'analisi dei 119 calvari integri disponibili, sui quali sono state effettuate undici misure necessarie al calcolo dei principali indici e di quelli che, in base alle nostre prime impressioni, si ritenevano più indicativi per il campione in studio.

Le misure, eseguite seguendo le indicazioni fornite da Martin e Saller (1959), sono le seguenti:

1 - Lunghezza massima del cranio (Glabella Opistocranion)

5 - Lunghezza della base cranica (Nasion - Basion)

8 - Larghezza massima del cranio (Eurion - Eurion)

17 - Altezza del cranio (Basion - Bregma)

20 - Altezza "auricolare" del cranio (Porion Bregma)

40 - Lunghezza della faccia (Basion - Prostion)

45 - Larghezza della faccia (Zighion - Zighion)

48 - Altezza della faccia (Nasion - Prostion)

49a - Distanza interorbitale (Dacrion - Dacrion)

60 - Lunghezza del palato (Prostion - Alveolare)

61 - Larghezza del palato (Ectomolare - Ectomolare)

Da queste sono stati derivati i seguenti indici:

Indice cranico orizzontale $(8 / 1)$ - descrive la forma del cranio visto superiormente

Indice vertico - longitudinale $(17 / 1)$ - descrive la forma del cranio visto lateralmente

Indice vertico - trasversale $(17 / 8)$ - descrive la forma del cranio visto posteriormente

Indice vertico - longitudinale auricolare $(20 / 1)$

Indice vertico - trasversale auricolare $(20 / 8)$

Indice facciale superiore $(48 / 45)$ - descrive la forma della faccia

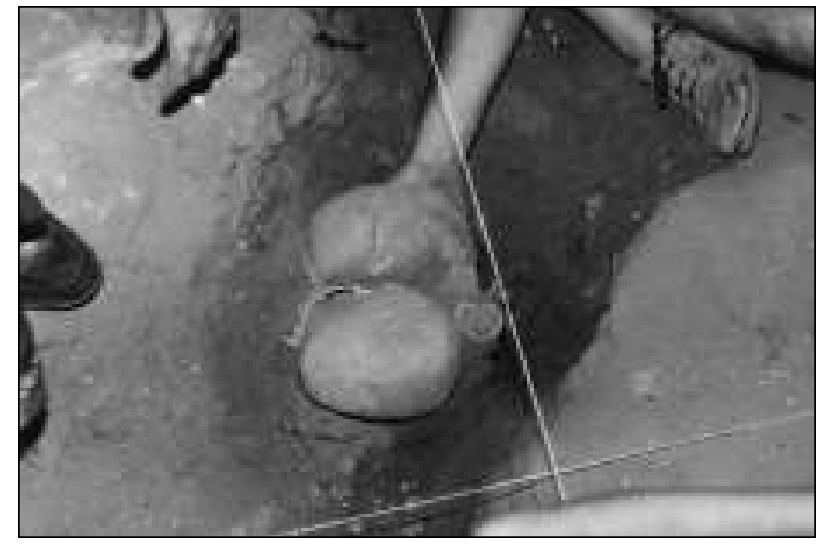

Fig. 2 - Recupero di due crani all'interno della grotta.

Indice alveolare $(40 / 5)$ - descrive il grado di prognatismo

Indice cranio - facciale longitudinale $(40 / 1)$

Indice cranio - facciale trasversale $(45 / 8)$

Indice alveolare - mascellare $(61 / 60)$ - descrive la forma del palato

In base agli standards proposti da Martin e Saller (1959), gli individui riesumati dal Camposanto Vecchio di Alia, risultano nel complesso: Dolicocra $n i$ (cranio lungo e stretto visto superiormente), Or tocrani (cranio, visto lateralmente, in cui il rapporto fra altezza e lunghezza è medio) e Acrocrani (cranio alto e stretto visto posteriormente) (Metrio crani in base all'indice vertico-trasversale auricolare). Si riscontra poi una generalizzata Mesenia (faccia mediamente alta e larga), rivelata dai valori ottenuti calcolando l'indice facciale superiore. Il palato risulta in media piuttosto largo rispetto alla lunghezza (Brachiurania), anche se è presente una certa variabilità. In base all'Indice Gnatico $(40 / 5)$ i soggetti in esame appaiono per lo più Ortognati (palato "piatto" in relazione alla faccia) e Mesognati (con valori medi).

\subsection{Stima dell'età di morte}

La mancanza di connessioni anatomiche ha reso impossibile l'applicazione integrale dei metodi combinati, multifattoriali, per la determinazione dell'età di morte (Açsàdi e Nemeskéri, 1970; Lovejoy et al., 1985). Necessariamente, quindi, si è dovuto ricorrere, rinunciando ad una diagnosi accurata, a metodi meno raffinati. Abbiamo concentrato la nostra attenzione sullo studio dei calvari correlando l'età di morte al grado di sinostosi (di chiusura) delle suture craniche, secondo la metodica pro- 
posta da Lovejoy et al. (1985), e al grado di usura dentaria ricavata secondo il metodo di Murphy, così come standardizzato da Smith (1984).

Un'indagine più accurata è stata eseguita sui soggetti giovanili, sfruttando lo schema proposto da Ubelaker (1978), che deriva l'età di morte dal grado di eruzione dentaria.

Il risultato di quest'indagine permette di confrontare il grado di rappresentazione delle diverse classi di età nel nostro campione. Il confronto con il risultato dell'analisi demografica, effettuata sui registri dei defunti (parrocchiali e civili), porta ad identificare il campione dei calvari a nostra disposizione come altamente rappresentativo della popolazione deceduta durante l'epidemia di colera del 1837, tenendo presente la maggiore difficoltà di reperimento e di studio delle porzioni ossee appartenenti al campione sub-adulto.

\subsection{Stima del sesso}

Per la determinazione del sesso ci siamo avvalsi del metodo combinato di Açsàdi e Nemeskéri (1970) così come applicabile limitatamente ai calvari. Le caratteristiche particolari del campione hanno poi indotto ad ipotizzare una rivalutazione dei valori (Crisafulli, 1996) che, nel calcolo combinato, determinano l'importanza di ciascun tratto morfologico. Sono stati infine calcolati i gradi
Tab. II - Confronto tra differenti metodi per la stima del sesso nel nostro campione

\begin{tabular}{|l|c|c|c|}
\hline Metodi & Maschi & Femmine & $\begin{array}{c}\text { Indeter- } \\
\text { minati }\end{array}$ \\
\hline $\begin{array}{l}\text { Açsadi- } \\
\text { Nemeskéri (1970) }\end{array}$ & 45 & 29 & 37 \\
\hline Ferembach (1979) & 47 & 30 & 34 \\
\hline Revisione su Alia & 47 & 27 & 37 \\
\hline
\end{tabular}

di sessualizzazione anche in base alla revisione formulata da Ferembach (1979).

I risultati ottenuti con questi tre procedimenti non presentano sostanziali differenze, come evidenziato dalla tabella II.

\subsection{Caratteri epigenetici del cranio}

Lo studio dei caratteri discontinui si è rivelato essere metodica particolarmente utile per la ricerca delle distanze biologiche tra popolazioni, in quanto scarsamente influenzati dall'ambiente.

Nel campione scheletrico di Alia, l'analisi dei tratti epigenetici è stata effettuata seguendo il protocollo proposto da Berry e Berry (1967) che prevede il rilievo della presenza o assenza di trenta caratteri morfologici del cranio (tab. III).

Tab. III - Caratteri morfologici del cranio (Berry e Berry, 1967)

\begin{tabular}{|c|l|}
\hline 1 & Linea nucale suprema presente \\
\hline 2 & Ossicino al lamdba \\
\hline 3 & Ossicino lambdoideo presente \\
\hline 4 & Foro parietale assente \\
\hline 5 & Osso al bregma presente \\
\hline 6 & Metopismo \\
\hline 7 & Ossicino coronale presente \\
\hline 8 & Osso epiterico presente \\
\hline 9 & Pterion a Xo a K \\
\hline 10 & Osso incisura parieto-temporale \\
\hline 11 & Ossicino all'asterion \\
\hline 12 & Toro auditivo presente \\
\hline 13 & Foro di Huschke presente \\
\hline 14 & Foro mastoideo assente \\
\hline 15 & Foro mastoideo extrasuturale \\
\hline
\end{tabular}

\begin{tabular}{|l|l|}
\hline 16 & Canale postcondilare evidente \\
\hline 17 & Faccetta condilare doppia \\
\hline 18 & Tubercolo precondilare \\
\hline 19 & Canale ipoglosso diviso (doppio) \\
\hline 20 & Foro ovale incompleto \\
\hline 21 & Foro spinoso aperto \\
\hline 22 & Fori palatini minori multipli \\
\hline 23 & Toro palatino sagittale \\
\hline 24 & Toro mascellare \\
\hline 25 & Foro zigo-facciale assente \\
\hline 26 & Foro sopraorbitario completo \\
\hline 27 & Foro frontale (incisura) \\
\hline 28 & Foro etmoidale anteriore extrasuturale \\
\hline 29 & Foro etmoidale posteriore assente \\
\hline 30 & Foro infraorbitario accessorio presente \\
\hline
\end{tabular}




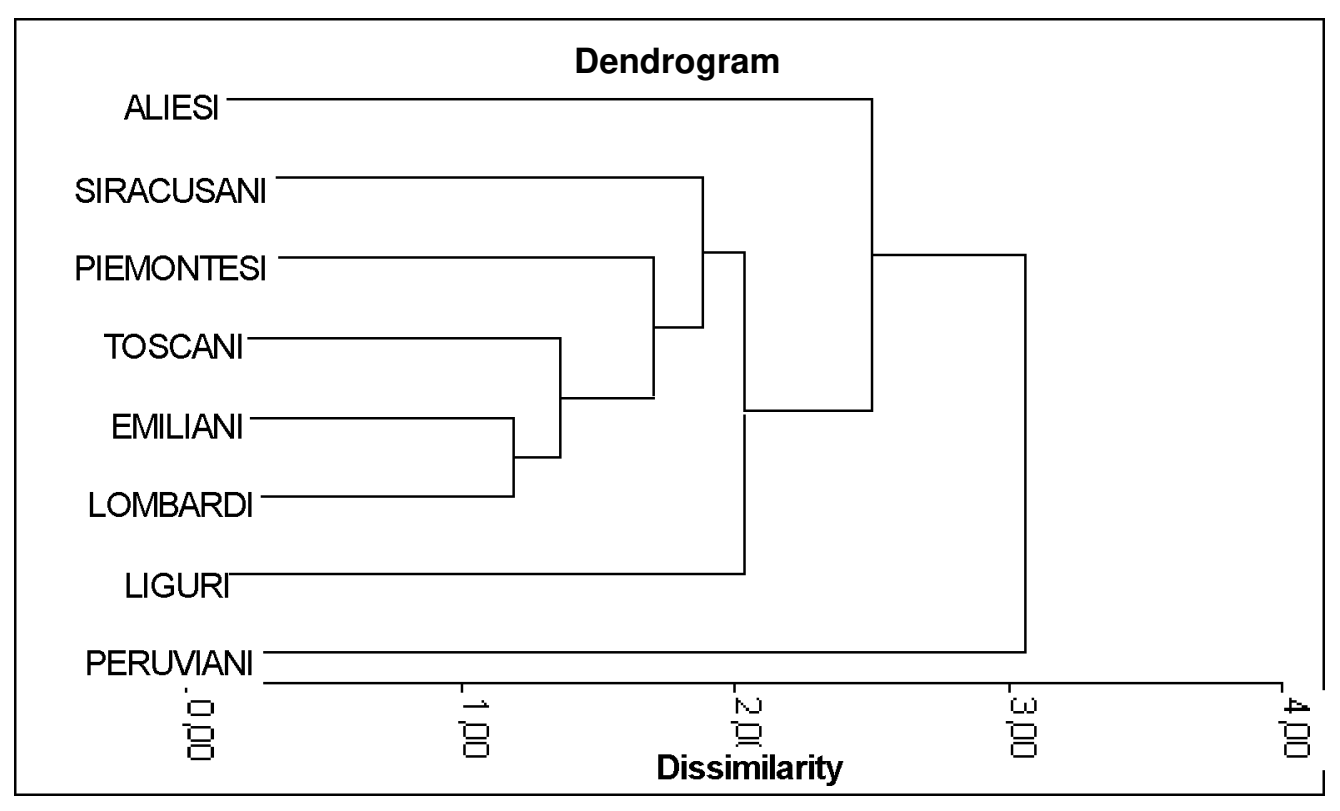

Fig. 3 - Diagramma che illustra l'affinità genetica della popolazione aliese con differenti gruppi geografici

I dati ottenuti sono quindi stati confrontati con quelli di popolazioni coeve di differente provenienza geografica, italiane (siracusana, emiliana, tosca na, piemontese, ligure, lombarda) e straniere (peru viana), al fine di determinare la loro maggiore o minore "affinità genetica" con il campione di Alia.

I campioni di confronto provengono tutti dalle collezioni osteologie del "Museo Nazionale di Antropologia e Etnologia" di Firenze.

I risultati dell'analisi statistica dei Clusters (UPGMA) effettuato sulla matrice di distanza (CHI quadro) è sintetizzata nel dendrogramma della figura 3.

Due particolari caratteri non appartenenti all'elenco precedente, quali il tubercolo zigo-mascellare e la cresta del processo mastoideo del temporale, anche se non utilizzati nel confronto con le altre popolazio$\mathrm{ni}$, si sono rivelati particolarmente frequenti in questa serie scheletrica e spesso presenti anche con un marcato grado di espressione.

\section{6. Studio odontologico}

Cercare di ottenere informazioni relative alle abitudini alimentari e all'igiene orale dall'analisi antropologica e patologica delle strutture residue dell'apparato stomatognatico è una pratica diffusa negli studi dei resti umani, così come si ritrovano in contesti archeologici.

Spesso, tuttavia, manca un riscontro oggettivo tra i dati rilevati e quelli proveniente da altre fon- ti. Ciò porta, seguendo un percorso obbligato, ad ipotizzare la causa dall'effetto. Disponendo, come nel nostro caso, di fonti storiche accurate relative all'economia del territorio, possiamo viceversa avere come punto di partenza un quadro qualitativo della dieta della popolazione.

L'economia di Alia nella prima metà dell'ottocento era ancora di semplice sussistenza e basata su agricoltura e pastorizia condotte con mezzi rudimentali. Il riflesso di quest'economia sull'alimentazione era una dieta povera e sbilanciata. Le fonti caloriche principali erano rappresentate da cereali (soprattutto grano, nelle diverse varietà, ed orzo) e legumi, consumati anche sotto forma di "sfarinati", possibilmente integrati con uova e latticini.

Fra le poche fonti alimentari esterne alla produzione locale merita citare le acciughe conservate

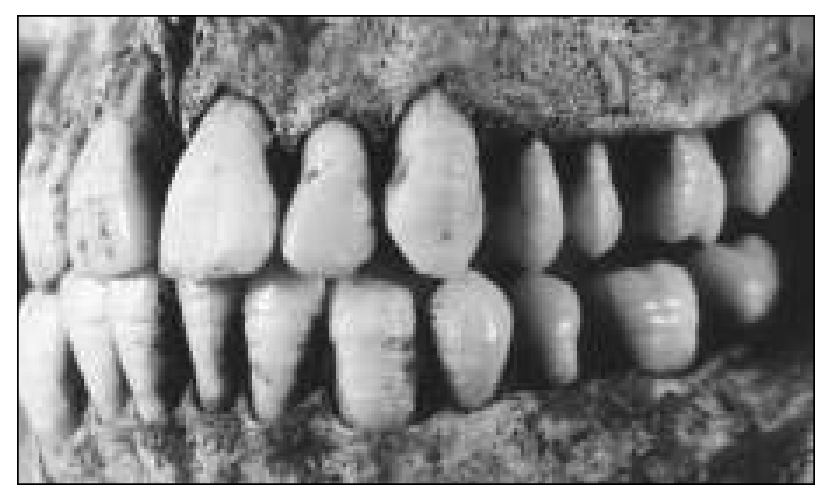

Fig. 4 - Esempio di "ipoplasia dello smalto" con i denti solcati dalle tipiche striature. 


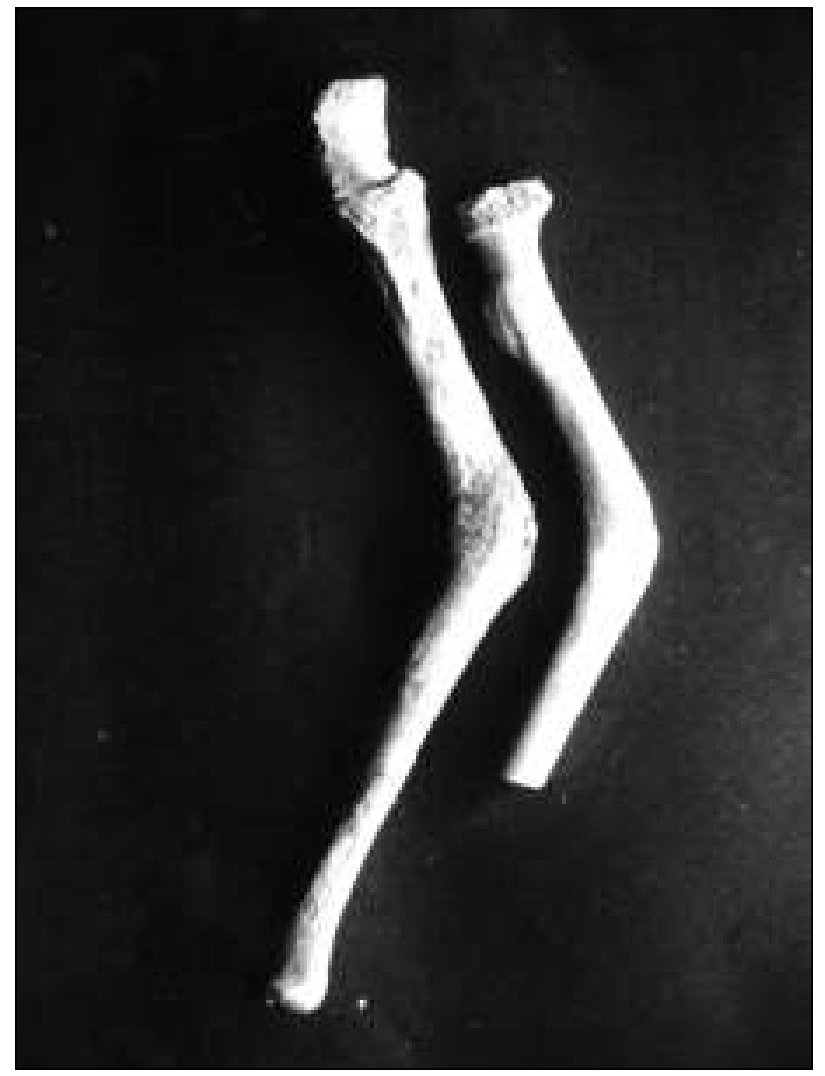

Fig. 5 - Frattura scomposta di ulna e radio

sotto sale, se non altro per il fatto che nei ceti me no abbienti spesso rappresentavano, con le olive in salamoia e le cipolle, l'unica forma di "companatico". Molto sporadico e non in tutta la popolazione era il consumo di carne.

Per quanto riguarda l'apporto di carboidrati semplici, esso era limitato al consumo di frutta stagionale spontanea, quali ad esempio fichi d'india e non, ciliegie, more, gelsi. Questa frutta poteva essere naturalmente conservata e consumata sotto forma di marmellate e composte.

Lo studio del materiale scheletrico ha evidenziato un'incidenza delle diverse patologie orali solo parzialmente allineabile alle conoscenze storiche sulle abitudini alimentari sopra citate. Possiamo difatti notare come la frequenza di carie, ascessi, parodontosi e perdite intra vitam, siano superiori a quelle che ragionevolmente potremmo attenderci. Una parziale spiegazione di tale discrepanza può essere attribuita ad un'insufficiente igiene orale e a possibili disturbi dell'odontogenesi, conseguenza di condizioni di vita piuttosto depresse e di una dieta sensibilmente sbilanciata.

Per quanto riguarda le patologie dentali - carie, ascessi, parodontosi, tartaro, perdita ante-mortem -

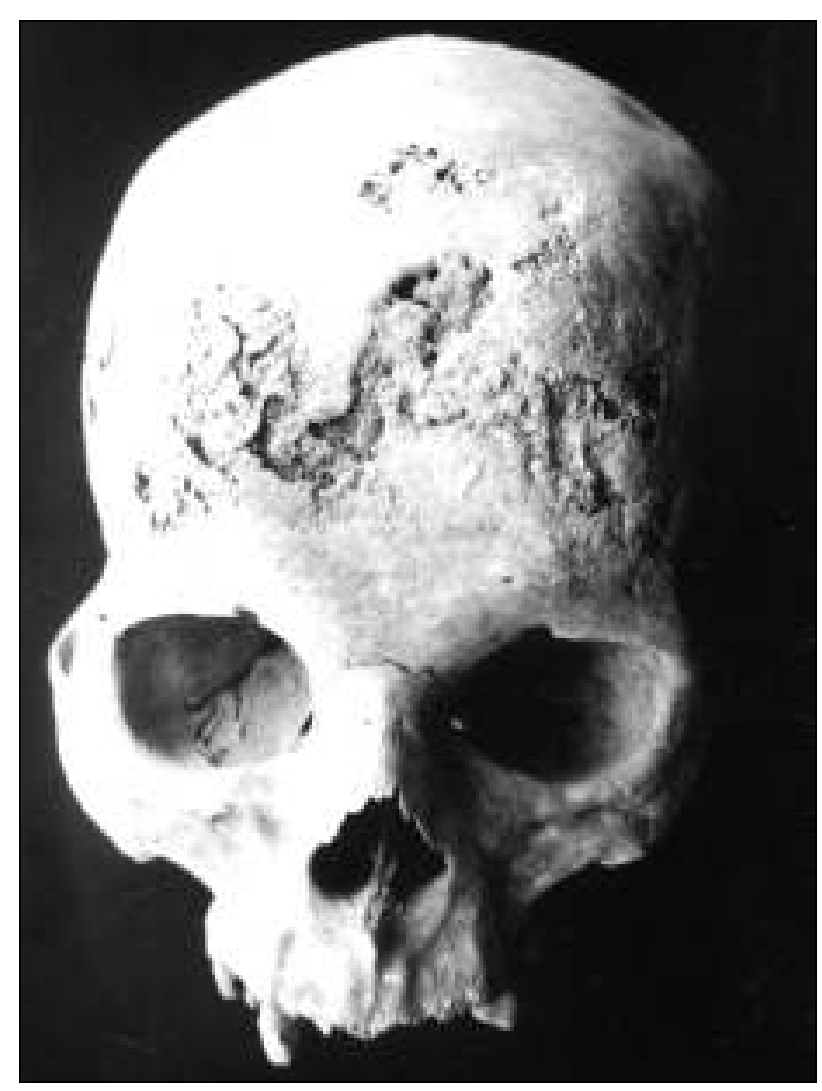

Fig. 6 - Tracce di malattia infettiva (sifilide?) sull'osso frontale.

sono state riscontrate frequenze superiori a quelle attese in base alle notizie storiche sul tipo di alimentazione, attribuibili con ogni probabilità ad uno scarso livello d'igiene orale.

L'alta presenza di ipoplasia dello smalto (fig. 4) diminuzione dello spessore dello smalto dentario dovuta ad un disturbo nell'amelogenesi - che colpisce l' $83,9 \%$ del campione, dà un'indicazione della probabile alta incidenza di patologie verificatesi durante l'infanzia, quali le ipovitaminosi A e D - conseguenza di forti carenze alimentari - il diabete materno, l'asfissia e l'ittero neonatale, le gastroenteriti.

Il quadro che emerge è coerente con quello riscontrato in altre popolazione ad economia prevalentemente agro-pastorale di semplice sussistenza.

\subsection{Studio paleopatologico}

Durante la suddivisione, il materiale osseo che presentava segni evidenti di patologie è stato separato e classificato a parte.

Da uno studio preliminare dello scheletro post-craniale è emersa la presenza di indicatori scheletrici di numerose patologie di diversa natura. Il rilievo di un'apprezzabile incidenza di trau- 
mi (fig. 5) e di alterazioni delle articolazioni, in particolar modo a livello della colonna vertebrale, sono in buon accordo con il tipo di vita di una popolazione rurale come quella aliese del XIX secolo, che esercita attività richiedenti un intenso lavoro fisico.

Lo stesso dicasi per la frequenza di lesioni infiammatorie causate da patologie infettive ascrivibili ai batteri più comuni, quali osteoperiostiti della tibia $(20,5 \%)$ e della fibula. Un caso a parte risulta essere quello testimoniato da un cranio (fig. 6), il cui aspetto morfologico mostra ampie zone di "erosione" e "proliferazione" ossea (manifestazioni osteoriduttive e osteoproduttive) concordi con la presenza di una specifica patologia infettiva quale la si filide. La mancanza di ossa del post-cranio, sicuramente attribuibili allo stesso soggetto e con le medesime caratteristiche, priva purtroppo la diagnosi di un importante riscontro.

La massiccia incidenza di "cribra orbitalia" $(23,7 \%)$ e di "iperostosi porotica" $(10,2 \%)$ - lesioni riscontrabili rispettivamente sul tetto delle orbite e sul tavolato della volta cranica - testimonia infine una presenza diffusa di stati anemici, spiegabile sia con un'alimentazione povera di ferro che con la probabile presenza della talassemia.

\section{Bibliografia}

Acsadi G., Nemeskery J., 1970. History of human life span and mortality. Akadémiai Kiadò, Budapest

Berry A.C., Berry R.J., 1967. Epigenetic variation in the human cranium. Journal of Anatomy, 101: 361-379

Crisafulli R., 1996. A Cholera Outbreak in Rural XIXth Century Sicily. Thesis of European Masters in Anthropology, University of Florence

Ferembach D., Schwidetzky I., Stloukal M., 1979. Raccomandazioni per la determinazione dell'età e del sesso sullo scheletro. Rivista di Antropologia, 60: 5-51, Roma,

Lovejoy C., Owen R.S., Meindl T.R., Prizbeck J.R., Mensforth R., 1985 Chronological Metamorphosis of the Auricolar Surfaceof the Ilium: ANew Method for the Determination of Adult Skeletal Age at Death. American Journal of Physical Anthropology, 68: 15-28

Martin R., Saller R., 1959. Lehrbuch der Anthropologie. Fischer Verlag, Stuggart

Smith B.H., 1984. Patterns of molar wear in hunter-gatherers and agriculturalists. American Journal of Physical Anthropology, 63: 39-56

Ubelaker D.H., 1989. Human skeletal remains: escavation, analysis, interpretation. In Manuals on Archeology 2. Smithsonian Institution, Washington.

Ringraziamenti: gli autori ringraziano i colleghi e amici Giuseppe D'Amore, Francesca Iandelli e Antonio Valletta, per il loro fondamentale contributo e i giovani di Alia, Roberto Falcone, Rosolino Di Prima e Jonathan La Barbera per l'aiuto, l'entusiasmo e l'interesse manifestato durante tutte le fasi dello studio del materiale effettuato in loco. 


\title{
STUDIO BIODEMOGRAFICO DELLA POPOLAZIONE DI ALIA NEL XIX SECOLO
}

\author{
De iasio S.*, Guccione I.**, Tulumello S.**, Bigazzi R.** \\ * Dipartimento di Biologia Evolutiva e Funzionale. Università di Parma \\ ** Laboratori di Antropologia, Dipartimento di Biologia Animale e Genetica. Università di Firenze \\ E-mail: deiasio@biol.unipr.it
}

I dati contenuti negli atti nominativi di nascita, matrimonio e morte dei registri Parrocchiali e di Stato Civile possono essere elaborati al fine di mettere in correlazione le informazioni relative ad ogni singola persona e famiglia, in modo da ricostruire le storie individuali (nascita, morte ed eventuali matrimoni), le storie familiari (per ogni matrimonio, la sua origine, durata e comportamento riproduttivo) e le genealogie ascendenti e discendenti attraverso le "fiches de familles".

Esse forniscono osservazioni sperimentali sui comportamenti della popolazione in relazione alle proprie vicissitudini storiche e sulle modalità di evoluzione da un punto di vista strettamente demografico, biologico e sociale.

Solo dopo aver effettuata la ricostruzione, risultano attendibili le analisi di alcuni parametri della struttura biologica della popolazione, quali i cognomi, le loro variazioni nel tempo e la comparazione tra i risultati ottenuti analizzando separatamente le fonti.

I cognomi, le loro frequenze e variazioni diacroniche, consentono di indagare sulle caratteristiche di struttura e sull'evoluzione biologica di una popolazione. Essi, nelle comunità patrilineari, possono essere considerati alla stregua di forme alleliche di un gene sito sul cromosoma $Y$ e trasmesso lungo la linea maschile (con l'eccezione dei figli illegittimi non riconosciuti che mantengono il cognome della madre). La loro presenza, la diversa distribuzione e rilevanza sono dovute all'interazione tra fattori socioculturali, biologici e demografici, con particolare riferimento al comportamento matrimoniale, riproduttivo e migratorio della popolazione. Trattandosi di alleli ad elevato polimor-

Ricerca sostenuta con il cofinanziamento della "Fondazione Dino Terra" di Lucca fismo, i cognomi hanno alta capacità di tipizzazione e sono in grado di differenziare finemente tra loro popolazioni diverse.

Essi, inoltre, definiscono per ciascun individuo un'identità al tempo stesso biologica e culturale, che si riflette a livello di popolazione, la cui composizione in cognomi può quindi contribuire ad individuare e definire l'identità culturale e biologica del proprio gruppo di appartenenza.

La comparazione tra le distribuzioni dei cognomi dedotte da fonti diverse può dare ulteriori informazioni sul differente comportamento demografico della popolazione: in particolare, i cognomi tratti dagli atti di nascita sono rappresentativi della frazione di popolazione che si riproduce e presentano alta ripetitività specialmente nei periodi a più alta fecondità.

I matrimoni consentono di valutare la struttura matrimoniale e forniscono indicazioni sugli incroci isonimici e sugli scambi tra popolazioni. I cognomi, desunti dai registri dei decessi, sono portati dalla quota vivente nella popolazione e forniscono risultati che risentono della struttura per età, dell'incidenza della mortalità infantile e della consuetudine di attribuire alle donne coniugate il cognome del marito.

\subsection{Classificazione delle famiglie}

"La famiglia costituisce il luogo preferenziale ove avviene la trasmissione dei caratteri biologici e nel quale si attua in parte, la trasmissione culturale".

Il canale attraverso cui si entra nell'intimo meccanismo di evoluzione di una popolazione, è proprio lo studio delle famiglie (come si formano, come si estendono, e come si sciolgono), poiché sono la causa principale della variabilità genetica influenzando la probabilità di trasmissione di un gene da genitori a figli. 
L'analisi demografica sulle famiglie deve essere affrontata in modo rigoroso poiché si deve disporre di elementi precisi per poter valutare correttamente l'età dei coniugi al matrimonio, alla nascita dei loro figli, allo scioglimento della loro unione dato molto significativo specie se riferito alla donna -. Le fonti aggregative sicuramente non forniscono risultati così precisi ed attendibili come quelle nominate, pur riferendosi ad una quantità di dati più consistenti.

La ricostruzione nominativa delle famiglie è una tecnica messa a punto da Louis Henry all'inizio degli anni Cinquanta con lo scopo di arrivare ad una corretta misura della fecondità delle popolazioni del passato superando il doppio limite imposto dalle fonti storico-demografiche: la quasi totale assenza sia degli "status animarum" nelle parrocchie francesi, sia dell'età della madre alla nascita dei figli nei registri parrocchiali di battesimo.

Questo metodo si articola in due fasi nettamente distinte:

- Dalle informazioni contenute nei registri si arriva a ricostruire la vicenda demografica di ciascuna "famiglia biologica";

- Dalla "scheda di famiglia (biologica)" si riaggregano i dati individuali per arrivare a misure di fecondità, nuzialità e mortalità.

In sostanza, dunque, si ricostruiscono biografie individuali all'interno di storie familiari. Quando la ricostruzione delle storie familiari avviene a partire dagli atti di matrimonio si possono ricreare quattro tipologie familiari, che, secondo la nomenclatura di Henry, assumono le seguenti denominazioni:

1. Mariage Fermé: si conosce la data esatta dello scioglimento dell'unione dovuta alla morte di uno dei coniugi (in epoca attuale causa alternativa può essere anche il divorzio), quindi si sa con precisione in quale periodo di tempo cercare i figli legittimi. In questo caso è nota la durata del periodo fertile della coppia, cioè il lasso di tempo in cui i genitori possono aver procreato figli legittimi.

2. Exterieur Fermé: all'opposto del tipo precedente di queste famiglie è conosciuta la data di fine unione ma non quella d'inizio; anche in questo caso non si può sapere la durata del matrimonio. Esse derivano da coppie sposatesi all'"esterno" e successivamente immigrate nell'area studiata.
3. Mariage Ouvert: non è possibile conoscere la data di scioglimento dell'unione coniugale, quindi è nota la durata precisa del periodo fertile della coppia; i figli legittimi saranno cercati in un lasso di tempo che va dalla data di matrimonio al compimento del quarantacinquesimo o cinquantesimo anno della madre, età in cui viene considerato finito, per convenzione, il periodo fertile della donna. In linea di massima, queste famiglie si sono formate ed hanno vissuto nell'area oggetto di studio, per poi migrare altrove; di conseguenza non sono rintracciabili gli atti di morte dei coniugi. Assimilabili agli MO sono le famiglie ricostruite sulla base dei soli atti di matrimonio e nascita dei figli, come nel presente caso: infatti, non essendo ancora stati presi in esame i decessi, non è possibile conoscere la data di scioglimento del matrimonio e, di concerto, stimare la durata del periodo fertile della coppia (in altri termini, non si possono definire gli "anni donna").

4. Exterieur Ouvert: non si conosce né la data del matrimonio né quella di fine unione della coppia. Se ne ha notizia perché in zona sono nati i loro figli. Si tratta di famiglie formatesi all'esterno, rimaste in zona il tempo necessario per avere almeno un figlio e poi sono migrate altrove.

\subsection{Il caso di Alia}

Lo studio biodemografico sulla popolazione di Alia (PA) è stato condotto a partire dagli atti nominativi di nascita, matrimonio e morte dello Stato Civile del Comune (disponibili dal 1820 in avanti), integrati con quelli dei registri parrocchiali per alcuni anni antecedenti e per altri di confronto.

Il volume della popolazione di Alia varia nell'Ottocento da 3855 abitanti (1798) a 6045 (1901). In conformità con l'incremento della popolazione, il trend delle nascite si presenta in crescita per tutto l'Ottocento, quasi raddoppiando gli eventi rispetto all'inizio del periodo di osservazione.

Dagli atti di nascita del periodo 1815-1899, si sono potute ricostruire 5397 coppie con figli e l'analisi è stata fatta sull'età della donna alla nascita di ciascun figlio.

Il confronto dei dati tra generazioni diverse è stato semplificato considerando due coorti di 25 anni ciascuna, cioè un intero arco generazionale. La prima coorte comprende 1297 donne nate dal 
Tab. I - Tabella generale della ricostruzione della famiglie di Alia suddivisa in 3 coorti

\begin{tabular}{|l|c|c|c|c|c|}
\hline $\begin{array}{l}\text { Coorti } \\
\text { di celebrazioni }\end{array}$ & $\begin{array}{c}\text { Totale } \\
\text { matrimoni }\end{array}$ & $\begin{array}{c}\text { Famiglie MO } \\
\text { ricostruite } \\
\text { (almeno 1 figlio) }\end{array}$ & $\begin{array}{c}\text { N. figli } \\
\text { nelle famiglie } \\
\text { MO }\end{array}$ & $\begin{array}{c}\text { \% famiglie MO } \\
\text { sul totale } \\
\text { dei matrimoni }\end{array}$ & $\begin{array}{c}\text { N. figli per } \\
\text { famiglia MO } \\
\text { ricostruita }\end{array}$ \\
\hline $\mathbf{1 8 2 0 - 1 8 3 9}$ & 645 & 436 & 1855 & 67.60 & 4.25 \\
\hline $\mathbf{1 8 4 0 - 1 8 5 9}$ & 980 & 645 & 2911 & 65.82 & 4.51 \\
\hline $\mathbf{1 8 6 0 - 1 8 7 5}$ & 824 & 643 & 3232 & 78.03 & 5.03 \\
\hline $\begin{array}{l}\text { TOTALE } \\
\text { 1820-1875 }\end{array}$ & $\mathbf{2 4 4 9}$ & $\mathbf{1 7 2 4}$ & $\mathbf{7 9 9 8}$ & $\mathbf{7 0 . 4 0}$ & $\mathbf{4 . 6 4}$ \\
\hline
\end{tabular}

1800 al 1824, la seconda 1438 donne nate tra il 1825 e il 1849 .

I tassi di natalità generici - calcolati per i periodi 1820-29 e 1890-99 - danno rispettivamente valori di $34.24 \%$ e 44.16 \% . Essi sono stati calcolati su 1630 (I periodo) e 2697 (II periodo) nascite, con una popolazione media che ammontava rispettivamente a 4.760 e 6.108 unità.

Per le analisi relative alla fecondità dagli atti di matrimonio, si sono stabilite tre coorti di confronto: le prime due ventennali $(1820-1839 ; 1830-$ 1859), l'ultima quindicennale (1860-1875). Infatti, il periodo utile per la loro formazione è compreso tra il 1815 ed il 1875, per un totale di 60 coorti annuali di matrimoni; ma, considerando 1) che gli atti relativi al primo quinquennio (181519) non riportano l'età della sposa e 2) che mancano gli atti relativi al 1860, il numero effettivo di coorti annuali utilizzabili è 55, suddivise nel modo indicato.

Dalla tab. I si vede che in totale sono state ricostruite 70 famiglie su 100: le coppie escluse dalla ricostruzione (il 30\% circa) si suppone siano, per il 10\%, coppie che effettivamente non hanno avuto figli e il restante $20 \%$, invece, sia escluso dai limiti imposti dal programma per effettuare linkage corretti. Infatti, sono stati considerati solo bambini i cui atti abbiano tutte le chiavi di ricerca presenti (cognome e $1^{\circ}$ nome del padre e cognome e $1^{\circ}$ nome della madre): per quelli con informazioni mancanti o differenti occorre la ricostruzione completa della storia individuale (comprensiva dunque anche dei decessi). Inoltre la terza coorte studiata, pur presentando un numero minore di matrimoni rispetto alla coorte precedente perché riferita ad un range temporale inferiore di 5 anni, ha la più alta percentuale di famiglie ricostruite: $i$ dati dei registri sono sicuramente riportati in modo migliore e completo.

Osservando il numero medio di figli per famiglia MO ricostruita, si può osservare che aumenta progressivamente nel succedersi temporale crescendo da 4.25 a 5.03: ciò può essere imputabile ad un abbassamento dell'età media al matrimonio e quindi ad una maggior durata del periodo fecondo a cui contribuisce anche la diminuita mortalità che nelle prime coorti, invece, incideva maggiormente sia sui genitori sia sui figli. Questo concorda in pieno con una precedente ricostruzione basata sulla fecondità delle coppie determinate sulla base dei soli atti di nascita. Tutto ciò può essere ricondotto al fenomeno della transizione de-

Tab. II - Confronto tra il numero totale di nascite del periodo ed i figli attribuiti alle coppie provviste di atto costitutivo di matrimonio

\begin{tabular}{|c|c|c|c|}
\hline Anno di nascita & Nati Totali & Nati nelle famiglie MO & $\begin{array}{c}\text { \% nati in famiglie MO } \\
\text { rispetto al totale }\end{array}$ \\
\hline $\mathbf{1 8 2 0 - 1 8 3 9}$ & 3212 & 1797 & 55.95 \\
\hline $\mathbf{1 8 4 0 - 1 8 5 9}$ & 3847 & 2628 & 68.31 \\
\hline $\mathbf{1 8 6 0 - 1 8 7 9}$ & 5090 & 3252 & 63.89 \\
\hline $\mathbf{1 8 8 0 - 1 8 9 9}$ & 6019 & 1106 & 18.38 \\
\hline TOTALE $\mathbf{1 8 2 0 - 1 8 9 9}$ & $\mathbf{1 8 1 6 8}$ & $\mathbf{8 7 3 3}$ & $\mathbf{4 8 . 3 4}$ \\
\hline
\end{tabular}


mografica, secondo il quale le popolazioni, da regimi ad alta natalità ed alta mortalità, passano a regimi a bassa natalità e bassa mortalità attraverso una fase intermedia nella quale ad una mortalità già in progressiva diminuzione fa riscontro una natalità che si mantiene ancora elevata, con un conseguente alto livello del tasso di incremento naturale della popolazione.

La tabella II riporta la situazione dei nati per coorti ventennali: circa il $50 \%$ dei nati non è stato attribuito ad alcuna famiglia. In questa percentuale sono compresi:

- tutti i figli illegittimi;

- tutti i bambini appartenenti a famiglie EF o $E O$, di cui non si possiedono gli atti di matrimonio;

- tutti i bambini nati nel primo ventennio da attribuire a coppie sposatesi prima del 1815;

- tutti i bambini nati nell'ultimo ventennio da attribuire a genitori sposatisi dopo il 1875.

\subsection{Calcolo della data di nascita presunta della madre/sposa}

In linea generale, la data di nascita della madre/sposa riportata sugli atti di matrimonio è più attendibile di quella riportata sugli atti di nascita. Partendo da questo presupposto e nel caso siano presenti le date su entrambe gli archivi, si è deciso di calcolare la data di nascita presunta della madre/sposa con questo metodo:

1. si considera la data di nascita della sposa sempre riportata eccetto che in 18 atti di matrimonio;

2. si osserva la data di nascita stimata della madre nell'archivio dei nati per ogni figlio avuto e se ne valuta la compatibilità con quella della sposa cui si riferisce;

3. si fa una media tra le date risultate compatibili e quella stimata al matrimonio.

Applicando questo metodo ad Alia si ottengono i seguenti risultati:

La tab. III mostra, per la popolazione di Alia, l'età della sposa al matrimonio, stimata facendo la differenza tra la data di nozze e la data di nascita calcolata tramite la ricostruzione delle famiglie. La tab. IV riferisce i dati osservati a 1000 matrimoni e ne mostra l'andamento per coorti. L'età media riportata nelle due tabelle diminuisce col passare del tempo da 24,4 a 23,2 anni per un'età media totale di 23,9 anni: ciò concorda con l'ipotesi che migliori progressivamente la qualità della vita e che, quindi, le coppie si sposino prima. In riferimento al grafico, infatti, si nota che la prima classe d'età si fa sempre più consistente col passare del tempo, che la classe 20-24, aumentando le sue dimensioni, rimane la classe modale in ogni ventennio analizzato e le classi più alte (già dai 35-39 anni in su) sono inconsistenti.

Tab. III - Matrimoni Mo ricostruiti. Età della sposa al matrimonio. Dati osservati

\begin{tabular}{|l|c|c|c|c|c|c|c|c|c|}
\hline $\begin{array}{l}\text { Coorte } \\
\text { matrimonio }\end{array}$ & $<=19$ & $20-24$ & $25-29$ & $30-34$ & $35-39$ & $40-44$ & $45->$ & Totale & $\begin{array}{c}\text { Età } \\
\text { media }\end{array}$ \\
\hline $1820-39$ & 87 & 181 & 109 & 36 & 14 & 7 & 2 & 436 & 24.4 \\
\hline $1840-59$ & 164 & 243 & 135 & 66 & 27 & 8 & 2 & 645 & 24.2 \\
\hline $1860-75$ & 217 & 257 & 90 & 38 & 27 & 11 & 3 & 643 & 23.2 \\
\hline Totale & 468 & 681 & 334 & 140 & 68 & 26 & 7 & 1724 & 23.9 \\
\hline
\end{tabular}

Tab. IV - Matrimoni Mo ricostruiti. Età della sposa al matrimonio. Dati osservati riferiti a 1000 matrimoni

\begin{tabular}{|l|c|c|c|c|c|c|c|c|c|}
\hline $\begin{array}{l}\text { Coorte } \\
\text { matrimonio }\end{array}$ & $<=\mathbf{1 9}$ & $\mathbf{2 0 - 2 4}$ & $\mathbf{2 5 - 2 9}$ & $\mathbf{3 0 - 3 4}$ & $\mathbf{3 5 - 3 9}$ & $\mathbf{4 0 - 4 4}$ & $\mathbf{4 5 - >}$ & Totale & $\begin{array}{c}\text { Età } \\
\text { media }\end{array}$ \\
\hline $\mathbf{1 8 2 0 - 3 9}$ & 200 & 415 & $\mathbf{2 5 0}$ & 83 & 32 & 16 & 5 & 1000 & $\mathbf{2 4 . 4}$ \\
\hline $\mathbf{1 8 4 0 - 5 9}$ & 254 & 377 & 209 & 102 & 42 & 12 & 3 & 1000 & $\mathbf{2 4 . 2}$ \\
\hline $\mathbf{1 8 6 0 - 7 5}$ & 337 & 400 & 140 & 59 & 42 & 17 & 5 & 1000 & $\mathbf{2 3 . 2}$ \\
\hline Totale & $\mathbf{2 7 1}$ & $\mathbf{3 9 5}$ & $\mathbf{1 9 4}$ & $\mathbf{8 1}$ & $\mathbf{3 9}$ & $\mathbf{1 5}$ & $\mathbf{4}$ & $\mathbf{1 0 0 0}$ & $\mathbf{2 3 . 9}$ \\
\hline
\end{tabular}


Tab. V - Età della sposa alla nascita del primogenito. Intervallo protogenesico medio.

\begin{tabular}{|c|c|c|c|c|}
\hline $\begin{array}{c}\text { Coorte } \\
\text { matrimoni }\end{array}$ & $\begin{array}{c}\text { Matrimoni MO } \\
\text { ricostruiti } \\
\text { al matrimonio }\end{array}$ & $\begin{array}{c}\text { Età media } \\
\text { della madre } \\
\text { alla primogenitura }\end{array}$ & $\begin{array}{c}\text { Età media } \\
\text { della madre } \\
\text { medio (in mesi) }\end{array}$ & $\begin{array}{c}\text { Intervallo } \\
\text { protogenesico }\end{array}$ \\
\hline $1820-39$ & 436 & 24,3 & 26,3 & 23,4 \\
\hline $1840-59$ & 644 & 24,2 & 26,4 & 25,4 \\
\hline $1860-75$ & 642 & 23,1 & 25,5 & 28,8 \\
\hline TOTALE & $\mathbf{1 7 2 2}$ & $\mathbf{2 3 , 8 7}$ & $\mathbf{2 6 , 0 7}$ & $\mathbf{2 5 , 8 7}$ \\
\hline
\end{tabular}

\subsection{Età della sposa alla nascita del primo figlio}

Lo studio dell'età della sposa alla nascita dei figli è particolarmente importante dal punto di vista biologico poiché esiste una stretta correlazione tra l'elevata età della madre e la comparsa di mutazioni nel neonato. Madri aventi figli a giovane età, per il resto del loro periodo fertile avevano avuto una fecondità minore: su questi risultati, Henry ipotizzò che la gravidanza prima che sia raggiunta la piena maturità fisiologica interferisca con la normale capacità riproduttiva per tutto il resto del periodo riproduttivo.

Supponendo che la maggior parte delle nascite sia legittima, l'età al matrimonio influenza in modo consistente la fitness della popolazione, sia quando la sposa è giovanissima (ne risente la dimensione), sia quando non lo è più (ne risente la qualità).

In caso di fecondità legittima, l'età della donna alla nascita del primogenito dipende dall'età alla quale si sposa e dall'intervallo temporale tra la data di nozze e quella del primo parto (intervallo protogenesico). Quindi, i fattori che intervengono a determinare l'età al matrimonio, influenzano di riflesso anche l'età della donna al primo figlio.

L'analisi viene anche qui condotta analizzando le famiglie ricostruite, aggregate in coorti ventennali. L'età della sposa alla nascita del primogenito viene calcolata facendo lo scarto tra la data di na- scita del primogenito meno la data nascita stimata della madre; l'intervallo protogenesico medio viene invece trovato sottraendo la data di nascita del primogenito alla data del matrimonio e trasformando in mesi il risultato (Tab. V). Così come l'età media della sposa al matrimonio, anche l'età media della madre alla primogenitura diminuisce col passare del tempo (da 26,4 ai 25,6 anni), mentre lo scarto tra le due età (intervallo protogenesico medio) aumenta progressivamente da 24,4 ai 29,1 mesi, per un valore medio di poco più di 2 anni (26,4 mesi) in quasi tutto l'arco dell'ottocento (Tab.VI).

In tab. VI sono riportati i dati osservati relativi alle età della sposa alla primogenitura. L'andamento osservato alla primogenitura segue quello delle spose in funzione della loro età al matrimonio. Le donne vengono raggruppate in classi d'età di 5 anni.

Il confronto può essere fatto con i dati riferiti a 1000 matrimoni (riportati in tab.VII):

In entrambi i casi, la classe modale è la classe d'età dai 20 ai 24 anni e le classi meno giovani sono quelle a dimensione minore; le nascite di primogeniti con madri aventi meno di 19 anni sono minori rispetto ai matrimoni, ciò significa che chi si sposa giovanissimo non fa immediatamente figli; inoltre la classe modale c'è un maggior numero di primogeniture rispetto ai matrimoni per classi d'età.

Tab. VI - Matrimoni MO ricostruiti. Età della sposa alla primogenitura. Dati osservati

\begin{tabular}{|l|c|c|c|c|c|c|c|c|c|}
\hline $\begin{array}{l}\text { Coorte } \\
\text { matrimoni }\end{array}$ & $<=\mathbf{1 9}$ & $\mathbf{2 0 - 2 4}$ & $\mathbf{2 5 - 2 9}$ & $\mathbf{3 0 - 3 4}$ & $\mathbf{3 5 - 3 9}$ & $\mathbf{4 0 - 4 4}$ & $\mathbf{4 5 - >}$ & Totale & $\begin{array}{c}\text { Età } \\
\text { media }\end{array}$ \\
\hline $\mathbf{1 8 2 0 - 3 9}$ & 47 & 159 & 135 & 64 & 18 & 13 & 0 & 436 & $\mathbf{2 6 . 4}$ \\
\hline $\mathbf{1 8 4 0 - 5 9}$ & 85 & 252 & 156 & 81 & 50 & 14 & 6 & 644 & $\mathbf{2 6 . 4}$ \\
\hline $\mathbf{1 8 6 0 - 7 5}$ & 114 & 262 & 141 & 60 & 39 & 19 & 7 & 642 & $\mathbf{2 5 . 6}$ \\
\hline Totale & $\mathbf{2 4 6}$ & $\mathbf{6 7 3}$ & $\mathbf{4 3 2}$ & $\mathbf{2 0 5}$ & $\mathbf{1 0 7}$ & $\mathbf{4 6}$ & $\mathbf{1 3}$ & $\mathbf{1 7 2 2}$ & $\mathbf{2 6 . 1}$ \\
\hline
\end{tabular}


Tab. VII - Matrimoni MO ricostruiti. Età della sposa alla primogenitura. Dati riferiti ad una coorte di 1000 matrimoni per periodo.

\begin{tabular}{|l|c|c|c|c|c|c|c|c|c|}
\hline $\begin{array}{l}\text { Corte } \\
\text { matrimoni }\end{array}$ & $<=19$ & $\mathbf{2 0 - 2 4}$ & $\mathbf{2 5 - 2 9}$ & $\mathbf{3 0 - 3 4}$ & $\mathbf{3 5 - 3 9}$ & $\mathbf{4 0 - 4 4}$ & $\mathbf{4 5 = >}$ & Totale & $\begin{array}{c}\text { Età } \\
\text { media }\end{array}$ \\
\hline $\mathbf{1 8 2 0 - 3 9}$ & 108 & 365 & 307 & 147 & 39 & 30 & 5 & 1000 & $\mathbf{2 4 . 4}$ \\
\hline $\mathbf{1 8 4 0 - 5 9}$ & 130 & 389 & 242 & 129 & 78 & 22 & 11 & 1000 & $\mathbf{2 4 . 2}$ \\
\hline $\mathbf{1 8 6 0 - 7 5}$ & 177 & 407 & 219 & 93 & 61 & 30 & 12 & 1000 & $\mathbf{2 3 . 2}$ \\
\hline TOTALE & $\mathbf{1 4 2}$ & $\mathbf{3 9 0}$ & $\mathbf{2 5 0}$ & $\mathbf{1 2 0}$ & $\mathbf{6 1}$ & $\mathbf{2 7}$ & $\mathbf{1 0}$ & $\mathbf{1 0 0 0}$ & $\mathbf{2 3 . 9}$ \\
\hline
\end{tabular}

\subsection{L'intervallo protogenesico}

Il valore di accrescimento di una popolazione è misurabile anche attraverso il numero di figli (nascite) insieme con i valori relativi alla loro mortalità. Questo, a sua volta, è influenzato da fattori biologici e sociali che interessano sia quanto, del periodo riproduttivo, è utilizzato effettivamente per la riproduzione sia la frequenza e la cadenza delle nascite durante il periodo fecondo.

Quanto, del periodo riproduttivo, è utilizzato effettivamente per la riproduzione è un aspetto descritto mediante l'analisi dell'età al matrimonio. Il periodo fecondo è delimitato da fattori biologici e sociali che decretano quando una coppia ha "il diritto" di riprodursi. Generalmente ci si riferisce all'età della donna perché la sua fertilità varia più velocemente in funzione del tempo rispetto a quella dell'uomo. La frequenza e cadenza delle nascite durante il periodo fecondo è un aspetto descritto mediante l'analisi degli intervalli protogenesico ed intergenesico. Il primo si riferisce al periodo di tempo tra il matrimonio e la nascita del primo figlio, il secondo, invece descrive l'intervallo temporale tra un figlio e l'altro. La durata di questi intervalli permette di valutare il comportamento riproduttivo di una popolazione specie se esistono meccanismi di controllo delle nascite o se si è, al contrario, in regime di "fecondità naturale", con riferimento alle popolazioni pre-moderne che non operavano un deliberato controllo a priori del numero e della distanza tra la nascita dei figli.

In un regime a fecondità naturale, la durata degli intervalli intergenesici si scompone nei seguenti fattori: durante il periodo di infecondabilità (23 mesi dopo il parto) non si verifica l'ovulazione. Questo periodo dipende anche dall'eventuale allattamento che può variare nelle diverse culture $\mathrm{o}$, all'interno di una stessa società, in funzione delle diverse classi sociali di appartenenza: comunque, è probabilmente il primo "strumento" utilizzato per prolungare l'intervallo intergenesico.

Accanto a questi, si trova anche la mortalità intrauterina: 1 gravidanza circa su 5 avvertite e riconosciute non va a buon fine per aborto spontaneo. In questo caso, si avrà un nuovo concepimento passato il normale tempo medio d'attesa. Le famiglie $M F$ ed $M O$ costituiscono un eccellente mezzo per indagare su questi parametri: infatti, la data di matrimonio insieme con la data di nascita di ogni figlio attribuito consentono una precisa valutazione degli intervalli sopracitati. L'analisi va fatta in termini di rapporto rispetto all'ammontare iniziale delle coppie: i risultati sono meglio evidenziati dalle tavole di eliminazione in cui, partendo da un contingente iniziale di 1000 individui (coorte), lo si segue nel tempo e progressivamente si assottiglia man mano che i componenti la coorte subiscono l'evento oggetto di studio. Si possono considerare delle tabelle di sopravvivenza di quel particolare gruppo nel tempo. Nel primo ventennio considerato, poco meno della metà delle coppie genera il primogenito durante il primo anno di matrimonio: ciò comporta che il concepimento avviene nei primi $2 / 3$ mesi dopo le nozze. Col passare del tempo, questo valore tende a decrescere.

Allo scadere del settimo anno di matrimonio, $1^{\prime} 88 \%$ di coniugi ha almeno un figlio e tutti, entro il decimo anno ha prole. Non si esclude che alcune tra le coppie più "attempate" si siano trasferite altrove durante i primi anni di matrimonio, abbiano fatto figli altrove e si siano ritrasferite ad Alia. Si osserva come, col passare del tempo, pur sposandosi prima, si tenda a controllare maggiormente le nascite: infatti, nel 1820-39 e nel 1840-59 il numero di primogeniti è costante dal terzo anno dopo le nozze in avanti. Dal 1860 al 1875, invece, diminuisce il numero di nati nell'anno della celebrazione e i primogeniti vengono diluiti meglio nel corso dei 10 anni successivi. 
Tab. VIII - Matrimoni MO ricostruiti. Intervallo protogenesico medio, in funzione dell' età della madre. Dati osservati.

\begin{tabular}{|l|c|c|c|c|c|c|c|c|c|c|c|c|}
\hline \multirow{2}{*}{$\begin{array}{l}\text { Coorte } \\
\text { matrimoni }\end{array}$} & \multicolumn{4}{|c|}{$\begin{array}{c}\text { Primogeniti secondo l'età } \\
\text { della madre al matrimonio }\end{array}$} & \multicolumn{4}{c|}{$\begin{array}{c}\text { Intervallo protogenesico medio (in mesi) } \\
\text { secondo l'età della madre al matrimonio }\end{array}$} \\
\cline { 2 - 15 } & $<=19$ & $20-24$ & $25-29$ & $30-34$ & $>=35$ & Totale & $<=19$ & $20-24$ & $25-29$ & $30-34$ & $>=35$ & Totale \\
\hline $1820-39$ & 87 & 181 & 109 & 36 & 23 & 436 & 32,2 & 23,7 & 18,4 & 18,1 & 19.6 & 23.4 \\
\hline $1840-59$ & 164 & 243 & 135 & 66 & 37 & 645 & 28.5 & 26.8 & 21.4 & 25.3 & 23.7 & 25.8 \\
\hline $1860-75$ & 217 & 257 & 90 & 38 & 41 & 643 & 32.3 & 28.1 & 24.8 & 23.0 & 33.6 & 29.1 \\
\hline TOTALE & 468 & 681 & 334 & 140 & 101 & 1724 & 30.9 & 26.5 & 21.3 & 22.8 & 26.8 & 26.4 \\
\hline
\end{tabular}

La distribuzione delle nascite ed i valori medi (in mesi) dell'intervallo protogenesico in funzione dell'età della madre al matrimonio sono riportati in tab. VIII.

Per le spose più giovani, l'intervallo protogenesico si aggira intorno ai 2 anni e mezzo dalla data del matrimonio e, per il periodo 1820-39 diminuisce molto rapidamente nella classe d'età successiva per poi stabilizzarsi nelle classi intermedie e diminuire ancora nella classe di età $<=35$ anni.

\subsection{Analisi dei cognomi dagli atti di nascita}

Dall'analisi degli atti di nascita di Alia dal 1815 al 1894 si riscontrano ben 1.150 forme cognominali diverse, ad occorrenza più o meno elevata. Tuttavia, i 20 cognomi a maggiore ripetitività ("forme alleliche" più diffuse) costituiscono poco meno di un terzo di tutte le forme presenti (tab. IX).

Un modo più analitico per stimare l'isolamento di una popolazione e l'entità degli scambi con

Tab. IX - Frequenze osservate dei 20 cognomi a maggiore ripetitività

\begin{tabular}{|l|c|c|c|c|c|c|c|c|c|}
\hline \multicolumn{1}{|c|}{ COGNOME } & $\mathbf{1 5 - 3 4}$ & $\mathbf{2 5 - 3 4}$ & $\mathbf{3 5 - 4 4}$ & $\mathbf{4 5 - 5 4}$ & $\mathbf{5 5 - 6 4}$ & $\mathbf{6 5 - 7 4}$ & $\mathbf{7 5 - 8 4}$ & $\mathbf{8 5 - 9 4}$ & Tot. \\
\hline MICELI & 39 & 44 & 34 & 50 & 49 & 58 & 81 & 73 & 428 \\
\hline TODARO & 46 & 39 & 37 & 27 & 44 & 75 & 77 & 79 & 424 \\
\hline GUCCIONE & 36 & 24 & 48 & 45 & 48 & 41 & 57 & 64 & 363 \\
\hline CARDINALE & 26 & 21 & 41 & 30 & 32 & 73 & 75 & 61 & 359 \\
\hline CHIMENTO & 33 & 20 & 30 & 48 & 37 & 37 & 62 & 62 & 329 \\
\hline COSTANZA & 33 & 27 & 27 & 36 & 32 & 56 & 51 & 36 & 298 \\
\hline BARCELLONA & 18 & 7 & 22 & 31 & 32 & 52 & 63 & 61 & 286 \\
\hline BIONDOLILLO & 16 & 31 & 31 & 28 & 35 & 44 & 47 & 42 & 274 \\
\hline MARTINO & 15 & 20 & 20 & 24 & 32 & 50 & 45 & 47 & 253 \\
\hline ALESSANDRA & 13 & 17 & 12 & 23 & 35 & 31 & 49 & 60 & 240 \\
\hline CENTANNI & 17 & 14 & 24 & 25 & 30 & 40 & 52 & 38 & 240 \\
\hline DI CARLO & 15 & 26 & 15 & 27 & 38 & 42 & 49 & 24 & 236 \\
\hline DITTA & 16 & 15 & 20 & 28 & 25 & 38 & 55 & 39 & 236 \\
\hline INCERTI PARENTI & 21 & 83 & 79 & 26 & 27 & 0 & 1 & 0 & 228 \\
\hline SAGONA & 30 & 18 & 9 & 24 & 22 & 21 & 42 & 46 & 212 \\
\hline DRAGO & 39 & 26 & 12 & 15 & 34 & 34 & 18 & 31 & 209 \\
\hline RUNFOLA & 28 & 23 & 23 & 16 & 26 & 33 & 39 & 19 & 207 \\
\hline SCACCIA & 23 & 10 & 13 & 20 & 29 & 24 & 25 & 58 & 202 \\
\hline FALCONE & 19 & 25 & 15 & 13 & 22 & 35 & 36 & 31 & 196 \\
\hline TARAVELLA & 18 & 16 & 20 & 32 & 27 & 26 & 37 & 20 & 196 \\
\hline
\end{tabular}


l'esterno consiste nel valutare il grado di "persistenza" dei cognomi tra un periodo e il successivo; la quantità di forme cognominali inedite immesse; la proporzione di forme "alleliche" estinte. In una popolazione isolata sufficientemente ampia, a variabilità in cognomi limitata, che non pratica il controllo delle nascite e senza riproduttività differenziale marcata, come Alia, ci si aspetta di ritrovare i medesimi cognomi da una generazione all'altra, con perdita progressiva di poche varietà per effetto del solo caso (ad esempio la nascita di sole femmine).

L'applicazione di questo tipo di studio agli atti di nascita di Alia è finalizzato alla distinzione entro la popolazione tra autoctoni, emigrati e immigrati. Gli autoctoni sono coloro che portano i tipici cognomi aliesi, ovvero i più frequenti. Con la stima dei cognomi perduti, è possibile misurare la porzione di popolazione emigrata, cioè di quegli individui che pur nascendo ad Alia, per qualche motivo, in un determinato momento della loro vita vi si allontanano prima di avere prole. Sulla base del conteggio della quantità di cognomi nuovi immessi nella popolazione è invece possibile individuare i figli di immigrati, ovvero di coloro che nascono da genitori di origine diversa da quella aliese e che quindi non portano $i$ suoi tipici cognomi.

Suddividendo i cognomi per periodi decennali, si sono distinti: (S): quantità di cognomi unici presenti in ogni periodo; (Si): il numero di cognomi nuovi immessi rispetto al periodo precedente, che non solo rappresentano il numero di immigrati, ma anche le variazioni linguistiche e i neonati abbandonati; (Sp): la quantità di cognomi perduti rispetto al periodo successivo, rappresentativa non solo dell'emigrazione, ma anche del fenomeno della deriva genetica nei casi in cui, per esempio, le coppie abbiano solo figlie femmine; (Spst): la porzione di cognomi comuni tra il periodo in esame ed il successivo, appartenenti ad individui autoctoni che si riproducono e rimangono ad Alia (Tab. X).

La distribuzione osservata dei cognomi è stata ottenuta considerando la popolazione suddivisa negli usuali 8 periodi e per ognuno dei quali si sono conteggiati quanti cognomi compaiono con frequenza $1,2,3 \ldots$ fino a 20 , accorpando le frequenze comprese tra 21 e 25 , tra 26 e 30 , tra 31 e 39 ed infine tra 40 e 83 , valore che rappresenta la ripetitività massima riscontrata nello studio sulle frequenze osservate dei 20 cognomi a maggior ri-
Tab. X - Presenza (S), immissione (Si), estinzione (Sp) e persistenza (Spst) dei cognomi rispetto al periodo precedente (frequenza)

\begin{tabular}{|l|c|c|c|c|}
\hline Periodo & S & Si & Sp & Spst \\
\hline $\mathbf{1 8 1 5 - 2 4}$ & 289 & - & - & - \\
\hline $\mathbf{1 8 2 5 - 3 4}$ & 242 & 64 & 111 & 178 \\
\hline $\mathbf{1 8 3 5 - 4 4}$ & 242 & 74 & 74 & 168 \\
\hline $\mathbf{1 8 4 5 - 5 4}$ & 285 & 102 & 59 & 183 \\
\hline $\mathbf{1 8 5 5 - 6 4}$ & 267 & 70 & 88 & 197 \\
\hline $\mathbf{1 8 6 5 - 7 4}$ & 452 & 240 & 55 & 212 \\
\hline $\mathbf{1 8 7 5 - 8 4}$ & 493 & 241 & 200 & 252 \\
\hline $\mathbf{1 8 8 5 - 9 4}$ & 485 & 220 & 228 & 265 \\
\hline
\end{tabular}

petitività. Inoltre si è preso in considerazione anche il totale di cognomi diversi presenti in ogni periodo. In questo modo si può fotografare la popolazione in diversi momenti storici e studiarne le variazioni temporali.

Lo studio della distribuzione di frequenza è utile per osservare i fenomeni immigratori nei diversi periodi, i quali sono tanto più rilevanti quanto più le percentuali dei cognomi in ciascuna classe di frequenza presentano valori via via decrescenti; in altri termini il grado di immigrazione è direttamente proporzionale alle classi di ripetitività più basse. $\mathrm{Al}$ contrario, il grado di isolamento esiste se vi è un'elevata occorrenza delle classi ad alta ripetitività. In questo modo la distribuzione è rappresentabile da una curva assimilabile ad una binomiale negativa.

È intuibile che tanto più il luogo di origine degli immigrati è vario e distante tanto più i loro cognomi differiscono. Infatti, se la popolazione di un determinato periodo è aperta, caratterizzata in altre parole da una più alta mobilità geografica, si ha un numero elevato di cognomi differenti con una sola o poche ricorrenze; al contrario, quando essa è chiusa, la distribuzione dei cognomi presenta un numero limitato di forme cognominali diverse che si distribuiscono con elevata frequenza.

\subsection{Distanze genetiche nella popolazione di differenti periodi}

Scopo di quest'analisi è di pervenire ad una misura sintetica della similarità e della differenza in base alla frequenza dei cognomi identici nelle popolazioni messe a confronto e di conseguenza 
esplorare l'evoluzione biologica della popolazione di Alia mediante le relazioni isonimiche.

Considerando nuovamente le popolazioni per ogni periodo è stato applicato il coefficiente di similarità stimato in base all'isonimia sia di una popolazione con se stessa sia tra popolazioni differenti (Chen et al., 1983).

Il metodo utilizzato è l'indice di distanza genetica di Nei (1973), il quale fornisce una valutazione sintetica della divergenza esistente tra i pool genetici della popolazione nei diversi decenni. Esso è basato sulla probabilità di uguaglianza in alleli ad uno stesso locus, estratti a caso dalle popolazioni a confronto, ponderata sulle probabilità di uguaglianza all'interno di ciascuna popolazione. I risultati ottenuti rivelano che tra le popolazioni in esa me non si verificano forti differenze genetiche e una maggiore stabilità a partire dal 1855.

\subsubsection{Applicazione del Multidimensional Scaling}

Le matrici risultanti di Nei sono state sintetizzate da mappe topologiche realizzate tramite il Multidimensional Scaling (MDS), che non richiede particolari presupposti statistici e geometrici nella distribuzione dei dati. Il concetto centrale dell'applicazione del MDS è la corrispondenza tra la distanza dij, ossia la distanza nello spazio multidimensionale, e la distanza lineare. Considerando il grafico (fig. 1) ed i risultati ottenuti si possono operare una serie di considerazioni. Ad Alia la distanza genetica più rilevante si osserva nel confronto tra le prime quattro popolazioni, le quali pertanto appaiono maggiormente dissimili.

In conclusione: dalle analisi dei cognomi si è potuto stabilire in che percentuale si siano verificati fenomeni di endogamia, consanguineità e isonimia della popolazione oggetto di studio durante

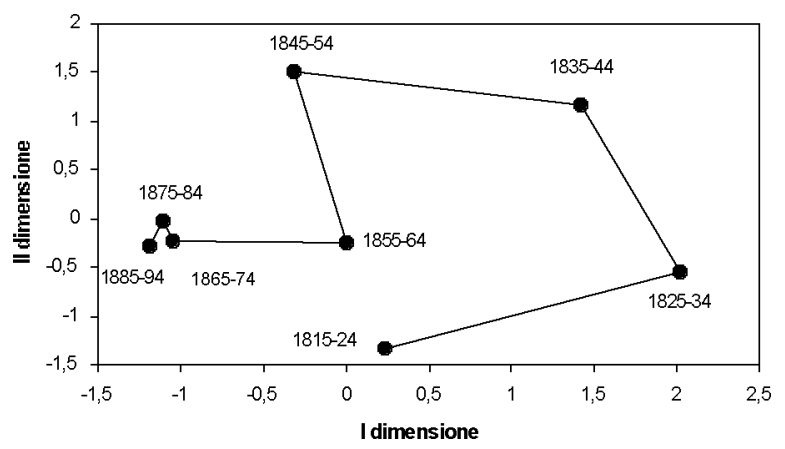

Fig. 1 - Atti nascita - Distanze genetiche tra periodi quasi tutto il secolo. Risulta chiaro un apprezzabile grado di isolamento riproduttivo. Tale isolamento genico si protrae per tutta la prima parte del secolo per poi arrestarsi con l'Unità d'Italia, quando si riscontra una maggiore apertura, ovvero un maggiore flusso migratorio della popolazione.

\section{8. Analisi dei cognomi dagli Atti di Matrimonio}

Il periodo di 60 anni preso in esame è stato suddiviso in quattro sottoperiodi di quindici anni il numero totale di atti rilevati è stato di 2692 (tab. XI).

Tab. XI - Atti di matrimonio

\begin{tabular}{|c|c|}
\hline Periodo & Matrimoni \\
\hline $1815-29$ & 501 \\
\hline $1830-44$ & 607 \\
\hline $1845-59$ & 760 \\
\hline $1860-75$ & 824 \\
\hline Totale & $\mathbf{2 6 9 2}$ \\
\hline
\end{tabular}

L'ammontare delle fome cognominali differenti presenti ad Alia è di 433 per gli sposi e di 381 per le spose (in totale 525) così ripartite nei quattro periodi (tab. XII).

Tab. XII - Cognomi differenti di sposi e spose

\begin{tabular}{|c|c|c|}
\hline PERIODI & SPOSI & SPOSE \\
\hline $\mathbf{1 8 1 5 - 2 9}$ & 186 & 172 \\
\hline $\mathbf{1 8 3 0 - 4 4}$ & 219 & 197 \\
\hline $\mathbf{1 8 4 5 - 5 9}$ & 228 & 212 \\
\hline $\mathbf{1 8 6 0 - 7 5}$ & 259 & 246 \\
\hline
\end{tabular}

\section{8. 1. SPOSI - I cognomi più frequenti}

Si sono evidenziati i venti cognomi più rappresentati nei quattro periodi (tab. XIII).

L'esiguità dei numeri permette solo poche considerazioni preliminari: 1 . I cognomi presenti tra $i$ primi venti in tutti i periodi (indice di un antico radicamento nel territorio) sono cinque (Todaro, Miceli, Costanza, Chimento, Biondolillo). 2. Il cognome Cardinale, con le frequenze maggiori nel secondo e nel quarto periodo non figura nel terzo. 
Tab. XIII - I venti cognomi degli sposi più rappresentati nei quattro periodi considerati.

\begin{tabular}{|c|c|c|c|c|c|c|c|}
\hline 1815-29 & N. & $1830-44$ & N. & 1845-59 & N. & $1860-75$ & N. \\
\hline TODARO & 16 & CARDINALE & 14 & MICELI & 28 & CARDINALE & 20 \\
\hline MICELI & 13 & $\mathrm{CIMO}^{\prime}$ & 13 & TODARO & 22 & SAGONA & 19 \\
\hline RUSSO & 10 & INCERTI PARENTI & 12 & CHIMENTO & 17 & MICELI & 19 \\
\hline PANEPINTO & 10 & BIONDOLILLO & 12 & COSTANZA & 14 & DI CARLO & 17 \\
\hline COSTANZA & 10 & GUCCIONE & 11 & SCACCIA & 12 & TODARO & 16 \\
\hline SCACCIA & 9 & CHIMENTO & 11 & MARTINO & 12 & TAULLI & 16 \\
\hline CARDINALE & 9 & TARAVELLA & 10 & GUCCIONE & 12 & BARCELLONA & 16 \\
\hline CHIMENTO & 8 & MICELI & 10 & RUSSO & 11 & CHIMENTO & 13 \\
\hline BIONDOLILLO & 8 & DITTA & 10 & INCERTI PARENTI & 11 & BLANDA & 13 \\
\hline RUNFOLA & 7 & COSTANZA & 10 & DRAGO & 11 & BIONDOLILLO & 13 \\
\hline MASCARELLA & 7 & TRIPI & 9 & DI CARLO & 11 & CENTANNI & 12 \\
\hline GENOVESE & 7 & DRAGO & 9 & BIONDOLILLO & 11 & MARTINO & 11 \\
\hline D'AMICO & 7 & TODARO & 8 & TARAVELLA & 10 & DI MARCO & 11 \\
\hline DRAGO & 7 & TAULLI & 8 & SAGONA & 10 & RUNFOLA & 10 \\
\hline DITTA & 7 & SCACCIA & 8 & PANEPINTO & 10 & RICOTTA & 10 \\
\hline BLANDA & 7 & MASCARELLA & 8 & DITTA & 10 & INCERTI PARENTI & 10 \\
\hline LO IACONO & 6 & MACALUSO & 8 & CENTANNI & 10 & GUCCIONE & 10 \\
\hline LEONE & 6 & DI MARCO & 8 & MARCHIAFAVA & 9 & COSTANZA & 10 \\
\hline $\mathrm{CIMO}^{\prime}$ & 6 & CENTANNI & 8 & MACALUSO & 9 & BAT TAGLIA & 10 \\
\hline ALESSANDRA & 6 & BAT T AGLIA & 8 & FALCONE & 9 & FIORITO & 9 \\
\hline
\end{tabular}

3. Nel primo periodo non compaiono cognomi assegnati agli "esposti" (Incerti Parenti, Fiorito), ben rappresentati nei successivi. Non vi sono ragioni plausibili per ritenere che tra la porzione di popolazione in età da matrimonio non vi fosse una percentuale di trovatelli analoga agli altri periodi; si può ipotizzare una registrazione superiore alla media con il cognome della famiglia adottiva o con un altro assegnato dal funzionario dello stato civile (pratica riscontrata ad Alia), ricordando che in questo periodo si collocano gli atti dal 1815 al 1820 , ricavati dalle registrazioni parrocchiali, in cui le informazioni risultano senz'altro di più difficile comprensione. Analizzando le frequenze percentuali nei diversi periodi dei 20 cognomi in assoluto più rappresentati, si è evidenziato che esse coprono in media - analogamente a quanto riscontrato dalle analisi sulle nascite - circa un terzo del totale. Ciò potrebbe essere interpretato come primo indicatore di un relativo grado di isolamen- to della popolazione, massimo nel terzo periodo $(31,7 \%)$, minimo nel secondo $(26,9 \%)$, con uno scarto tra i due di quasi cinque punti.

\subsubsection{Presenza, immissione,} persistenza e scomparsa di cognomi

Altre indicazioni in merito si possono ricavare analizzando la presenza simultanea di un cognome in due differenti periodi (tab. XIV).

Tab. XIV - Numero di cognomi presenti simultaneamente (due a due) nei vari periodi.

\begin{tabular}{|l|c|c|c|c|}
\hline Periodo & $\mathbf{1 8 1 5 - 2 9}$ & $\mathbf{1 8 3 0 - 4 4}$ & $\mathbf{1 8 4 5 - 5 9}$ & $\mathbf{1 8 6 0 - 7 5}$ \\
\hline $\mathbf{1 8 1 5 - 1 8 2 9}$ & 186 & 127 & 134 & 115 \\
\hline $\mathbf{1 8 3 0 - 1 8 4 4}$ & & 219 & 129 & 135 \\
\hline $\mathbf{1 8 4 5 - 1 8 5 9}$ & & & 228 & 145 \\
\hline $\mathbf{1 8 6 0 - 1 8 7 5}$ & & & & 259 \\
\hline
\end{tabular}


Tab. XV - Valori assoluti

\begin{tabular}{|l|c|c|c|c|}
\hline Periodo & Presenti & Nuovi & Perduti & Persistenti \\
\hline $1815-1829$ & 186 & 0 & 0 & 0 \\
\hline $1830-1844$ & 219 & 92 & 59 & 127 \\
\hline $1845-1859$ & 228 & 99 & 90 & 129 \\
\hline $1860-1875$ & 259 & 114 & 83 & 145 \\
\hline
\end{tabular}

Si osserva che le maggiori somiglianze si riscontrano tra il primo e il terzo e non tra periodi contigui. Anche rispetto al secondo intervallo non si nota un andamento lineare col trascorrere del tempo. Difatti si ritrovano 129 forme comuni nel terzo contro 135 nel quarto periodo. Solamente il periodo postunitario sembra avere una successione "coerente", condividendo un numero di cognomi progressivamente maggiore con i periodi a lui più vicini.

Pare quindi che alla maggiore mobilità riscontrata nel secondo periodo faccia seguito una chiusura in se stessa della popolazione fino al momento dell'Unità. È di questo periodo l'inizio dei lavori che apriranno le nuove direttrici viarie che lambiscono Alia, favorendo così una maggiore immigrazione dall'esterno.

L'aumento del fenomeno immigratorio (afflusso di cognomi nuovi), dopo la creazione dello Stato unitario, è abbastanza semplice da comprendere con l'abbattimento delle frontiere che facilita la circolazione delle merci e delle persone. Più complesso è spiegare il maggiore isolamento registrato nel periodo che va dal 1845 al 1859, specialmente dopo l'apertura determinatasi in quello precedente.

Occorre forse tener conto del fatto che nel secondo periodo (1830-1844) si colloca la devastante epidemia di colera che colpì il paese nel 183637 , a differenza di quella del 1855, più debole, e dell'epidemia di tifo petecchiale del 1816-17, che non interessò la popolazione siciliana. La consistente decimazione di individui in tutte le fasce d'età - e in proporzione maggiore quelli delle classi intermedie, come vedremo in seguito - potrebbe aver reso necessario un maggiore allontanamento dal luogo di origine per la ricerca del partner, diminuendo così il numero di cognomi in comune rispetto al periodo precedente. Il termine della condizione di "necessità" avrebbe in seguito ristabilito le abitudini precedenti, fino alla nascita del Regno d'Italia.

L'analisi delle distribuzioni assolute e percentuali di presenza, persistenza, immissione e scom-
Tab. XVI - Valori percentuali

\begin{tabular}{|l|c|c|c|}
\hline Periodo & Nuovi & Perduti & Persistenti \\
\hline $1815-1829$ & - & - & - \\
\hline $1830-1844$ & 49,5 & 31,7 & 68,3 \\
\hline $1845-1859$ & 45,2 & 41,1 & 58,9 \\
\hline $1860-1875$ & 50,0 & 36,4 & 63,6 \\
\hline
\end{tabular}

parsa dei cognomi nei quattro intervalli di tempo determinati può senza dubbio fornire dei dati più consistenti per valutare il grado di isolamento o di mobilità della popolazione, permettendo di testare così le varie ipotesi (Tabb. XV e XVI).

Continua a delinearsi il quadro che vede Alia chiudersi nel terzo periodo, con un'immissione di nuovi cognomi inferiore a quanto registrato nel precedente e nel successivo (45,2\% contro 49,5 e $50 \%$ ). A conferma di quanto affermato, nel terzo periodo si registra invece un $41,1 \%$ di cognomi perduti contro un $58,9 \%$ di persistenti.

\subsubsection{Il rapporto $S / N$}

Un buon indicatore per ottenere maggiori informazioni riguardo la stima dei flussi migratori e il grado di isolamento della popolazione è costituito dal rapporto tra il numero di cognomi (S) rilevati rispetto al numero totale dei matrimoni $(\mathrm{N})$. Esso può essere utilizzato correttamente nel nostro caso per valutare le variazioni nel tempo, in quanto le popolazioni esaminate mantengono dimensioni sufficientemente costanti.

Analizzando gli andamenti e comparandoli con quelli delle curve teoriche, si può ipotizzare il raggiungimento del nucleo storico. Dall'evoluzione del rapporto $S / N$ (tab. XVII) si nota come ad Alia questo diminuisca leggermente (I-II), poi sensibilmente (II-III) e quindi risalga, non raggiungendo però i livelli dei primi due (III-IV).

Occorre tener conto che la diminuzione tra primo e secondo periodo può essere dovuta al valore

Tab. XVII - Rapporto S/N

\begin{tabular}{|c|c|c|c|}
\hline PERIODO & $\mathbf{S}$ & $\mathbf{N}$ & S/N \\
\hline $\mathbf{1 8 1 5 - 2 9}$ & 186 & 501 & 0,371 \\
\hline $\mathbf{1 8 3 0 - 4 4}$ & 219 & 607 & 0,361 \\
\hline $\mathbf{1 8 4 5 - 5 9}$ & 228 & 760 & 0,300 \\
\hline $\mathbf{1 8 6 0 - 7 5}$ & 259 & 824 & 0,314 \\
\hline
\end{tabular}


di S/N nell'intervallo 1815-1829, probabilmente più alto del previsto a causa del numero anomalo delle celebrazioni del 1819, che interessarono interi gruppi familiari.

Un sensibile aumento nello stesso anno è dovuto probabilmente alla già citata abolizione dei diritti feudali.

Il comportamento matrimoniale degli sposi, che ricordiamo essere soggetti a mobilità rilevante, sembra comunque far emergere una tendenza progressiva all'isolamento della popolazione aliese, con un'inversione dopo l'Unità d'Italia.

\subsubsection{Distanze genetiche}

Il metodo della distanza di Nei evidenzia la notevole omogeneità generale di Alia, con differenze quantitativamente piccole tra i diversi periodi. Si riscontra una maggiore somiglianza tra primo e terzo periodo e nel quarto, mentre sono ancora il secondo e il quarto a manifestare le differenze più evidenti.

Attraverso l'analisi delle prime due componenti principali - non si è utilizzato il Multidimensional Scaling, avendo suddiviso il campione dei matrimoni in soli quattro intervalli, invece degli otto dell'analisi sulle nascite - si è ottenuta una rappresentazione topologica che permette la visualizzazione delle distanze genetiche tra i diversi periodi (fig. 2).

Seguendo un procedimento analogo, si sono analizzati separatamente i dati riguardanti le spose, al fine di evidenziare se vi siano differenze apprezzabili o meno tra la struttura della popolazione maschile e femminile che contrae matrimonio nel comune di Alia.

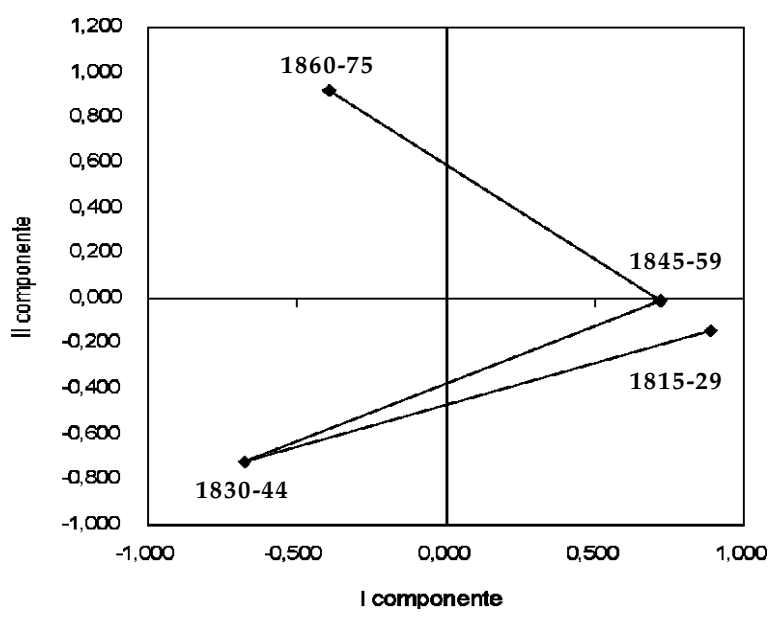

Fig. 2 - Sposi. Distanze genetiche tra periodi.

\subsubsection{SPOSE - I cognomi più frequenti}

Dall'osservazione dei 20 cognomi più frequenti (tab. XVIII) per periodo si nota che sono sei quelli sempre presenti, tre dei quali lo erano anche negli sposi (Miceli, Chimento e Todaro). Gli altri tre, presenti comunque in almeno un periodo tra i primi venti nei maschi, sono i cognomi Tripi, Sagona e Runfola.

Il cognome Cardinale risulta presente, come nei maschi, nel I, II e III periodo, facendo così ipotizzare una migrazione temporanea del nucleo familiare nel terzo periodo.

Il cognome Guccione è presente nei tre periodi finali, come negli sposi, con il valore più alto nel terzo e il secondo nel quarto. Considerando che questo è il cognome della famiglia economicamente e socialmente più importante di Alia, un così alto numero di ricorrenze fa pensare alla presenza di molti "rami cadetti". È abbastanza singolare il fatto che sia estremamente scarsa la frequenza dei cognomi dati ai trovatelli. Non si ritrova Incerti Parenti, mentre Fiorito appare, come per gli sposi, solo nel periodo finale.

Dall'analisi dei registri delle nascite abbiamo evidenziato un'alta frequenza di questi due cogno$\mathrm{mi}$, ripartiti più o meno equamente nei due sessi. Non c'è una ragione plausibile che spieghi un abbandono preferenziale di bambini di sesso maschile o un'adozione maggiore per quelli di sesso femminile. Si potrebbe forse ipotizzare una registrazione con altro cognome al momento della nascita o la perdita dell'appellativo di "esposto" in seguito all'adozione da parte di una nuova famiglia, più frequente nelle femmine per una consuetudine di ordine culturale.

Analizzando le frequenze percentuali nei quattro periodi dei venti cognomi in assoluto più rappresentati, si osserva come "Miceli" sia il più frequente di Alia, dato che occupava la medesima posizione anche negli sposi.

Tra i primi venti, ben tredici sono quelli in comune con il campione maschile (Miceli, Guccione, Chimento, Cardinale, Biondolillo, Costanza, Panepinto, Todaro, Martino, Runfola, Sagona, Centanni, Drago), a testimonianza di un forte radicamento di questi cognomi nella popolazione aliese.

Si osserva infine che le percentuali complessive dei venti cognomi a più alta ripetitività, rispetto a quelle determinate sugli sposi, risultano più alte di tre punti nei primi due periodi e di un punto nel quarto, mentre si ha uno scarto di oltre due punti 
Tab. XVIII - I venti cognomi delle spose più rappresentati per ogni periodo.

\begin{tabular}{|c|c|c|c|c|c|c|c|}
\hline $1815-29$ & N. & $1830-44$ & N. & 1845-59 & N. & $1860-75$ & N. \\
\hline ROTULO & 22 & CHIMENTO & 16 & GUCCIONE & 25 & COSTANZA & 25 \\
\hline MICELI & 17 & MICELI & 14 & PANEPINTO & 17 & GUCCIONE & 19 \\
\hline CARDINALE & 16 & CIMO' $^{\prime}$ & 14 & BARCELLONA & 17 & MICELI & 17 \\
\hline BIONDOLILLO & 15 & ROTULO & 13 & TODARO & 16 & MARTINO & 15 \\
\hline TRIPI & 13 & CARDINALE & 12 & FALCONE & 15 & CHIMENTO & 15 \\
\hline RIILI & 10 & TAULLI & 11 & MICELI & 14 & BIONDOLILLO & 15 \\
\hline CHIMENTO & 10 & TRIPI & 10 & COSTANZA & 13 & BARCELLONA & 15 \\
\hline SEDITA & 9 & TODARO & 10 & DRAGO & 12 & TARAVELLA & 14 \\
\hline MASCARELLA & 9 & SAGONA & 10 & TRIPI & 11 & CENTANNI & 14 \\
\hline CAT ALANO & 9 & GUCCIONE & 10 & SCACCIA & 11 & CARDINALE & 14 \\
\hline VICARI & 8 & D'AMICO & 10 & RUNFOLA & 11 & PANEPINTO & 13 \\
\hline MARTINO & 8 & CATALANO & 10 & CHIMENTO & 11 & TRIPI & 12 \\
\hline MACALUSO & 8 & RUNFOLA & 9 & SAGONA & 10 & SAGONA & 11 \\
\hline LOMBINO & 9 & MARCHIAFAVA & 9 & RUSSO & 10 & RUNFOLA & 11 \\
\hline SAGONA & 7 & LO IACONO & 9 & MARTINO & 10 & FIORITO & 11 \\
\hline RUNFOLA & 7 & CIRRINCIONE & 9 & DI CARLO & 10 & DRAGO & 11 \\
\hline MARCHIAFAVA & 7 & BARCELLONA & 9 & TARAVELLA & 9 & DI MARCO & 10 \\
\hline D'AMICO & 7 & VICARI & 8 & PECORARO & 9 & TODARO & 9 \\
\hline TODARO & 6 & PANEPINTO & 8 & BIONDOLILLO & 9 & PECORARO & 9 \\
\hline TARAVELLA & 6 & GRANATA & 8 & VIVIRRITO & 8 & MACALUSO & 9 \\
\hline
\end{tabular}

a favore dei maschi nel terzo periodo, da correlarsi forse con l'isolamento maggiore della popolazione in questo momento storico, evidenziato nell'analisi dei cognomi degli sposi.

\subsubsection{Presenza, immissione persistenza e scomparsa di cognomi}

Dal confronto tra i cognomi presenti contemporaneamente in due diversi periodi (tab. XIX), emerge che ad Alia - in misura comunque meno evidente rispetto ai maschi - il periodo 1845-1859 presenti somiglianze con il primo periodo maggiori del secondo. Da questo momento in poi, però, l'andamento si mostra lineare nel tempo, con affinità maggiori tra periodi contigui.

Sono state quindi analizzate le frequenze assolute e percentuali della presenza, immissione, scomparsa e persistenza dei cognomi tra un periodo e il successivo (tab. XX).
Tab. XIX - $\mathrm{N}^{\circ}$ di cognomi presenti simultaneamente (due a due) nei vari periodi

\begin{tabular}{|l|c|c|c|c|}
\hline Periodo & $\mathbf{1 8 1 5 - 2 9}$ & $\mathbf{1 8 3 0 - 4 4}$ & $\mathbf{1 8 4 5 - 5 9}$ & $\mathbf{1 8 6 0 - 7 5}$ \\
\hline $\mathbf{1 8 1 5 - 1 8 2 9}$ & 172 & 121 & 123 & 114 \\
\hline $\mathbf{1 8 3 0 - 1 8 4 4}$ & & 197 & 135 & 130 \\
\hline $\mathbf{1 8 4 5 - 1 8 5 9}$ & & & 212 & 141 \\
\hline $\mathbf{1 8 6 0 - 1 8 7 5}$ & & & & 246 \\
\hline
\end{tabular}

Tab. XX - Presenza, persistenza, immissione e scomparsa di cognomi. Valori percentuali.

\begin{tabular}{|l|c|c|c|}
\hline Periodo & Nuovi & Perduti & Persistenti \\
\hline $\mathbf{1 8 1 5 - 1 8 2 9}$ & - & - & - \\
\hline $\mathbf{1 8 3 0 - 1 8 4 4}$ & 44,2 & 29,7 & 70,3 \\
\hline $\mathbf{1 8 4 5 - 1 8 5 9}$ & 39,1 & 31,5 & 68,5 \\
\hline $\mathbf{1 8 6 0 - 1 8 7 5}$ & 49,5 & 33,5 & 66,5 \\
\hline
\end{tabular}


Tab. XXI - Rapporto S/N

\begin{tabular}{|c|c|c|c|}
\hline PERIODO & $\mathbf{S}$ & $\mathbf{N}$ & S/N \\
\hline $\mathbf{1 8 1 5 - 2 9}$ & 172 & 501 & 0,343 \\
\hline $\mathbf{1 8 3 0 - 4 4}$ & 197 & 607 & 0,325 \\
\hline $\mathbf{1 8 4 5 - 5 9}$ & 212 & 760 & 0,279 \\
\hline $\mathbf{1 8 6 0 - 7 5}$ & 246 & 824 & 0,299 \\
\hline
\end{tabular}

Rispetto al campione degli sposi, si osservano percentuali di persistenza più alte in tutti i periodi (indice di un radicamento maggiore per i cognomi delle spose, abbastanza prevedibile).

La percentuale d'immissione è, in generale, più simile tra i due sessi. Si differenziano abbastanza nettamente le spose terzo periodo, quando la percentuale di immissione e di perdita risulta molto più bassa $(6,1$ e 9,6 punti) e quella di persistenza più alta $(9,6 \%)$ che negli sposi.

\subsubsection{Il rapporto $S / N$}

Abbiamo già riscontrato come l'analisi del rapporto tra il numero totale dei cognomi riscontrati e quello dei matrimoni risulti altamente informativo del grado di isolamento della popolazione.

Seppur con valori leggermente inferiori, l'andamento risultante ricalca quello ottenuto per gli sposi, con un processo di isolamento progressivo, interrotto dal processo di unificazione del Regno d'Italia. I valori più bassi rispetto al campione maschile confermano l'idea di una maggiore mobilità matrimoniale di quest'ultimo, riscontrata pressoché ovunque (tab. XXI).

\subsubsection{Distanze genetiche}

$\mathrm{Al}$ contrario di quanto visto negli sposi, rispetto al primo periodo (1815-29) è il terzo (1845-59) che appare il più distante. In generale poi si ritrovano distanze più ampie tra i diversi periodi, sintomo di un maggiore ricambio della popolazione femminile (fig. 3).

\subsubsection{Il metodo delle coppie ripetute}

Il metodo delle "coppie ripetute", applicato ai cognomi desunti dagli atti di matrimonio permette di valutare se all'interno della popolazione in esame esista un'unione matrimoniale preferenziale tra individui appartenenti ad alcune linee familia-
Tab. XXII - Valori del coefficiente RP

\begin{tabular}{|c|c|}
\hline Periodo & RP \\
\hline $\mathbf{1 8 1 5 - 2 9}$ & 0,0519 \\
\hline $\mathbf{1 8 3 0 - 4 4}$ & 0,0659 \\
\hline $\mathbf{1 8 4 5 - 5 9}$ & 0,0697 \\
\hline $\mathbf{1 8 6 0 - 7 5}$ & 0,0583 \\
\hline
\end{tabular}

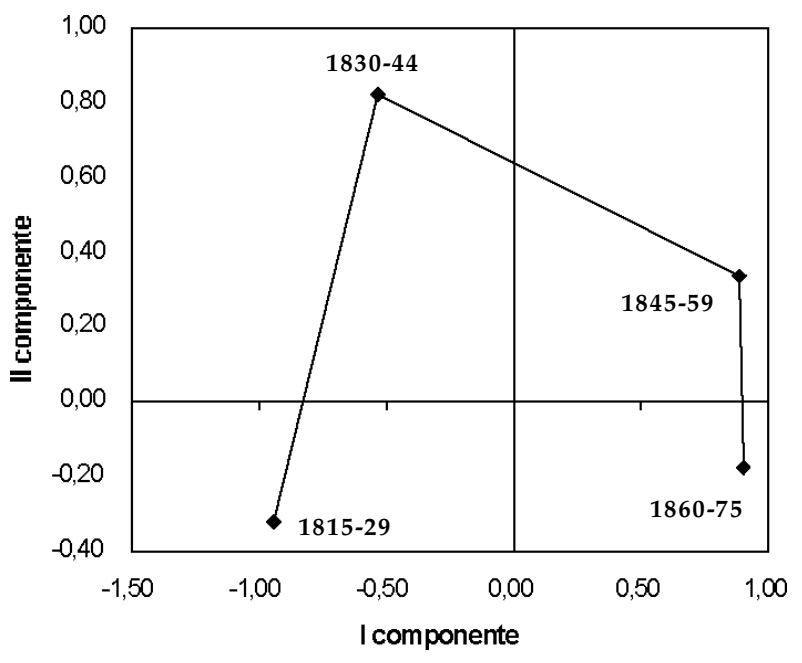

Fig. 3 - Spose. Distanze genetiche tra periodi.

ri, tale da determinare un aumento della frequenza di omozigoti. La distribuzione dei valori di RP (tab. XXII) rilevati risulta in accordo con il quadro finora emerso attraverso l'analisi degli altri indica tori. Per quanto riguarda l'andamento temporale, si osserva che ad Alia si conferma una graduale chiusura della popolazione, massima nel terzo periodo, testimoniata dai valori crescenti di RP. Il processo si inverte al momento della creazione dello Stato unitario.

\subsection{Conclusioni}

Il quadro emerso dallo studio biodemografico di Alia è, pertanto, quello di un paese nel quale si registra un progressivo processo di isolamento genico per tutta la prima parte del secolo, processo che sembra arrestarsi e invertire la tendenza con l'avvento dell'Unità d'Italia e solamente fino alla massiccia ondata emigratoria di fine secolo (nel 1901 negli Stati Uniti vivevano più di 3.000 individui originari di Alia).

Ciò concorda sostanzialmente con quanto si desume dalle fonti storiche, che descrivono Alia come un centro interessato solo marginalmente dalle prin- 
cipali vie commerciali della Sicilia e privo di attrattive economiche tali da determinare un afflusso importante di persone dall'esterno del suo territorio.

\section{Bibliografia}

Azevedo E., Pinto da Costa T., Silva M. C., Ribeiro L. R., 1983. The use of surnames for interpreting gene frequency distribution and past racial admixture. Human Biology, 5 (2) : 235-242

Barrai I., Barbujani G., Beretta M., Maestri I., Russo A., Formica G., Pinto Cisternas J., 1987. Surnames in Ferrara: distribution, isonimy and levels of imbreeding. Ann. Hum. Biol., 14: 415-422

Barrai I., Formica G., Scapoli C., Beretta M., Mamolini E., Volinia S., Barale R., Ambrosino P., Fontana F., 1992. Microevolution in Ferrara: isonimy 1890-1990. Ann. Hum. Biol., 19: 371

Barrai I., Scapoli C., Canella R., Formica G., Barale R., Beretta M., 1991. Isonimy in records of birth and death in Ferrara. Ann. Hum. Biol., 18: 395

Chen K., Cavalli Sforza L.L., 1983. Surnames in Taiwan: interpretation based on geography and history. Hum. Biol., 5 (2): 367-374

Fisher R. A., 1943. The relation between the number of species and the number of individuals in a random sample of animal population. J. Anim. Ecol., 12:42

Karlin S., Mc Gregor J., 1972. Addendum a W. Ewens. Theor. Pop. Biol., 3: 113-117
Karlin S., Mc Gregor J., 1967. The number of mutant forms maintained in a population. Proc. Fifth Berkeley Symp. Math. Stat. Prob., 4: 415-438

LaskerG.W., 1977. A coefficient of relationship by isonimy: a method for estimating the genetic relationship between populations. Hum. Biol., 49: 489-493

Lasker G.W., 1978. Increments through migration to the coefficient or relationship between communities by isonimy. Hum. Biol., 50: 235-240

Lasker G.W., 1985. Surnames and Genetic Structure. Cambridge University Press, Cambridge

Morton N.E., 1973.Kinship and population structure. In: Genetic Structure of Populations : 66-71. A cura di Morton N.E. University Press of Hawaii, Honolulu

Relethford J.H., 1988. Estimation of kinship and genetic distance from surnames. Hum. Biol., 60: 475

Rodriguez-Larralde A., Pavesi A., Scapoli C., Conterio F., Siri E., Barrai I., 1994. Isonimy and the genetic structure of Sicily. J. Biosoc. Sci., 26: 924

Weiss V., 1980 Imbreeding and genetic distance between hierarchically structured populations measured by surname frequencies. Mankind Quarterly, XXI: 135-149

Yasuda N., Cavalli Sforza L.L., Moroni A., SkolnicK M., 1974. The evolution of surnames: an analysis of their distribution and extinction. Theor. Pop. Biol., 5: 123142

Zei G., Guglielmino C., Siri E., Moroni A., Cavalli Sforza L. L., 1983. Surnames in Sardinia. Fit of frequency distribution for neutral alleles and genetic population structure. Annals of Human Genetics, 47: 329-352 



\title{
ANALISI DEMOGRAFICA DELLE CRISI DI MORTALIT À: L'EPIDEMIA DI COLERA DEL 1837
}

\author{
Bigazzi R.*, Torres Joerges $X .{ }^{* *}$, Tulumello S. ${ }^{*}$, De Iasio S.*** \\ * Laboratori di Antropologia. Dipartimento di Biologia Animale e Genetica. Università di Firenze \\ ** Dipartimento di Biologia. Università Autonoma di Madrid \\ *** Dipartimento di Biologia Evolutiva e Funzionale. Università di Parma \\ E-mail: rbigazzi@unifi.it
}

\begin{abstract}
L'evoluzione demografica dell'Europa in generale e dell'Italia in particolare dal medioevo al secolo scorso, è stata influenzata dalle diverse epidemie che in quel tempo si sono succedute. Peste, tifo, vaiolo e colera hanno provocato crisi di mortalità i cui effetti si sono fatti sentire in tutti i parametri demografici. Nel XIX secolo, le malattie che hanno avuto maggiore incidenza a livello demografico sono state il tifo petecchiale o esantematico e il colera. L'effetto di entrambe sulla popolazione è stato diverso come diverse sono le loro caratteristiche, sia sul piano clinico sia su quello epidemico.
\end{abstract}

\subsection{L'epidemia di colera del 1837 in Sicilia}

A partire dal 1829 l'Europa fu invasa da una epidemia di colera che provocò numerose vittime e non pochi disagi, anche di natura politico economica. Nel Regno delle Due Sicilie al problema dell'epidemia colerica fu posta attenzione già a partire del 1831, anno in cui fu stabilito un cordone sanitario intorno ai porti dell'Adriatico e del Tirreno. Questo cordone fu abolito poco tempo dopo a causa degli intralci e difficoltà che esso creava al commercio. Le autorità borboniche tornarono ad occuparsi seriamente del fenomeno epidemico nel 1835, quando l'epidemia, dopo aver percorso l'Asia centrale, la Russia e l'Europa arriva in Italia. $\mathrm{Si}$ disposero misure preventive di carattere generale, tendenti a formare un cordone sanitario per preservare il Regno dal contagio. Il Regno delle Due Sicilie fu, nel 1836, l'ultimo stato europeo ad essere invaso dal colera.

Agli inizi del giugno 1837 il morbo fece la sua apparizione in Sicilia. La malattia, sviluppatasi a Palermo, andò sempre più assumendo il caratte-

Ricerca sostenuta con il cofinanziamento della "Fondazione Dino Terra" di Lucca re epidemico e si diffuse rapidamente in alcuni comuni vicini, causando numerose vittime. Anche nell'isola erano stati fatti lavori di prevenzione e campagne per informare l'opinione pubblica; un esempio fu la pubblicazione, nell'agosto del 1835, di "Istruzione popolare", nella quale erano indicati i mezzi di prevenzione, i segni con i quali il colera si manifestava e le precauzioni da osservare prima dell'arrivo del medico. Ogni località fu anche informata sull'approntamento d'ospedali e camposanti, sulle regole di trasporto dei morti e sul modo di seppellirli (Leoni F., 1990).

Si voleva informare la popolazione, ma la realtà era che di fronte all'arrivo di quest'epidemia il disorientamento tra scienziati e medici era grande, il popolo non aveva fiducia in loro, e non badava ai consigli delle autorità e questo, di certo, non favoriva l'isolamento della malattia.

Tutti questi fattori, uniti alle condizioni igienico- sanitarie delle città, facevano diventare in pratica inutili tutti gli sforzi fatti da parte dei governi per cercare di evitare il contagio o almeno per limitarne i danni.

La situazione dell'ordine pubblico nell'isola diventò a poco a poco preoccupante, perché alla paura dovuta alla malattia si sommavano le crescenti difficoltà per conseguire viveri e vettovaglie, conseguenza dello stabilimento di un cordone sanitario marittimo.

A questo caos si aggiunsero le voci che proponevano che la malattia non era tale, ma un intento di avvelenare il popolo siciliano da parte dei Borboni. Questo fu sufficiente per mescolare le rivolte popolari frutto del panico con quelle di carattere indipendentista.

Il clima di rivolte ostacolò gli intenti di frenare l'epidemia e come conseguenze di questa situazione, le vittime di colera in Sicilia nel 1837 ammontarono circa 70.000 . 


\subsection{L'epidemia di colera del 1837 ad Alia}

La malattia, sviluppatasi a Palermo, assunse ben presto carattere epidemico e si diffuse rapidamente in alcuni comuni vicini, tra cui Alia.

L'andamento dei fenomeni demografici è abbastanza costante fino al 1837, per il quale si osserva un picco di mortalità - raddoppia il numero dei decessi - e una diminuzione delle nascite (fig. 1). L'anno seguente si assiste ad un prevedibile calo delle morti e ad una ripresa dei matrimoni, con conseguente aumento delle nascite negli anni successivi.

Come si può osservare nella figura 2 , non si notano fenomeni particolari prima dell'epidemia, che divampa nei mesi di luglio (116 morti contro i circa 20 dei mesi precedenti), agosto (83) e settembre (84) del 1837.

A causa dell'accumularsi in un periodo così breve di un elevato numero di decessi, nei mesi seguenti e fino a tutto il 1838, la mortalità resta a livelli inferiori al periodo precedente il colera, mentre il numero dei matrimoni, scarsi in luglio e assenti in agosto, ricresce ben presto, raggiungendo livelli insoliti nel mese di novembre.

La numerosità delle nascite non sembra risentire degli effetti dell'epidemia durante il suo manifestarsi; esse invece diminuiscono nei mesi successivi, per riprendere, con frequenze anche più elevate, solo alla fine del 1838.

Nel secolo scorso, la distribuzione delle morti in funzione dell'età (fig. 3) vedeva fortemente colpita la popolazione infantile. La maggior parte dei funerali officiati erano di bambini di età inferiore ai cinque anni, con una mortalità leggermente maggiore nei maschi.

Ciò che si evince dai grafici è un aumento del numero assoluto di morti pressoché in tutte classi di età nell'anno dell'epidemia. Una visione più attenta ci rivela però che non tutte le classi risultano colpite allo stesso modo. Quelle giovanili, e in particolare i bambini di età inferiore ad un anno, ri-

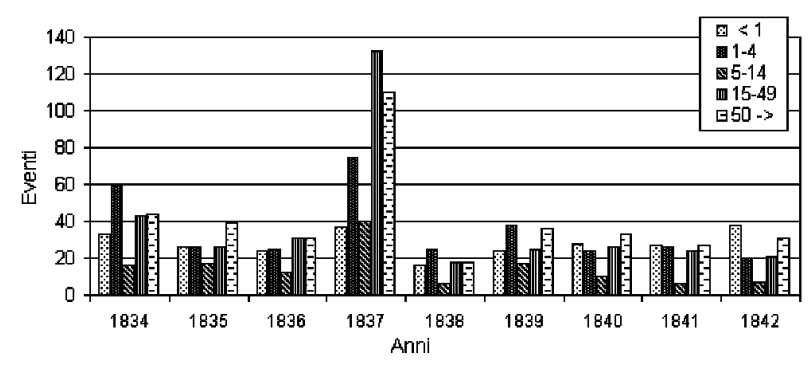

Fig. 3 - Decessi per classi d'età 1834-1842.

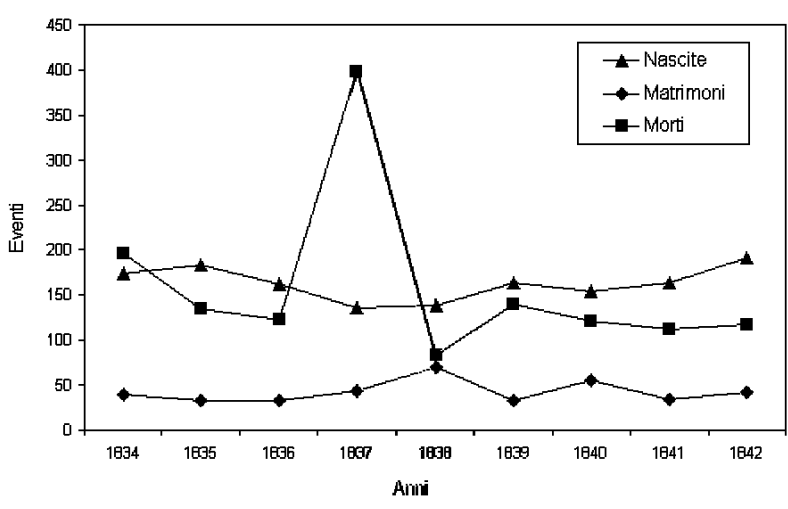

Fig. 1 - Eventi demografici ad Alia 1834-1842.

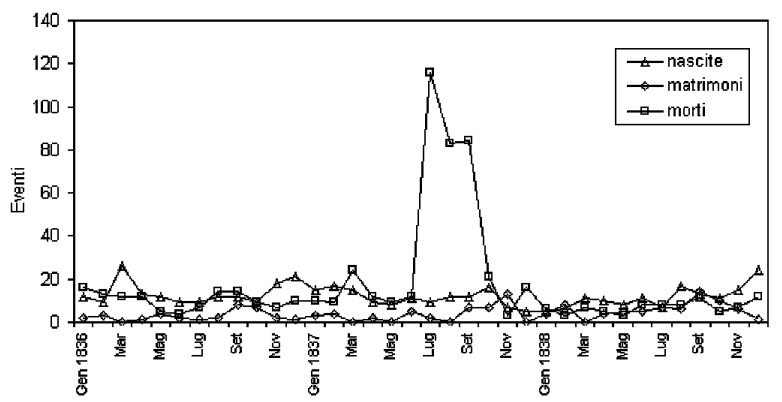

Fig. 2 - Eventi demografici per mese ad Alia 1836-38.

sentono di meno della crisi di mortalità causata dal colera e l'incidenza sul totale delle morti arriva a dimezzarsi (fig. 4).

Di contro cresce nettamente la percentuale di decessi nelle classi adulte, con un picco tra i 15 e i 49 anni, che appaiono colpite in modo preferenziale dal morbo. Un dato molto interessante, che conferma la diffusione del morbo del colera in tutta Italia per il periodo considerato, viene da studi condotti su un paese montano in provincia di Cuneo: Bellino. In questo paese sono stati studiati gli andamenti demografici lungo un arco di tempo di due secoli (1770-1970), analizzando le classi di età che più venivano coinvolte in crisi di mortalità. Mentre tra i morti del periodo 1915-1918 e 19401945 si osserva un'elevata percentuale di maschi in

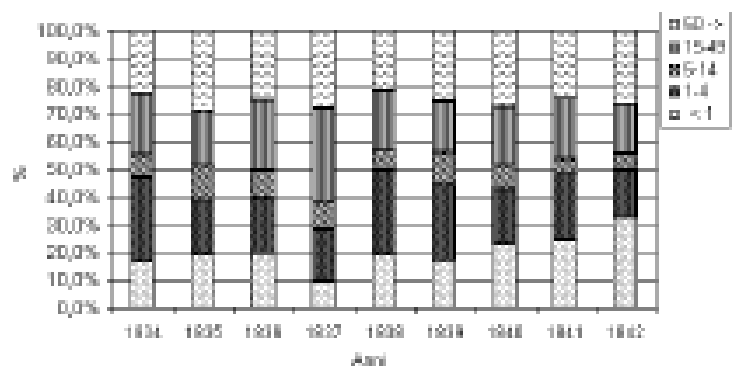

Fig. 4 - Incidenza delle morti per classi d'età. 


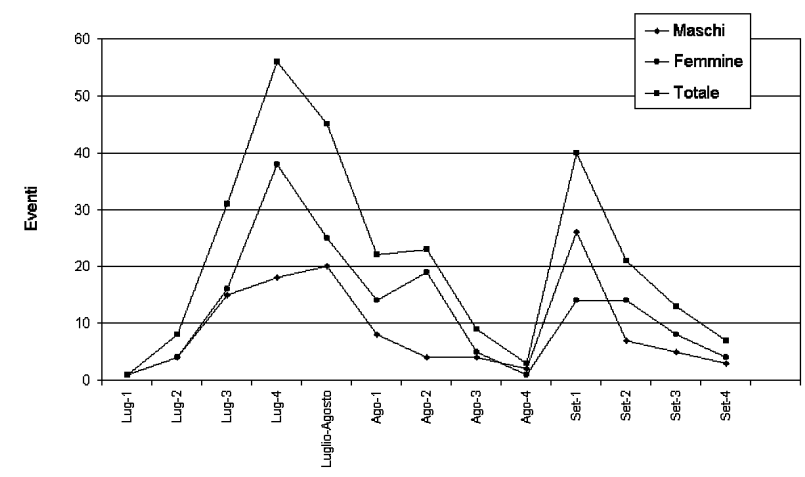

Fig. 5 - Decessi per settimana.

età compresa tra i 20 e i 34 anni e non si nota per detto periodo aumento della mortalità perinatale, nel periodo compreso tra il 1840 e il 1859 si può rilevare un marcatissimo incremento nella percentuale di mortalità perinatale e infantile. Ciò può suffragare l'ipotesi che la elevata mortalità del periodo 1840-1856, registrata nella comunità, sia dovuta a una epidemia.

L'analisi settimanale dei decessi durante l'epidemia ci offre una visione ancora più chiara dell'insorgenza e dello sviluppo del fenomeno. Innanzitutto si osserva che all'interno del periodo esistono due picchi di mortalità: uno tra la terza settimana di luglio e la seconda di agosto ed un altro nelle prime settimane di settembre (fig. 5).
Quest'ultima recrudescenza potrebbe essere dovuta ad una sottovalutazione della pericolosità del morbo dovuta a due settimane di bassa mortalità.

Le donne risultano colpite in modo preferenziale, ad eccezione della prima settimana di settembre, e per un periodo prolungato rispetto agli uomini, indice forse di una maggiore esposizione al contagio causata dalle cure portate agli ammalati. Anche in questo caso in entrambi i sessi, le classi intermedie risultano le più colpite dall'epidemia.

Si evidenzia inoltre che i decessi maschili avvengono in due periodi circoscritti per tutte le classi di età, mentre l'estensione della mortalità femminile per un periodo maggiore è soprattutto a carico della fascia di età tra i 15 e i 49 anni (figg. 6 e 7).

L'analisi della mortalità in relazione allo stato sociale (tab. I e fig. 8) è stata operata solamente per il sesso maschile, in quanto negli atti di morte la professione delle donne è risultata mancante in circa il $50 \%$ dei casi.

Inoltre, non conoscendo il numero totale dei contagiati all'interno delle diverse famiglie e degli appartenenti a ciascuna classe sociale risulterebbe azzardato anche solo ipotizzare una maggiore o minore resistenza alla malattia di questa o quella classe. È comunque interessante notare il fatto che la classe meno abbiente viene colpita in maniera crescente nel primo mese dell'epidemia, mentre le altre

Tab. I - Decessi maschili per "status sociale"

\begin{tabular}{|c|c|c|c|c|c|}
\hline Mese & $\begin{array}{c}\text { Contadini } \\
\text { Pastori }\end{array}$ & $\begin{array}{c}\text { Artigiani } \\
\text { Commercianti }\end{array}$ & $\begin{array}{c}\text { Possidenti } \\
\text { Benestanti }\end{array}$ & Totale & $\begin{array}{c}\text { Senza } \\
\text { classificazione }\end{array}$ \\
\hline Luglio-1 & 1 & & & & \\
\hline Luglio-2 & 9 & 3 & & 4 & \\
\hline Luglio-3 & 13 & 3 & 2 & 15 & \\
\hline Luglio-4 & 14 & 3 & 1 & 18 & 2 \\
\hline Luglio-Agosto & 4 & 1 & 1 & 6 & 2 \\
\hline Agosto-1 & 3 & 1 & & 4 & \\
\hline Agosto-2 & 3 & 1 & & 4 & 1 \\
\hline Agosto-3 & 2 & & & 2 & \\
\hline Agosto-4 & 20 & 5 & & 25 & 1 \\
\hline Settembre-1 & 5 & 1 & 1 & 7 & \\
\hline Settembre-2 & 2 & 2 & & 4 & 1 \\
\hline Settembre-3 & 3 & & & 3 & \\
\hline Settembre-4 & $\mathbf{7 9}$ & $\mathbf{2 3}$ & $\mathbf{8}$ & $\mathbf{1 1 0}$ & $\mathbf{7}$ \\
\hline Totale & & & & & \\
\hline
\end{tabular}




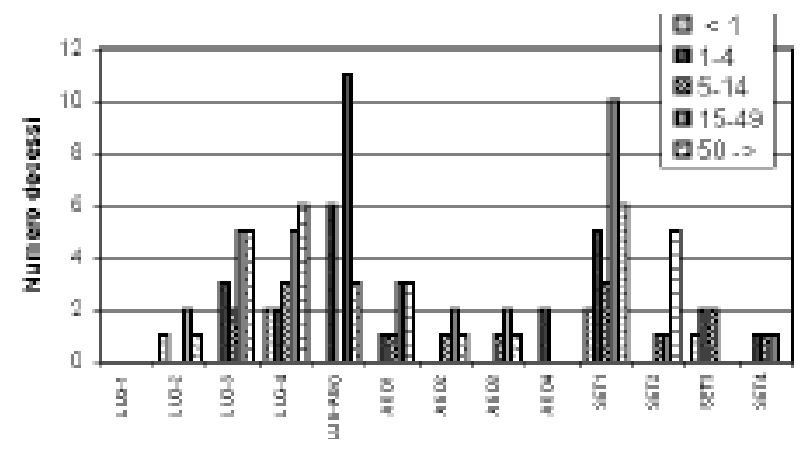

Fig. 6 - Maschi deceduti per grandi classi di età.

due classi tendono a mantenere costante o a diminuire la mortalità nello stesso periodo. Parrebbe quindi ragionevole ipotizzare che le classi agiate, dopo le prime manifestazioni del morbo, abbiano trovato il modo di proteggersi meglio rispetto ai più poveri, grazie forse alle migliori condizioni igieniche delle loro abitazioni, che fornivano senza dubbio una barriera più efficace contro il contagio.

Una reazione sociale all'epidemia di colera è data dalla ripresa del numero dei matrimoni fin dalla fine del 1837.

Dalle tabelle II, III, IV e V si traggono però anche altre notizie riguardo al fenomeno, collegate principalmente al fatto che tra le vittime dell'epidemia vi era una preponderanza di donne giovani. Si potrebbe vedere un risvolto di ciò nel fatto che il giovane

Tab. II - Matrimoni celebrati da settembre a dicembre 1837

\begin{tabular}{|l|c|c|}
\hline Stato civile & Donne nubili & Donne vedove \\
\hline Uomini celibi & 18 & 2 \\
\hline Uomini vedovi & 8 & 1 \\
\hline
\end{tabular}

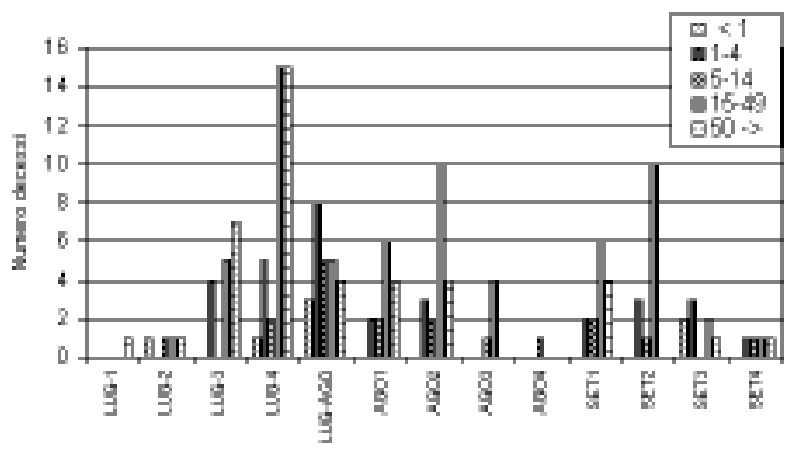

Fig. 7 - Femmine deceduti per grandi classi di età.

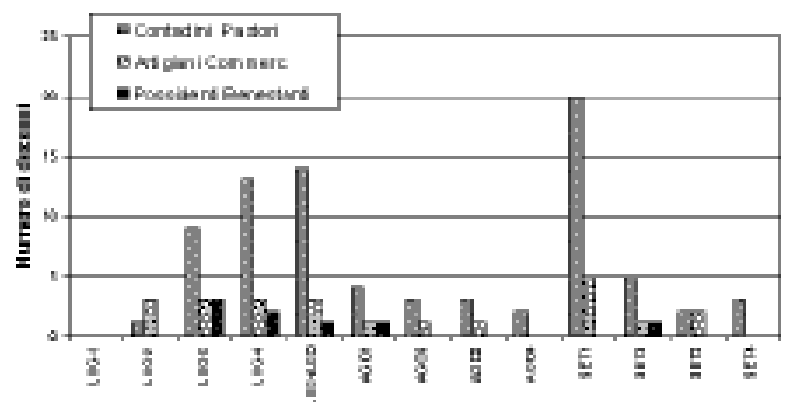

Fig. 8 - Decessi maschili per condizione socio-economica.

vedovo ha più possibilità di scelta rispetto alla donna, sia nubile che vedova. Ma si può anche ipotizzare che un vedovo abbia più bisogno di una vedova di risposarsi, perché meno adatto a vivere da solo.

Tab. III - Matrimoni celebrati dal settembre 1837 alla fine del 1838

\begin{tabular}{|l|c|c|}
\hline Stato civile & Donne nubili & Donne vedove \\
\hline Uomini celibi & 59 & 8 \\
\hline Uomini vedovi & 25 & 7 \\
\hline
\end{tabular}

Tab. IV - Matrimoni dal settembre 1837 a tutto il 1838

\begin{tabular}{|c|c|c|c|c|c|c|c|c|c|}
\hline Età al matrimonio & $<=\mathbf{1 9}$ & $\mathbf{2 0 - 2 4}$ & $\mathbf{2 5 - 2 9}$ & $\mathbf{3 0 - 3 4}$ & $\mathbf{3 5 - 3 9}$ & $\mathbf{4 0 - 4 4}$ & $\mathbf{4 5 - 4 9}$ & $\mathbf{5 0 - 5 4}$ & $\mathbf{5 5 - >}$ \\
\hline$<=\mathbf{1 9}$ & & 1 & 1 & & & & & & \\
\hline $\mathbf{2 0 - 2 4}$ & 7 & 10 & 4 & 1 & 2 & & 2 & & \\
\hline $\mathbf{2 5 - 2 9}$ & 5 & 11 & 7 & 3 & 1 & & & & \\
\hline $\mathbf{3 0 - 3 4}$ & 3 & 7 & 4 & 4 & & & & & \\
\hline $35-39$ & & 4 & 2 & 1 & 3 & & & & \\
\hline $\mathbf{4 0 - 4 4}$ & & & & 1 & 1 & & & & \\
\hline $\mathbf{4 5 - 4 9}$ & & & 3 & 2 & 1 & & & & \\
\hline $\mathbf{5 0 - 5 4}$ & & 2 & & & 1 & & & & \\
\hline $\mathbf{5 5 - >}$ & & & 1 & & 1 & & 2 & & 1 \\
\hline
\end{tabular}


Tab. V - Matrimoni dal settembre 1837 a tutto il 1838 secondo lo stato civile degli sposi

\begin{tabular}{|c|c|c|c|c|c|c|c|c|c|c|c|c|c|c|c|c|c|c|}
\hline Uomini vedovi & \multicolumn{9}{|c|}{ Donne nubili } & \multicolumn{7}{|c|}{ Donne vedove } \\
\hline Età al matrimonio & $<=19$ & $20-24$ & $25-29$ & $30-34$ & $35-39$ & $40-44$ & $45-49$ & $50-54$ & $55->$ & $<=19$ & $20-24$ & $25-29$ & $30-34$ & $35-39$ & $40-44$ & $45-49$ & $50-54$ & $55->$ \\
\hline$<=19$ & & & & & & & & & & & & & & & & & & \\
\hline $\mathbf{2 0 - 2 4}$ & 1 & & & 1 & & & & & & & & & & & & & & \\
\hline $\mathbf{2 5 - 2 9}$ & & 5 & & 1 & & & & & & & & & & & & & & \\
\hline $\mathbf{3 0 - 3 4}$ & 1 & 4 & & 2 & & & & & & & & & 1 & & & & & \\
\hline $\mathbf{3 5 - 3 9}$ & & & 1 & 1 & 1 & & & & & & & & & & & & & \\
\hline $\mathbf{4 0 - 4 4}$ & & & & & & & & & & & & & & 1 & & & & \\
\hline $\mathbf{4 5 - 4 9}$ & & & 3 & & 1 & & & & & & & & 1 & & & & & \\
\hline $\mathbf{5 0 - 5 4}$ & & 1 & & & 1 & & & & & & & & & & & & & \\
\hline $\mathbf{5 5 - >}$ & & & 1 & & & & & & & & & & & 1 & & 2 & & 1 \\
\hline
\end{tabular}

\begin{tabular}{|c|c|c|c|c|c|c|c|c|c|c|c|c|c|c|c|c|c|c|}
\hline Uomini celibi & \multicolumn{9}{|c|}{ Donne nubili } & \multicolumn{7}{|c|}{ Donne vedove } \\
\hline Età al matrimonio & $<=19$ & $20-24$ & $25-29$ & $30-34$ & $55-39$ & $40-44$ & $45-49$ & $50-54$ & $55->$ & $<=19$ & $20-24$ & $25-29$ & $30-34$ & $35-39$ & $40-44$ & $45-49$ & $50-54$ & $55->$ \\
\hline$<=19$ & & 1 & 1 & & & & & & & & & & & & & & & \\
\hline $\mathbf{2 0 - 2 4}$ & 6 & 10 & 4 & & & & 1 & & & & & & & 2 & & 1 & & \\
\hline $\mathbf{2 5 - 2 9}$ & 5 & 6 & 5 & 1 & 1 & & & & & & & 1 & 1 & & & & & \\
\hline $\mathbf{3 0 - 3 4}$ & 2 & 3 & 4 & 1 & & & & & & & & & & & & & & \\
\hline $\mathbf{3 5 - 3 9}$ & & 4 & 1 & & 1 & & & & & & & & & 1 & & & & \\
\hline $\mathbf{4 0 - 4 4}$ & & & & & & & & & & & & & & & & & & \\
\hline $\mathbf{4 5 - 4 9}$ & & & & & & & & & & & & & 1 & & & & & \\
\hline $\mathbf{5 0 - 5 4}$ & & 1 & & & & & & & & & & & & & & & & \\
\hline $\mathbf{5 5 - >}$ & & & & & & & & & & & & & & & & & & \\
\hline
\end{tabular}

\begin{tabular}{|c|c|c|c|c|c|c|c|c|c|c|c|c|c|c|c|c|c|c|}
\hline Donne vedove & \multicolumn{9}{|c|}{ Uomini celibi } & \multicolumn{7}{|c|}{ Uomini vedovi } \\
\hline Età al matrimonio & $<=19$ & $20-24$ & $25-29$ & $30-34$ & $35-39$ & $40-44$ & $45-49$ & $50-54$ & $55->$ & $<=19$ & $20-24$ & $25-29$ & $30-34$ & $35-39$ & $40-44$ & $45-49$ & $50-54$ & $55->$ \\
\hline$<=19$ & & & & & & & & & & & & & & & & & & \\
\hline $\mathbf{2 0 - 2 4}$ & & & & & & & & & & & & & & & & & & \\
\hline $\mathbf{2 5 - 2 9}$ & & & 1 & & & & & & & & & & & & & & & \\
\hline $\mathbf{3 0 - 3 4}$ & & & 1 & & & & 1 & & & & & & 1 & & & 1 & & \\
\hline $\mathbf{3 5 - 3 9}$ & & & & & 1 & & & & & & & & & & 1 & & & 1 \\
\hline $\mathbf{4 0 - 4 4}$ & & & & & & & & & & & & & & & & & & \\
\hline $\mathbf{4 5 - 4 9}$ & & 1 & & & & & & & & & & & & & & & & 2 \\
\hline $\mathbf{5 0 - 5 4}$ & & & & & & & & & & & & & & & & & & \\
\hline $\mathbf{5 5 - >}$ & & & & & & & & & & & & & & & & & & 1 \\
\hline
\end{tabular}

\begin{tabular}{|c|c|c|c|c|c|c|c|c|c|c|c|c|c|c|c|c|c|c|}
\hline Donne nubili & \multicolumn{9}{|c|}{ Uomini celibi } & \multicolumn{9}{|c|}{ Uomini vedovi } \\
\hline Età al matrimonio & $<=19$ & $20-24$ & $25-29$ & $30-34$ & $35-39$ & $\mid 40-44$ & $45-49$ & \begin{tabular}{|l|}
$50-54$ \\
\end{tabular} & 55-> & $<=19$ & $20-24$ & $25-29$ & $30-34$ & $35-39$ & $40-44$ & $45-49$ & 50-54 & 55-> \\
\hline$<=19$ & & & & & & & & & & & & & & & & & & \\
\hline $20-24$ & 1 & 10 & 6 & 3 & 4 & & & 1 & & & & 5 & 4 & & & & 1 & \\
\hline $25-29$ & 1 & 4 & 5 & 4 & 1 & & & & & & & & & 1 & & 3 & & 1 \\
\hline $30-34$ & & & 1 & 1 & & & & & & & 1 & 1 & 2 & 1 & & & & \\
\hline $35-39$ & & & 1 & & 1 & & & & & & & & & 1 & & 1 & 1 & \\
\hline $40-44$ & & & & & & & & & & & & & & & & & & \\
\hline $45-49$ & & 1 & & & & & & & & & & & & & & & & \\
\hline $50-54$ & & & & & & & & & & & & & & & & & & \\
\hline $55->$ & & & & & & & & & & & & & & & & & & \\
\hline
\end{tabular}




\section{Bibliografia}

Bigazzi R., Bramanti B., Chiarelli B., De Iasio S., Hermann B., Sineo L. Tartarelli G., Vianello M., 1999. Aspetti biologici e demografici della popolazione di Alia (PA). XIII Congresso degli Antropologi Italiani: Attualità dell'Antropologia. Ricerca e Insegnamento nel XXI secolo, Roma e Sabaudia (LT), 4-8 ottobre 1999

Bigazzi R., De Iasio S., Torres X., 1999. Alia (PA): le crisi di mortalità nella prima metà dell'ottocento. Convegno S.I.De.S: Salute e malattia fra ' 800 e ' 900 in Sardegna e nei Paesi dell'Europa Mediterranea, Alghero, 3-5 giugno 1999

Ciavarello M., 1981. Il colera a S. Marco in Lamis nel 1837. Gruppo cittadella Est. San Marco in Lamis.

De Iasio S., 1999. WinFamy. Speech Assistant Manuale+ CD Software

De Iasio S., Bigazzi R., 1999. Analisi biodemografica sulla popolazione di Alia (PA) nel XIX secolo. XIII Congresso degli Antropologi Italiani "Attualità dell'Antropologia. Ricerca e Insegnamento nel XXI secolo", Roma e Sabaudia (LT), 4-8 ottobre 1999

De Iasio S., Bigazzi R. Lucchetti E., 1997. L'epidemia di colera del 1837 ad Alia (PA). XII Congresso degli Antropologi Italiani. Palermo, settembre 1997. Antropologia Contemporanea, 20 (1-3):77-79

Del Panta L., 1980. Le epidemie nella storia demografica italiana (secoli XIV-XIX). Loescher, Torino.

Fleury, M., Henry L., 1965. Des registres paroissiaus à l'histoire de la population: manuel de dépouillement et d'exploitation de l'état civil ancien. I.N.E.D., Paris
Henry, L., 1968. The verification of data in Historical Demography. Population Studies, XXII (1): 385-396.

Henry, L., 1983. Manual de demografía histórica: técnicas de análisis.. Crítica. Barcelona

Leoni F., 1990. Il colera nell'Italia meridionale (1836-1837). Apes, Roma.

Livi Bacci, M. 1968. Fertility and Nuptiality Changes in Spain from the late 18 th to the early 20th Century. Population Studies, XXII (1): 83-102, (2): 211-234.

Manfredini M., De Iasio S., Lucchetti E., 1995. Dinamica di una popolazione e struttura delle famiglie: aspetti metodologici e prime applicazioni. In: L'adattamento umano all'ambiente. Passato e presente. Atti dell'XI Congresso degli Antropologi Italiani. Isernia, settembre 1995 (Peretto C., Milliken S. eds) ABACO, Forlì pp. 443-450

Nadal, J., 1996. La población española (siglos XVI a XX). Ariel.. Barcelona

Pérez Moreda, V., 1980. La crisis de mortalidad en la España interior (S. XVI-XIX). Siglo Veintiuno de España, Madrid, etc.

Sannino Cuomo A. L., 1984. L'incidenza in Basilicata delle grandi crisi epidemiche e di sussistenza su mortalità, natalità e nuzialità. In: Ricerche di storia sociale e religiosa.

Sorcinelli P., 1979. Miseria e malattie nel XIX secolo, i ceti popolari nell'Italia centrale fra tifo petecchiale e pellagra. In: La società italiana moderna e contemporanea. Franco Angeli, Milano.

Torres X., Bigazzi R., De Iasio S., Prado C., Chiarelli B., 1999. Mortalidad diferencial por sexos y grupos de edad nel pueblo de Alia (provincia de Palermo, Sicilia) a causa de la epidemia de colera del 1837. Santiago de Compostela (Spagna). 
Capitolo 5

\title{
ALIA: ALCUNE CONSIDERAZIONI DI ANTROPOLOGIA MOLECOLARE
}

\author{
Vona G., Ghiani M.E., Vacca L., Mameli G.E., Succa V., Calò C.M. \\ Dipartimento di Biologia Sperimentale, Sezione di Scienze Antropologiche, \\ Università di Cagliari
}

Lo studio e l'analisi delle caratteristiche biologiche di una popolazione necessitano dell'ausilio non solo dei metodi propri della genetica e dell'antropologia, ma anche delle conoscenze che provengono da numerose altre discipline. Per una corretta interpretazione dei dati genetici e antropologici sono fondamentali, ad esempio, le conoscenze relative agli eventi storici e demografici vissuti dalla popolazione che si vuole studiare. In altre parti del volume vengono trattati alcuni aspetti storici e demografici della popolazione di Alia che sono di grande utilità per interpretare $i$ dati che proporremo. Qui è sufficiente ricordare brevemente che le tracce archeologiche, che testimoniano della presenza dell'uomo in Sicilia, le più antiche delle quali risalgono ad alcune decine di migliaia di anni fa, cioè al Paleolitico o Antica Età della Pietra, e gli innumerevoli documenti storici mostrano che la Sicilia ha subito influssi da parte di varie aree del Mediterraneo fin dai tempi preistorici e fanno ritenere che l'isola sia stata sempre un importante punto d'incontro di culture e rotte commerciali.

$\mathrm{E}^{\prime}$ importante sottolineare che l'area su cui sorge l'attuale Alia vide il passaggio successivo di tutti quei gruppi che hanno animato la storia dell'isola, come testimoniano i reperti fenici, greci, punici, romani, bizantini, arabi, spagnoli.

Il ritrovamento nel 1995 dei resti dei deceduti per il colera del 1837 ha suscitato grande interesse nella comunità scientifica italiana e internazionale, tanto da richiamare numerosi gruppi di ricerca di varie Università italiane che si sono interessati allo studio di tematiche diverse riguardanti la popolazione attuale di Alia. In particolare il gruppo di ricerca dell'Università di Cagliari, coordinato dal Prof. Giuseppe Vona, si è occupato delle caratteristiche genetiche della popolazione aliese attuale in rapporto alle altre popolazioni siciliane e dell'area mediterranea.

\subsection{I documenti dell'analisi antropogenetica}

Per poter affrontare questo tipo di studio si è partiti dal prelievo di campioni di sangue: circa 150 abitanti, aliesi almeno da tre generazioni, hanno collaborato alla realizzazione della ricerca offrendo una piccola quantità del loro sangue.

Il sangue è un elemento importantissimo del nostro organismo che contiene una grande varietà di sostanze, le proteine, necessarie alla vita dell'organismo Il nostro corpo costruisce queste sostanze, circa 100.000, partendo da un messaggio che è contenuto nei "geni", piccoli tratti di una molecola formata da due filamenti avvolti tra loro a spirale, il DNA, che costituisce i cromosomi situati nel nucleo di ogni cellula.

I 46 cromosomi che ognuno di noi possiede provengono metà dalla propria madre e metà dal proprio padre. Ciò significa che metà del DNA, quindi dei geni, è di origine materna e l'altra metà di origine paterna. $\mathrm{E}^{\prime}$ per questo che i figli somigliano ai genitori. Ma non bisogna credere che la somiglianza tra genitori e figli sia limitata a quei caratteri del corpo che percepiamo con immediatezza come la statura, il colore degli occhi e dei capelli, la forma della testa o del corpo. Le somiglianze riguardano moltissimi altri caratteri che i nostri occhi non percepiscono, come quelli di natura biochimica, ad esempio i gruppi sanguigni.

Ognuno di noi dovrebbe conoscere il proprio gruppo sanguigno per una corretta trasfusione di sangue in caso di necessità, cioè dovrebbe sapere se il proprio gruppo è $0, \mathrm{~A}, \mathrm{~B}$ oppure $\mathrm{AB}$. $\mathrm{E}$ ancora se è Rh+ oppure Rh-, Kell positivo o negativo. Il possedere un gruppo oppure l'altro dipende dalla combinazione di geni che abbiamo ricevuto dai nostri genitori. $\mathrm{E}$ così è per tutte le altre sostanze presenti nel nostro corpo. 
Il fatto che tutte queste sostanze siano sotto il controllo dei geni che vengono trasmessi dai genitori ai figli, quindi da una generazione all'altra, rende i gruppi sanguigni, gli enzimi e le proteine ottimi strumenti di indagine per lo studio della storia genetica di una popolazione, ossia dei marcatori genetici.

Un'altra importante osservazione è necessaria: le popolazioni umane, come del resto i singoli individui, non sono uguali sotto l'aspetto genetico. I geni che controllano il sistema $\mathrm{AB} 0$ sono tra loro lievemente differenti (alleli) e producono proteine che si somigliano per struttura e funzione, ma non sono perfettamente identiche. Per questo un individuo può essere di gruppo A e un altro di gruppo B. Potrà accadere che in una popolazione gli individui portatori del gruppo A siano più numerosi degli individui di gruppo B, come si verifica nella popolazione siciliana nel suo complesso, mentre un'altra popolazione potrà essere composta di un numero di individui di gruppo B maggiore di quelli di gruppo A, come accade in alcune popolazioni dell'Asia centrale.

Per il nostro studio, partendo dai campioni di sangue, abbiamo esaminato 13 marcatori genetici e le loro distribuzioni nella popolazione di Alia le cui frequenze sono state poi confrontate con quelle di altre aree della Sicilia (Agrigento, Caltanissetta, Catania, Enna, Messina, Palermo, Ragusa, Siracusa e Trapani).

I polimorfismi genetici studiati sono: 8 sistemi enzimatici presenti nei globuli rossi del sangue, cioè la Fosfatasi acida eritrocitaria (ACP), Adenosinadeaminasi (ADA), Adenilato Kinasi (AK), Esterasi-D (ESD), Gliossalasi (GLO), 6 Fosfato Deidrogenasi (PGD), Fosfoglucomutasi (PGM) e Superossidodismutasi (SOD); 3 proteine che si trovano nel siero del sangue: Gruppo specifico Componente (GC), Transferrina (TF) e alfa-1-antitripsina (PI); e infine i gruppi dei due sistemi sanguigni $\mathrm{ABO}$ e $\mathrm{Rh}$.

Sono questi i documenti dei quali ci siamo serviti per analizzare la struttura genetica di Alia e abbiamo cercato di ricostruirne la storia biologica.

\subsection{Alia e le altre popolazioni siciliane}

Dai risultati rilevati dalle distribuzioni dei geni nella popolazione di Alia, questa appare caratterizzata da alcune frequenze alleliche particolari. L'allele $\mathrm{AB} 0 * \mathrm{~A}$ del sistema sanguigno $\mathrm{AB} 0$ si presenta con una frequenza che risulta essere la più bassa fra

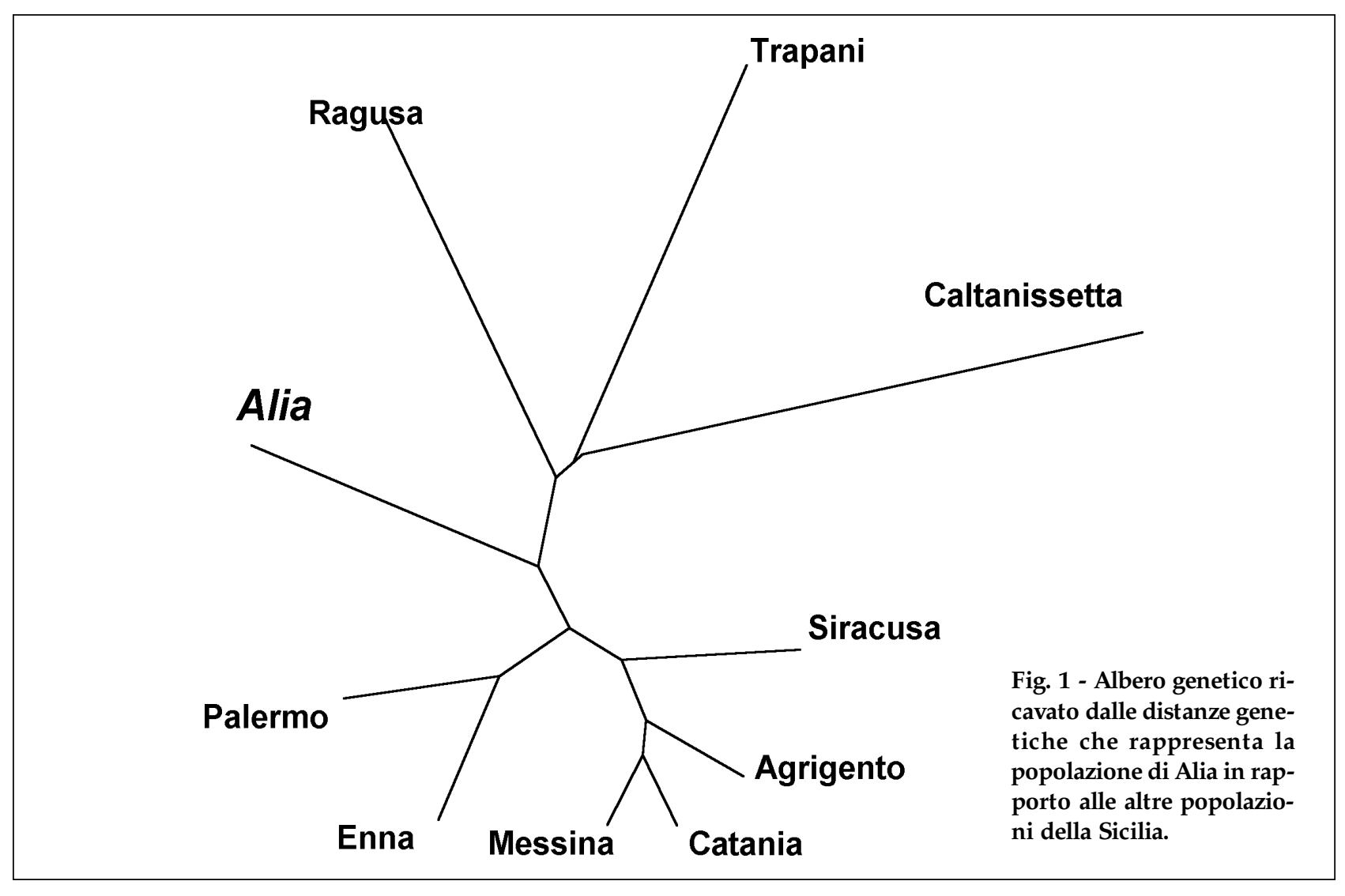




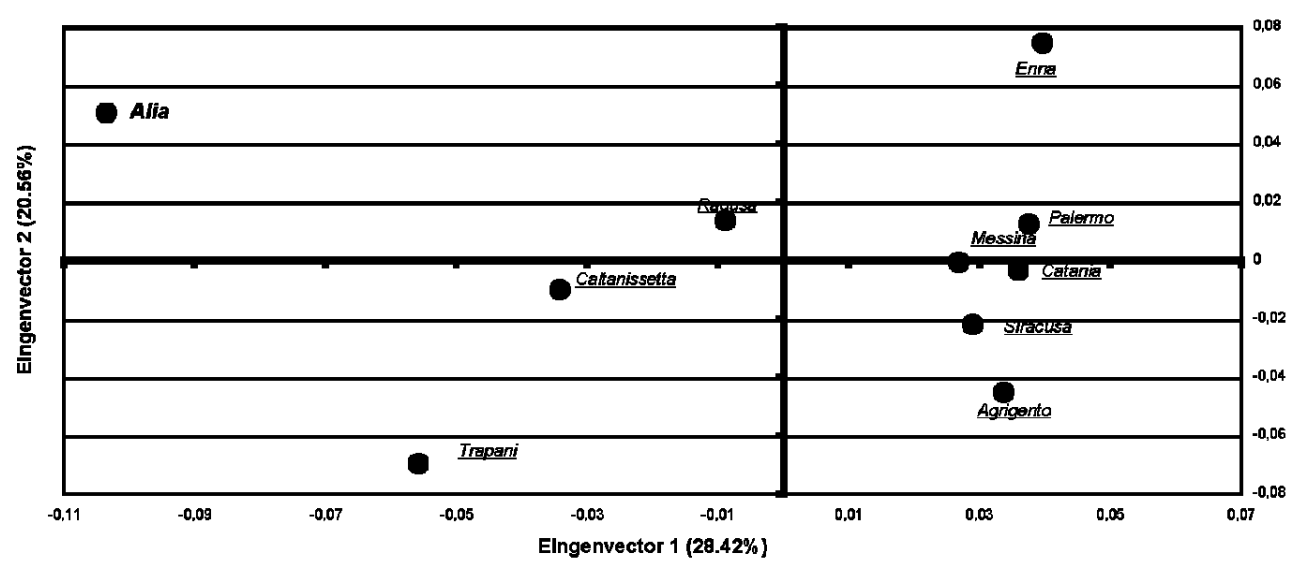

Fig. 2 - Grafico bidimensionale ottenuto dall'analisi dell'R-matrix.

quelle riscontrate in Sicilia, mentre la frequenza dell'allele $\mathrm{AB} 0 * \mathrm{~B}$ è, al contrario, la più elevata. Ancora le frequenze di Alia per gli alleli dell'enzima fosfatasi acida eritrocitaria, $\mathrm{ACP}^{*} \mathrm{~A}$ e $\mathrm{ACP}^{*} \mathrm{~B}, \mathrm{CO}^{-}$ stituiscono, rispettivamente, $\mathrm{i}$ valori più basso $\mathrm{e}$ più alto delle frequenze trovate negli altri campioni della Sicilia. E interessante osservare, inoltre, che nella popolazione di Alia è stato ritrovato un allele della sieroproteina alfa-1-antitripsina, il $\mathrm{PI}^{*} \mathrm{M} 4$, che non era stato rilevato in nessuno degli altri campioni siciliani studiati in precedenza.

Utilizzando contemporaneamente tutte le frequenze alleliche dei marcatori analizzati, attraverso delle elaborazioni statistiche, è possibile stabilire il grado di somiglianza genetica di due o più popolazioni o, in alternativa, quanto le popolazioni nel corso della loro esistenza siano divenute differenti sotto l'aspetto genetico. Questo è reso pos sibile dal calcolo delle distanze genetiche che separano le popolazioni e dalla rappresentazione dei rapporti che dalle distanze emergono attraverso un grafico a forma di albero.

Nella figura 1 compare appunto l'albero che rappresenta le relazioni esistenti tra Alia e le altre popolazioni della Sicilia, albero che è derivato dalle distanze genetiche calcolate. Alia si trova su un ramo dell'albero che appare molto separato rispetto a tutte le altre popolazioni indicando un'accentuata diversificazione genetica. Questa riguarda non solo quelle popolazioni che sono molto di-

Fig. 3 - Le distanze genetiche derivate dalle frequenze dei marcatori esaminati individuano barriere genetiche, una delle quali isola la popolazione di Alia 
stanti geograficamente da Alia, come Catania e Messina, ma anche le popolazioni di quelle aree che sono limitrofe, come Palermo e Agrigento. Complessivamente l'albero evidenzia una grande variabilità genetica interna all'isola che è legata oltre che agli aliesi, anche alle popolazioni di Ragusa, Trapani e Caltanissetta. L'osservazione diretta dei valori delle distanze genetiche conferma una forte caratterizzazione di Alia rispetto alle aree di confronto: le distanze variano tra $9.3 \times 10^{-3}$ e 15.5 x $10^{-3}$, più elevate di quelle che si sono ottenute per le altre popolazioni $\left(2.0 \times 10^{-3}-15 \times 10^{-3}\right)$.

La peculiarità di Alia viene ancora più messa in risalto da un'altra analisi statistica, quella dell'Rmatrix (Harpending e Jenkins 1973), che partendo dalle frequenze geniche permette di rappresentare le popolazioni su un piano in base alle loro somiglianze o differenze complessive.

Alia si colloca così nella figura 2 in una posizione fortemente appartata. E abbastanza isolate appaiono anche le popolazioni di Trapani, Caltanissetta e Ragusa.

Le distanze genetiche hanno permesso di ricavare un'altra importante osservazione, sfruttando un metodo particolare, quello delle triangolazioni angolari e l'algoritmo del Monmonier (1973). Si sono potute così individuare delle barriere, cioè due zone di discontinuità marcata delle frequenze geniche all'interno della Sicilia, come mostra in modo evidente la figura 3. Una barriera genetica è stata disegnata intorno ad Alia, con la sua origine tra Alia e Agrigento. Essa, oltre ad isolare completamente la popolazione di Alia, separa anche l'area occidentale da quella centro-meridionale. Un'altra zona di improvviso cambio di frequenze geniche percorre l'isola da sud a nord separando la zona orientale da quella centroccidentale.

\subsection{Il DNA mitocondriale e la popolazione di Alia}

Oltre ai marcatori genetici che, come si è detto, sono controllati dal DNA nucleare che viene ereditato da ambedue i genitori, è stato studiato nella popolazione di Alia un altro tipo di DNA quello mitocondriale.

Il DNA mitocondriale è una piccola molecola circolare localizzata all'interno dei mitocondri, piccoli corpuscoli situati nella cellula fuori dal nucleo, nella parte detta citoplasma. Essi rappresentano le centrali energetiche delle cellule. In ogni singolo mitocondrio vi sono numerosi anelli di
DNA (mtDNA), ciascuno dei quali comprende 37 geni interessati nella produzione di energia.

Una caratteristica del mtDNA è quello di essere ereditato esclusivamente per via materna, vale a dire che ognuno di noi ha ereditato il mtDNA dalla sola madre, a differenza del DNA nucleare, per il quale, come si è ricordato in precedenza, il padre e la madre contribuiscono in uguale misura nel determinare il DNA del proprio figlio.

Già dal 1981 si conosce la struttura completa del mtDNA che è stato interamente sequenziato da Anderson e dai suoi collaboratori. Si tratta di un tipo di DNA a catena singola (aploide), al contrario di quello nucleare che risulta costituito da una catena doppia (diploide), di 16569 paia di basi (bp).

Il mtDNA è soggetto a cambiamenti, cioè mut tazioni, che si esprimono con sostituzioni delle singole unità (basi) che lo costituiscono, che possono essere anche causa di gravi patologie. La frequenza con la quale avvengono le mutazioni nel mtDNA è estremamente elevata, circa 10 volte superiore a quella del DNA nucleare, e questo permette di utilizzare il DNA mitocondriale nello studio dei fenomeni che riguardano l'evoluzione a breve termine delle popolazioni. Le analisi comparate di molecole di mtDNA, effettuate su individui sparsi in tutto il mondo, hanno consentito di ricostruire le principali migrazioni degli esseri umani anatomicamente moderni che hanno percorso i vari continenti. Esse hanno permesso anche di stabilire date approssimative per il popolamento non solo dei diversi continenti, ma anche di aree geograficamente più limitate.

All'interno della molecole del mtDNA è presente una zona denominata D-loop, costituita da due distinti segmenti (I e II), che controlla le funzione a cui la molecola è deputata. L'interesse di molti ricercatori si è rivolto con una certa preferenza al segmento I di tale zona, che sembra presentare il più elevato tasso di evoluzione della molecola.

Tenendo conto delle interessanti informazioni che possono derivare dall'analisi del DNA mitocondriale, è stato effettuato il sequenziamento di 388 bp della regione di controllo del mtDNA, comprese tra la posizione 16023 e 16410 della sequenza di riferimento di Anderson, in un campione di 49 individui della popolazione di Alia. È la prima volta che nella letteratura scientifica viene riportato questo tipo di dati su una popolazione siciliana.

I risultati ottenuti rivelano anche nel caso del mtDNA, come già per i marcatori genetici classi$\mathrm{ci}$, che la popolazione aliese emerge per alcune ca- 


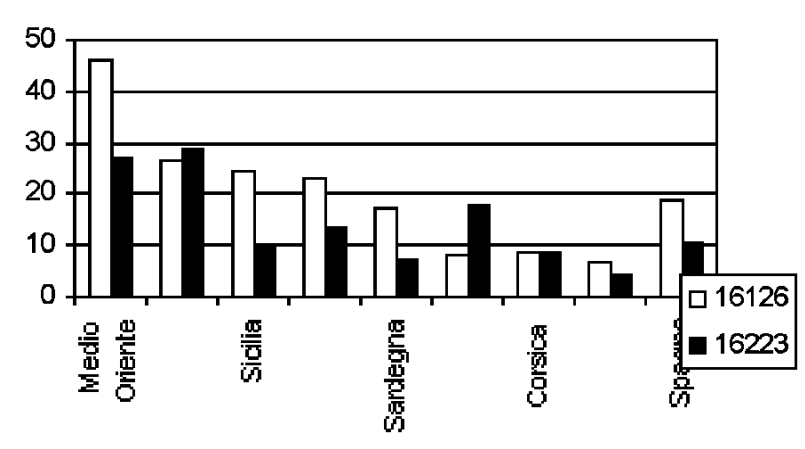

Fig. 4 - Variazioni delle mutazioni presenti nei siti 16126 e 16223 della sequenza mtDNA che mostrano un andamento decrescente dall'Oriente verso $\mathrm{l}^{\prime}$ Occidente mediterranei.

ratteristiche sue proprie quando è confrontata con altre popolazioni di origine euromediterranea. La nostra analisi ha messo in luce che i Siciliani, per quanto riguarda le sequenze del mtDNA, hanno alcune frequenze intermedie a quelle trovate nelle popolazioni di confronto. Ciò è particolarmente evidente nella distribuzione di alcune sostituzioni, che collocano il campione siciliano in una posizione centrale tra le popolazioni orientali e quelle occidentali del Mediterraneo. Ad esempio le sostituzioni che si registrano nei siti 16069, 16126 e 16223 della sequenza hanno delle frequenze che decrescono passando dal Vicino Oriente verso Occidente (Figura 4 ).

Servendoci delle frequenze delle varie mutazioni è stato possibile calcolare, come per i marcatori genetici di cui si è parlato in precedenza, le distanze genetiche e da queste abbiamo costruito l'albero genetico riportato in figura 5.

Appare subito evidente che alle due estremità della parte dell'albero che riguarda le popolazioni mediterranee, non tenendo quindi conto dell'Africa e dell'Asia, si trovano le popolazioni del Medio Oriente da una parte e i Baschi, unitamente ai Corsi, dall'altra.

L'analisi della distribuzione delle differenze nelle sequenze del mtDNA degli aliesi sembra indicare che, in un passato non molto recente, si sia verificato in Sicilia un episodio di espansione della popolazione. La popolazione iniziale costituita da circa 300-900 individui sarebbe aumentata sino ad un numero compreso tra 12.000 e 35.000 .

Ma quando si sarebbe verificato tale aumento demografico della popolazione? Le stime suggerite dall'analisi delle sequenze del DNA mitocondriale indicano un periodo che oscilla tra 20.732 e 59.691 anni fa, con un valore intermedio di 39.679 anni.

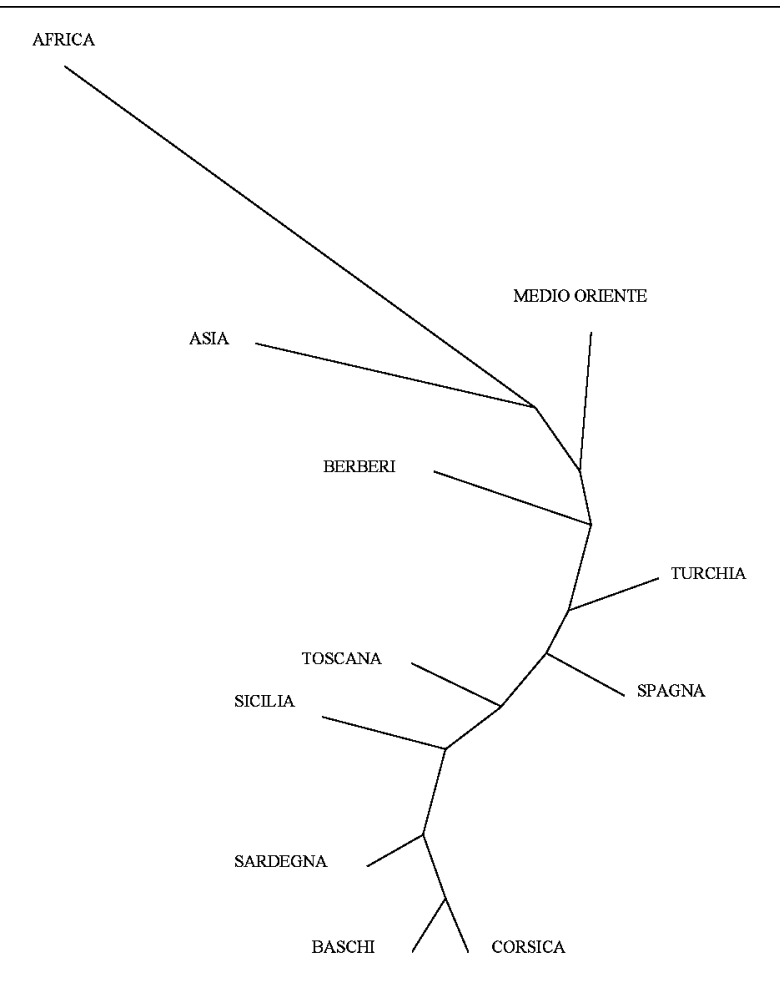

Fig. 5 - Albero genetico ricavato dalle distanze ottenute per il DNA mitocondriale. L'albero mostra una crescente differenziazione nel Mediterraneo da Oriente verso Occidente.

Anche le popolazioni di confronto mostrano un unico maggiore episodio di espansione che si sarebbe verificato in tempi diversi rispetto a quelli della Sicilia, dapprima in Oriente e poi in Occidente. La popolazione che avrebbe avuto l'espansione più antica, indicata tra 47.000 e 135.000 anni fa circa, sarebbe quella del Medio Oriente. All'opposto la più recente espansione si sarebbe verificata nei Baschi tra 14.000-41.000 anni fa circa.

I suggerimenti che quindi vengono dalle diverse analisi effettuate sembrano concordare con una migrazione delle popolazioni da Oriente verso Occidente all'interno del Mediterraneo, migrazione che è stata sostenuta anche da molti altri autori (Comas et al., 1996; Francalacci et al., 1996; Varesi et al., 2000 ).

Un'altra fonte di informazione che proviene dall'analisi del DNA mitocondriale sta nel fatto che nella sequenza di un individuo possono essere presenti contemporaneamente più mutazioni che, se considerate congiuntamente, costituiscono un'associazione detta aplotipo.

Se analizziamo le frequenze degli aplotipi, notiamo che la Sicilia, rappresentata da Alia, ha in al- 
cuni casi dei valori intermedi tra quelli delle popolazioni mediterranee orientali e quelli delle popolazioni occidentali. Come ad esempio la frequenza dell'aplotipo che corrisponde alla sequenza di Anderson. In altri casi la popolazione siciliana mostra aplotipi rari comuni solamente ad alcune delle altre popolazioni del confronto come, ad esempio, un aplotipo comune con gli Spagnoli o quello comune con i Sardi. Altri singoli aplotipi sono condivisi con i Toscani, con i Berberi e con la popolazione medio orientale.

Ma possiamo osservare anche che il $45 \%$ degli aplotipi ritrovati ad Alia non sono presenti nelle altre popolazioni e sembrano essere quindi caratteristici di questa popolazione.

\subsection{Alia e il punto di vista dell'antropologia molecolare}

I risultati ottenuti analizzando la struttura genetica della popolazione di Alia mediante i marcatori genetici costituiti dai gruppi sanguigni, dagli enzimi e dalle proteine del sangue e dal sequenziamento del DNA mitocondriale, permettono di arrivare ad alcune osservazioni che riguardano sia la storia biologica di questa popolazione sia, più in generale, di quella dell'intera Sicilia.

Secondo alcuni studiosi non vi sarebbe all'interno della Sicilia attuale una variabilità genetica tale da permettere una suddivisione in sottopopolazioni e nelle sue caratteristiche genetiche non sarebbe possibile riconoscere nessuna influenza attribuibile ai gruppi e alle popolazioni che nell'arco dei millenni a partire dalla Preistoria sono giunti sul suolo siciliano.

Ma secondo altri autori in Sicilia sono presenti delle differenze genetiche interne che possono essere fatte risalire molto indietro nella storia dell' $i$ sola. Sicani, Elimi, Siculi potrebbero essere all'origine della variabilità attuale e il retaggio da essi lasciato avrebbe prodotto una differenziazione tra l'area occidentale e quella orientale dell'isola (Piazza et al., 1988). Anche la colonizzazione greca avrebbe dato un contributo forte alla variabilità genetica interna della Sicilia che avrebbe ricevuto un successivo apporto anche dai Cartaginesi, Romani, Arabi, Normanni, Spagnoli ecc. In una ricerca condotta da Semino e collaboratori (1989) veniva ipotizzata, in base ai dati rilevati, una migrazione di geni dall' Africa nera verso la Sicilia, valutabile intorno al 10\%. Questi geni sarebbero stati introdotti nell'isola dall'arrivo di schiavi neri giunti al seguito di Fenici e Romani e/o dalle migrazioni arabe. Ma dai dati della nostra ricerca sul mtDNA non emerge alcuna caratteristica comune tra la popolazione siciliana e le popolazioni nere dell'Africa, come ci si sarebbe potuto attendere in base ai risultati del lavoro citato. L'attesa di un'influenza africana era supportata anche dalla considerazione che la Sicilia è l'unica regione del Mediterraneo, insieme con la Grecia, a possedere una frequenza non trascurabile di emoglobina $S$ e del gene che la determina. Questo, che è responsabile di una grave forma di anemia detta falciforme o siclemia, è notevolmente diffuso in Africa tanto da essere un gene caratteristico di molte delle popolazioni che vivono specialmente nelle aree centrali in questo continente. La stessa indicazione proviene dall'esistenza nel complesso dei geni (pool genico) della popolazione siciliana di altri geni che si ritengono di origine africana (Vona et al., 1998, 2000). Tuttavia alcuni aplotipi, che emergono dalle sequenze da noi studiate, risultano comuni ai Siciliani e ai Berberi e suggeriscono quindi la possibilità che vi sia stato un certo contatto con le popolazioni dell'Africa settentrionale.

Ma al di là della ricerca delle tracce che una popolazione o l'altra hanno potuto lasciare nel pool genico dei Siciliani, cosa possibile solamente in alcuni casi particolari, una considerazione appare certa: la Sicilia non è una unità omogenea dal punto di vista della sua struttura genetica.

Alcune ricerche, precedenti alla nostra, sviluppate mediante i marcatori genetici classici (Piazza et al., 1988) e attraverso l'uso delle frequenze e delle distribuzioni dei cognomi e dei nomi presenti nell'attuale popolazione siciliana (Guglielmino et al., 1991), rivelano l'esistenza tra la parte occidentale e la parte orientale dell'isola di una certa differenziazione che a volte si traduce nella comparsa di alcuni cambiamenti graduali delle frequenze da est verso ovest.

La Sicilia non presenta sul suo territorio strutture orografiche tali da far pensare che vi siano state forme di isolamento geografico che possano spiegare le differenze che i risultati ottenuti hanno messo in evidenza, ma vi devono essere stati altri meccanismi che hanno concorso a produrre le diversità riscontrate. Vi è una variazione culturale interna alla Sicilia che viene evidenziata dall'analisi dei cognomi e dei nomi la cui differente distribuzione è indicativa di diverse condizioni storiche e sociali. Questa analisi suggerisce che la Sicilia è divisa in differenti regioni e che la principale sud- 
divisione, con un gradiente nella stessa direzione di variazione delle distribuzioni delle frequenze geniche, è in direzione est-ovest (Guglielmino et al., 1991). I risultati dello studio della struttura genetica che emergono dai cognomi e dai nomi, sottolinea inoltre una persistenza dell'influenza greca attraverso i secoli.

Un segnale della differenziazione interna viene anche dal rilevamento dell'esistenza di barriere genetiche interne da parte di diversi ricercatori (Barbujani et al., 1992; Rickards et al., 1992; Guglielmino et al., 1991; Zei et al., 1993). Un improvviso e significativo cambiamento delle frequenze geniche è stato ravvisato tra le aree occidentali e centrali dell'isola oltre che a sud-est e nord-est (Barbujani et al., 1992). Una barriera intorno ad Enna, nel centro dell'isola, e un'altra ad occidente tra Agrigento e Trapani sarebbero presenti secondo Rickards et al. (1998).

I risultati che abbiamo ottenuti ad Alia in rapporto alle altre popolazioni della Sicilia sembrano concordare con quegli autori che sostengono l'assenza di uniformità genetica interna all'isola. Non solo, ma essi sembrano suffragare anche l'esistenza di una divergenza genetica tra le aree occidentali e quelle orientali dell'isola, avendo evidenziato l'esistenza di alcune barriere genetiche che percorrono l'isola dividendola in modo abbastanza netto in tre grandi aree. Quindi si può ritenere che la Sicilia attuale non è caratterizzata affatto da un'uniformità genetica, ma da una certa variabilità interna che si manifesta in alcuni casi attraverso l'esistenza di gradienti di distribuzione delle frequenze geniche, in altri attraverso significative barriere genetiche. $\mathrm{Si}$ potrebbe perciò pensare alla popolazione siciliana come costituita da un insieme di sottopopolazioni.

Ci si potrebbe chiedere in che modo possa essere spiegata la particolarità genetica che sembra caratterizzare la popolazione aliese, quali siano i fattori che l'hanno determinata.

La singolarità di Alia potrebbe essere legata al parziale isolamento che per lunghi periodi l'ha contraddistinta. Infatti, per tutta la prima parte del XIX secolo d.C. la popolazione di Alia visse un processo di progressivo isolamento che si interruppe solamente dopo l'unificazione dell'Italia (1860) e che riprese con la forte ondata emigratoria che si verificò nell'ultima parte dello stesso secolo. L'analisi dei cognomi rivela, specialmente nel periodo centrale del secolo XIX, un numero estremamente ridotto di cognomi diversi presenti ad Alia: circa 13 su 100 (Bigazzi, 2000). Ciò significa che Alia aveva pochi scambi matrimoniali con le altre popolazioni, cioè gli aliesi preferivano scegliere il proprio coniuge all'interno della loro comunità. Questo determinò quindi anche uno scambio o flusso di geni veramente ridotto con le popolazioni limitrofe. La struttura matrimoniale aliese era basata su matrimoni che avvenivano preferenzialmente entro il paese e spesso tra parenti. Così nel periodo tra il 1830 e il 1844, nel quale cadde l'epidemia di colera, Alia conservò solamente 127 cognomi diversi dei 219 presenti nei periodi precedenti (Bigazzi, 2000). Questo notevole decremento dei cognomi era in realtà l'indice della repentina contrazione del numero degli individui che costituivano la popolazione. $\mathrm{E}^{\prime}$ possibile che una riduzione tanto consistente e improvvisa della popolazione abbia in qualche modo rimescolato le frequenze geniche, abbia potuto cioè aumentare 0 ridurre la frequenza di un particolare gene o di un particolare aplotipo, modificando casualmente la struttura genetica complessiva (fenomeno della deriva genetica). La popolazione sopravvissuta al colera avrebbe potuto presentare frequenze geniche molto diverse rispetto a quelle preesistenti all'evento epidemico e a quelle delle altre regioni della Sicilia. L'isolamento avrebbe poi favorito il mantenimento di tale struttura.

Vi è la possibilità che anche un altro fattore abbia agito sulla popolazione di Alia. La divergenza genetica dettata da alcuni dei parametri del DNA mitocondriale e dalla peculiarità di alcune sequenze può essere stata causata anche da alcune espansioni più recenti che essendo più vicine a noi in termini di tempo non possono essere rilevate dagli attuali metodi impiegati. Tali espansioni potrebbero aver incrementato la variabilità mitocondriale locale, mantenuta poi dall'isolamento. Durante il periodo del colera, come si è già detto, scomparvero ad Alia un gran numero di cognomi presenti nella popolazione, ma furono introdotti negli anni successivi un numero pressoché identico di cognomi nuovi provenienti principalmente dalle aree limitrofe.

La posizione occupata dalla popolazione della Sicilia nel novero del Mediterraneo conferma da una parte la sua origine antica e dall'altra la conservazione della sua identità genetica.

Le date del maggior episodio di espansione della popolazione della Sicilia Occidentale, che sarebbe avvenuta durante il Paleolitico, concordano con quanto suggeriscono i ritrovamenti archeologici.

Nelle caratteristiche della popolazione di Alia si possono riconoscere i contatti che la Sicilia ha avu- 
to con le varie popolazioni dell'area mediterranea dei quali permane traccia nella comunanza di alcune mutazioni e di diversi aplotipi. E' evidente che il pool genico dei siciliani attuali è stato in qualche modo influenzato dalle altre popolazioni mediterranee. Un contributo da parte delle popolazioni del Medio Oriente è indubitabile. Ma apporti sono pervenuti anche da altre regioni del Mediterraneo. Alcune frequenze, che variano in direzione oriente-occidente o nel senso inverso e che trovano in Sicilia molto spesso il loro valore intermedio, fanno pensare che l'isola sia stata sempre un punto d'incontro non solamente culturale e commerciale, ma anche genetico e le popolazioni che hanno in qualche modo attraversato la Sicilia sembrano aver lasciato un retaggio non solo culturale ma anche genetico. In molti casi questo può essere fatto risalire come si è detto al Paleolitico, ma anche durante il Neolitico, cioè nel periodo della grande migrazione che accompagnò la diffusione dell'agricoltura dal Vicino Oriente verso le aree occidentali del Mediterraneo, e durante le epoche successive vi furono immissioni di geni.

$\mathrm{Ma}$, dall'altro canto, alcune caratteristiche della popolazione di Alia sembrano essere state modellate dagli effetti dei fenomeni casuali della deriva genetica e conservate dall'isolamento come rivelano alcuni fatti storici e alcuni venti demografici.

Rimangono ancora alcuni interrogativi ai quali dare risposta. Quanto somiglia la popolazione attuale di Alia, sotto l'aspetto genetico, alla popolazione che preesisteva all'epidemia di colera del 1837? Quanto questo evento drammatico che decimò la popolazione influì e cambiò la struttura genetica della popolazione che sopravvisse al colera stesso?

Lo studio approfondito che si sta conducendo sulla popolazione sub-fossile, rappresentata dagli scheletri ritrovati nella grotta del Camposanto Vecchio, potrà probabilmente chiarire in un confronto con i dati sulla popolazione attuale quali legami genetici tengano ancora avvinta la popolazione attuale a quella che abitò Alia prima del colera.

\section{Bibliografia}

Anderson S., Bankier A.T., Barrel B.G., De Bruijn M.H.L., Coulson A.P., Drouin J., Eperon I.C., Nierlich D.P., Roe B.A., Sanger F., Schreier P.H., Smith A.J.H., Staden R., Young I.G., 1981. Sequence and organisation of the human mitochondrial genome. Nature, 290: 457-465.

Barbujani G., Vian P., Fabbris L., 1992. Cultural barriers associated with large gene frequency differences among Italian populations. Hum. Biol., 64: 479-495.
Bigazzi R., 2000. Analisi microevolutive sulla struttura biologica e demografica della popolazione di Alia (PA) del XIX sec. Tesi di dottorato di Ricerca in Scienze Antropologiche all'Università di Firenze.

Comas D., Calafell F., Mateu E., Pérez-Lezaun A., Bertranpetit J, 1996. Geographic variation in

human mitochondrial DNA control region sequence: the population history of Turkey and its

relationship to the European populations. Mol. Biol. Evol., 13 (8): 1967-1077.

Culotta P., 1995. L'architettura della Gurfa. In: La Gurfa e il Mediterraneo. Ed. Comune di Alia.

Cumbo G., 1995. Le grotte della Gurfa ed altre emergenze archeologiche nella Sicilia centrale, zona cuscinetto, tra le idrovie Platani e Torto. Ed. Comune di Alia.

Francalacci P., Bertranpetit J., Calafell F., Underhill P.A. 1996. Sequence diversity of the control region of mitochondrial DNA in Tuscany and its implications for the peopling of Europe. Am. J. of Phys. Anthrop., 100: 443-460.

Guglielmino C.R., Zei G., Cavalli-Sforza L.L., 1991. Genetic and cultural transmission in Sicily as revealed by names and surnames. Hum. Biol., 63: 607-627.

Harpending H.C., Jenkins T., 1973. Genetic distance among southern African populations. In: Methods and Theories in Anthropological Genetics. A cura di: MH Crawford and PL Workman. Albuquerque University of New Mexico.

Monmonier M., 1973. Maximum-difference barriers: an alternative numerical regionalization method. Geogr. Analit., 3: 245-261.

Piazza A., Capello E.N., Olivetti E., Rendine S., 1988. A genetic history of Italy. Ann. of Hum. Genet., 52: 203213.

Rickards O., Biondi G., De Stefano G.F., Vecchi F., Walther H., 1992. Genetic Structure of the Population of Sicily. Am. J. of Phys. Anthrop., 87: 395-406.

Rickards O., Martinez-Labarga C., Scano G., De Stefano G.F., Biondi G., Pacaci M., WaltherH., 1998. Genetic History of the Population of Sicily. Hum. Biol., 7: 669-714.

Semino O., Torroni A., Scozzari R., Brega A., De Benedictis G:, Santachiara Benerecetti A.S., 1989. Mithocondrial DNA polymorphisms in Italy. III. Population data from Sicily: a possible quantitation of maternal African ancestry. Ann. of Hum. Genet., 53: 193-202.

Varesi L., Memmì M., Cristofari M.C., Mameli G.E., Calò C.M., Vona G. 2000. Mitochondrial control-region sequence variation in the Corsican population, France. Am. J. of Hum. Biol., 12: 339-351.

Vona G., Calò C.M., Autuori L., G.E.Mameli., Lixi. M.F., Ghiani M.E., Di Gaetano C., 1998. Genetic structure of western Sicily. Int. J. of Anthrop., 13: 137-147.

Vona G., Chiarelli B., Ghiani E., Sineo L., 2000. Genetic structure of Sicily: a review. Biennial Book of EAA1: 63-78.

Zei G., Barbujiani G., Lisa A., Fiorani O., Menozzi P., Siri E., Cavalli- Sforza L.L., 1993. Barriers to gene flow estimated by surname distribution in Italy. Ann. of Hum. Genet., 57: 123-140. 


\title{
Capitolo 6 \\ STUDIO DELLE IMMUNOGLOBULINE E DELLE EMOGLOBINE NELLA POPOLAZIONE DI ALIA
}

\author{
Cerutti Giorza N., Rabino Massa E. \\ Dipartimento di Biologia Animale e dell’Uomo. Università di Torino
}

\subsection{Presentazione e finalità della ricerca}

Con il proposito di contribuire al progetto avviato su Alia dal Prof. Brunetto Chiarelli, abbiamo condotto un'indagine su due sistemi biologici fondamentali per la sopravvivenza di tutti gli organismi animali, compresa la nostra specie: le immunoglobuline, note più comunemente come anticorpi, e le emoglobine.

È noto, infatti, che gli anticorpi rappresentano una delle principali difese immunitarie contro le malattie causate da microrganismi patogeni (virus, batteri, protozoi, funghi, ecc.). Fino alla scoperta di molti farmaci, primi tra tutti gli antibiotici, l'uomo è stato sottoposto a una fortissima selezione naturale ad opera delle malattie infettive, che, nonostante i grandi progressi medici, giocano ancor oggi un ruolo decisivo nella sopravvivenza della nostra specie soprattutto nelle aree del terzo mondo. L'osservazione che non tutti gli individui presentano lo stesso tipo di anticorpi (differenze allotipiche) e che la distribuzione di queste diverse forme è notevolmente differenziata nei vari gruppi umani, indicherebbe un probabile vantaggio di tale variabilità. Infatti le differenze allotipiche degli anticorpi (sistema $\mathrm{Gm}$ e $\mathrm{Km}$ ) potrebbero riflettere una maggiore resistenza o suscettibilità a certe malattie.

D'altra parte l'emoglobina è sicuramente la proteina più conosciuta di tutti i sistemi proteici studiati in biologia, soprattutto a causa di certe alterazioni patologiche ereditarie (in quanto avvenute nel nostro patrimonio genetico e quindi trasmissibili) note come emoglobinopatie e talassemie presenti nel Sud Italia e nel Delta Padano. L'emoglobina è presente nei globuli rossi, le cellule del sangue, e la sua funzione è quella di trasportare l'ossigeno dai polmoni a tutti i tessuti del nostro organismo e l'anidride carbonica in senso inverso. Risulta evidente come la buona funzionalità di questa biomoleco- la risulti di fondamentale importanza per la nostra sopravvivenza. Un trasporto insufficiente di ossigeno, può causare il cattivo funzionamento delle cellule che costituiscono il nostro organismo, se non addirittura la morte. Infatti, il cervello e tutti gli organi, grazie all'ossigeno, possono produrre energia per svolgere le loro funzioni vitali.

Nell'uomo, fino ad oggi, sono state evidenziati più di 700 difetti emoglobinici per lo più clinicamente silenti. Si tratta generalmente di alterazioni della struttura o di sintesi delle catene polipeptidiche che costituiscono l'emoglobina. È noto che l'attuale distribuzione geografica di alcune emoglobinopatie è il risultato di un processo selettivo da parte della malaria, un'infezione molto grave, talvolta letale, causata da un genere di microrganismi parassiti, detti Plasmodi, che si moltiplicano all'interno dei globuli rossi causandone la morte cellulare. Gli individui portatori sani (in quanto eterozigoti, portano un allele sano e l'allele difettoso) di alcuni difetti ereditari dell'emoglobina presentano una maggiore resistenza alla moltiplicazione del parassita malarico, grazie a una più intensa fagocitosi e distruzione delle cellule alterate. Così, nonostante il carico genetico (infatti coloro che presentano tutti e due gli alleli difettosi sono affetti da grave anemia) le popolazioni in ambienti malarici sono caratterizzate da elevate frequenze di anomalie emoglobiniche, di tipo diverso nelle varie aree geografiche.

In generale, l'uomo presenta un'elevata variabilità nel suo patrimonio genetico. L'esistenza di numerose forme alternative dei geni (alleli) ha permesso alla nostra specie di affrontare condizioni e variazioni ambientali anche molto rapide. Infatti, grazie alla variabilità funzionale e strutturale dei sistemi biologici nei diversi individui, naturalmente entro i limiti fisiologici, le risposte adattative possono essere molteplici garantendo così una maggiore probabilità di sopravvivenza della nostra specie. 
I sistemi proteici, dal momento che sono variabili da un individuo all'altro, e poiché sono i geni che determinano tale variabilità, sono detti polimorfismi genetici. Essi presentano una distribuzione molto diversificata tra gli individui e tra le popolazioni. È stato possibile costruire delle vere e proprie mappe geografiche sulla distribuzione dei geni nei diversi continenti. I caratteri genetici polimorfici permettono anche di valutare quantitativamente le relazioni tra gli individui appartenenti a uno stesso gruppo o quelle intercorrenti tra gruppi umani diversi, attraverso le distanze genetiche, stimate a partire dalle frequenze alleliche.

Il principale obiettivo della nostra indagine è stato quello di determinare la struttura genetica della popolazione di Alia, mediante il sistema Gm e Km e i difetti emoglobinici, e di stimare i rapporti genetici con altre popolazioni mediterraneee.

In alcuni casi sono stati individuati dei geni particolarmente frequenti in certe popolazioni ma rarissimi in altre. Grazie a questa peculiarità, tali geni possono essere utilizzati come marcatori delle popolazioni. Lo studio della distribuzione dei marcatori genetici ci permette quindi di ricostruire i flussi di geni avvenuti tra le popolazioni, da questi stabilire le migrazioni e i contatti secolari avvenuti tra gli abitanti di Alia e gli altri popoli dell'area mediterranea.

\subsubsection{Il sistema $\mathrm{Gm}$ e $\mathrm{Km}$}

Le immunoglobuline (Ig) comprendono un vasto gruppo di proteine chimicamente legate, aventi la funzione di anticorpi e rappresentano uno dei principali meccanismi immunitari contro le infezioni da agenti patogeni. Esse sono prodotte dai linfociti $\mathrm{B}$, grazie all'interazione con i linfociti $\mathrm{T}$ helper, in presenza di antigeni estranei (HLA compatibili) nell'organismo.

Queste proteine hanno in comune una struttura molecolare costituita da 4 catene polipeptidiche unite da ponti disolfuro, di cui 2 catene pesanti identiche $(\mathrm{H})$ con p.m. 55.000-75.000 e 2 catene leggere (L) con p.m. 23.000 (Porter, 1973). I siti di legame, altamente specifici, dell'anticorpo risiedono in regioni ipervariabili, localizzate nell'estremità amminica terminale delle 4 catene polipeptidiche che costituiscono la molecola.

Sono stati identificati cinque tipi diversi di catene pesanti $(G, M, A, D$ e $E)$ in base ai quali si possono distinguere 5 classi di immunoglobuline (Ig G, Ig M, Ig A, Ig D ed Ig E), alcune delle qua- li, in base a differenze antigeniche più lievi, sono ulteriormente divisibili in sottoclassi (IgG1, IgG2, IgG3, IgG4, IgA1 e IgA2). Inoltre, sono stati evidenziati due tipi di catena leggera ( $\kappa$ e $\lambda$ ), comuni a tutte le 5 classi Ig.

Queste catene sono costituite a loro volta da una serie di unità, chiamate domini, in cui le sequenze aminoacidiche possono essere identiche oppure diverse nelle diverse molecole Ig. Le catene pesanti presentano quattro o cinque domini, mentre le catene leggere ne presentano sempre due. Il primo dominio, denominato VL per le catene leggere e $\mathrm{VH}$ per le catene pesanti, parte dalla porzione $\mathrm{NH}_{2}$ terminale e rappresenta la regione variabile della catena, diversa in ogni anticorpo. Il complesso VL e VH costituisce infatti il sito di attacco dell'antigene.

Gli altri domini sono regioni costanti e vengono denominate rispettivamente $\mathrm{CL}$, per le catene leggere, $\mathrm{e} \mathrm{CH}_{1}, \mathrm{CH}_{2}, \mathrm{CH}_{3}$ e $\mathrm{CH}_{4}$, per le catene pesanti. Queste regioni costanti possono essere diverse negli individui e, dunque, sono polimorfiche. Come per i più noti gruppi sanguigni $\mathrm{AB} 0 \mathrm{e}$ $\mathrm{Rh}$, anche se in modo più lieve, possono scatenare una risposta immunitaria in caso di trasfusione di sangue non compatibile.

Sono stati individuati quattro sistemi polimorfici nelle immunoglobuline ( $\mathrm{Gm}$, Am, Em e Km). Di questi il sistema $\mathrm{Gm}$ mostra il più alto grado di variabilità e per questo è il più studiato dai genetisti e dagli antropologi. Il polimorfismo $\mathrm{Gm}$ è ristretto alla sottoclasse IgG1, è localizzato sui domini costanti $\mathrm{CH} 1, \mathrm{CH} 2$ e $\mathrm{CH} 3$ delle catene pesanti e viene denominato rispettivamente $\mathrm{G} 1 \mathrm{~m}$, G2m e G3m.

I geni che codificano per le catene pesanti sono stati localizzati in loci molto vicini sul cromosoma 14 , al punto da essere ereditati in combinazioni fisse, dette aplotipi, poiché molto raramente possono essere coinvolte in processi di ricombinazione (crossing over) durante la meiosi.

Il sistema Km è un altro polimorfismo delle immunoglobuline, è situato sulla regione costante (CL) della catena leggera $\kappa$, presente in tutte le classi Ig, e il suo gene è localizzato sul cromosoma 2.

\subsubsection{I difetti emoglobinici}

L'emoglobina è un'emoproteina composta da una frazione proteica ad alto peso molecolare (p.m. 64.456) detta globina, e da 4 frazioni non proteiche a basso peso molecolare (p.m. 616) det- 
te eme o gruppi prostetici formate dalla protoporfirina IX combinata con un atomo ferro. L'assorbimento dell'ossigeno da parte dell'emoglobina implica un'ossidazione degli atomi di ferro contenuti nei gruppi funzionali.

Nell'uomo le emoglobine, riscontrabili nei diversi stadi dello sviluppo, sono tutte tetrameri costituiti da una coppia di catene $\alpha$ o $\alpha$ simili e da una coppia di catene $\beta$ o $\beta$ simili. In condizioni normali, infatti, nel corso della vita, compresa quella intrauterina, sono presenti diversi tipi di emoglobine che differiscono tra loro per la composizione delle catene che costituiscono la globina. Le catene globiniche di tipo $\alpha$ e $\beta$ sono codificate da due raggruppamenti genici (clusters) localizzati rispettivamente sul braccio corto del cromosoma 16 e sul braccio corto del cromosoma 11.

Nell'adulto sono presenti normalmente tre tipi di emoglobina: $\mathrm{l}^{\prime} \mathrm{Hb} \mathrm{A}, \mathrm{l}^{\prime} \mathrm{Hb} \mathrm{A}_{2}$ e l'Hb F. L'Hb A costituisce circa il 97\% dell'emoglobina dell'individuo normale, $\mathrm{l}^{\prime} \mathrm{Hb} \mathrm{A}_{2}$ il 2,0-2,5\%. L'Hb F è l'emoglobina propria della vita fetale ed è presente nell'adulto solo in tracce. $\mathrm{L}$ ' $\mathrm{Hb} \mathrm{A}$ è composta da due catene $\alpha$ e due catene $\beta, 1^{\prime} \mathrm{Hb} \mathrm{A}_{2}$ da due catene $\alpha$ e due catene $\delta, l^{\prime} \mathrm{Hb} \mathrm{F}$ da due catene $\alpha$ e due catene $\gamma$.

In certe condizioni patologiche, la sintesi di emoglobine embrionali e fetali persiste fino ad un periodo successivo a quello di normale disattivazione dei rispettivi geni globinici.

I difetti emoglobinici che interessano le catene $\alpha$ e $\beta$ sono le più diffuse (rispettivamente $31 \%$ e $55 \%$ ) mentre quelle relative alle catene $\gamma_{0} \delta$ hanno minore rilevanza e sono di più raro riscontro $(1.5 \%)$.

Le varianti $\beta$ sono maggiormente conosciute di quelle $\alpha$, perché in genere queste ultime tendono ad avere conseguenze cliniche più lievi. Infatti, un'alterazione di una delle quattro copie dei geni $\alpha$ produce effetti meno evidenziabili di quanti ne produca un'alterazione di una delle due copie $\beta$. Inoltre, poiché le catene $\alpha$ sono già presenti nelle emoglobine embrionali e fetali, una loro alterazione può essere letale già durante la vita prenatale (aborto precoce), mentre ciò non può accadere per le catene $\beta$ sintetizzate solo dopo la nascita.

In generale, i difetti delle emoglobine possono essere distinti in quattro raggruppamenti:

1. le varianti strutturali (alterazioni della struttura di una catena polipeptidica con conseguente sintesi di una emoglobina anomala come $\mathrm{Hb} \mathrm{S}$, $\mathrm{Hb} \mathrm{C}$, ecc.);
2. le talassemie (alterazioni della sintesi di una catena polipeptidica. Esistono talassemie $\alpha, \beta, \delta$ o $\gamma$, a seconda del tipo di catena colpito. Sono causate da mutazioni spesso a livello intronico o a delezioni del gene globinico);

3. le emoglobine anomale (costituite da catene polipeptidiche normali ma unite nel tetramero in modo anomalo);

4. la persistenza ereditaria di $\mathrm{Hb}$ fetale o $\mathrm{HPFH}$ (deriva da delezioni geniche che causano la persistenza della sintesi delle $\gamma$ catene nell'adulto senza un'associazione con la talassemia).

\subsection{Svolgimento della ricerca}

Il nostro coinvolgimento nel progetto di Alia parte nel 1997, con la seconda edizione del Campo Scuola Estivo di Antropologia, in occasione della quale, grazie alla vivace collaborazione degli studenti del Corso di Genetica delle Popolazioni Umane, abbiamo organizzato la raccolta di campioni di sangue presso il piccolo ambulatorio comunale. Il nostro invito a tutti gli Aliesi, da almeno due generazioni, a donare un campione di sangue per la nostra ricerca è stato accolto da circa un centinaio di volontari. A tutti i donatori è stato consegnato gratuitamente un tesserino personale con il gruppo sanguigno $\mathrm{ABO}$ e $\mathrm{Rh}$, le analisi di trigliceridi, colesterolo e glicemia. I campioni ematici sono stati aliquotati in plasma, siero e cellule, congelati fino al momento dello studio.

Nell'estate del 1998, grazie alla gentile collaborazione della Dott.ssa Maria Grazia Andollina e dell'associazione Thalassa, è stato possibile raccogliere altri prelievi in Alia ed estendere il campionamento a Palermo e ad altri due piccoli comuni (Cerda e Valledolmo).

Complessivamente sono stati studiati 392 campioni (di cui 145 provenienti da Alia) per il sistema $\mathrm{Gm}$ e $\mathrm{Km}$ delle immunoglobuline, 158 casi per i difetti emoglobinici e sono stati estratti 258 campioni di DNA.

L'analisi delle immunoglobuline è stata effettuata su siero addizionato di $\mathrm{N}_{3} \mathrm{Na}$ allo $0.02 \%$ conservato a $-20^{\circ} \mathrm{C}$ fino al momento della tipizzazione. I campioni sono stati testati per gli allotipi G1m 1, 2, 3, 17 della catena pesante $\gamma_{1}$, per l'allotipo G2m 23 della catena pesante $\gamma_{2}$, per gli allotipi G3m 5, 6, 10, 11, 13 , 14, 15, 16, 21, 24, 28 della catena pesante $\gamma_{3}$ e infine per l'allotipo Km 1 della catena leggera $\kappa$. Nel presente lavoro è stato impiegato un test di inibizione dell'emoagglutina- 
zione passiva, metodo comunemente utilizzato nella determinazione degli allotipi umani, che permette di fare una stima semiquantitativa della concentrazione dei determinanti antigenici.

Le frequenze alleliche degli aplotipi Gm e degli alleli $\mathrm{Km}$ sono state calcolate mediante il metodo della massima verosimiglianza (Edwards, 1984). L'analisi della distribuzione nei diversi gruppi considerati è stata realizzata mediante il test $\chi^{2}$ con la correzione di Yates e il test $\mathrm{G}$ con la correzione di Williams, quando il numero di casi era molto piccolo.

Dalle matrici di distanza genetica (calcolate secondo Nei, Reynolds e Cavalli Sforza) abbiamo costruito dei dendrogrammi, utilizzando i metodi cladistici di Fitch (1967), kitsch e neighbor joining (Felsenstein, 1989), per illustrare le relazioni genetiche intercorrenti tra Alia, gli altri comuni delle Madonie e alcune popolazioni mediterranee. La verifica dell'attendibilità dei dendrogrammi ottenuti partendo dalle matrici di distanza è stata realizzata mediante tecniche di bootstrap (Felsenstein, 1985). Sono state programmate 1000 replicazioni di bootstrap, ed è stato costruito un albero di consenso con il metodo del majority rule. Al fine di controllare ulteriormente i risultati ottenuti è stato costruito un dendrogramma direttamente sulle frequenze aplotipiche secondo il principio di maximum likelihood (Weir, 1990) per controllare i raggruppamenti non verificabili mediante boot strap quando troppo deboli.

Infine sono stati utilizzati metodi di analisi multivariata, quali le componenti principali e l'analisi fattoriale, al fine di concentrare tutte le informazioni sulle frequenze aplotipiche in poche variabili e fornire un quadro sintetico sul sistema $\mathrm{Gm}$ ad Alia e in altre popolazioni del bacino mediterraneo.

Per semplificare il carico computazionale sono stati utilizzati alcuni dei software statistici più comuni, Statistica e Statgraphics, e altri più specifici, quali Genepop v. 3.1 (Raymond et al., 1995), e Phylip v. 3.5c (Felsenstein, 1989).

La caratterizzazione delle emoglobine è stata effettuata su sangue intero in EDTA, conservato a $4^{\circ} \mathrm{C}$, e poi congelato a $-20^{\circ} \mathrm{C}$ fino al momento dell'estrazione del DNA per la caratterizzazione molecolare.

Tutti i campioni sono stati sottoposti a esami preliminari che permettono di identificare le varianti emoglobiniche o i casi sospetti di $\alpha$ o $\beta$ talassemia. Per tale caratterizzazione è stato seguito un iter di protocollo per la diagnostica di I livello dei difetti emoglobinici che prevede l'esame emocromocitometrico e il dosaggio delle emoglobine mediante cromatografia liquida ad alte prestazioni (HPLC). In alcuni casi, sono stati eseguiti esami elettroforetici e il test di falcizzazione, che possono essere già risolutivi per la caratterizzazione di alcune varianti emoglobiniche.

I campioni, in cui sono state evidenziate anomalie fenotipiche riferibili a difetti talassemici, sono stati sottoposti a indagini dirette del DNA, mediante tecniche quali l'amplificazione genica (PCR), la digestione con gli enzimi di restrizione, il reverse dot blot, ecc..

\section{3. Risultati sui gruppi sanguigni $A B 0$ e $R h$}

I gruppi sanguigni, scoperti da Karl Landsteiner cento anni fa, rappresentano i primi polimorfismi genetici osservati nell'uomo. La loro scoperta ha rivoluzionato la medicina permettendo la conoscenza dei meccanismi che stanno alla base della compatibilità per le trasfusioni di sangue e di importanti malattie come l'eritroblastosi fetale. Meno noti ma altrettanto interessanti sono gli studi condotti sulla distribuzione dei gruppi sanguigni nelle popolazioni umane, grazie ai quali è emerso che il sistema $\mathrm{AB} 0$ e gli aplotipi Rh, come molti altri sistemi proteici, sono presenti in frequenze molto diversificate nei vari gruppi umani.

I dati relativi ai sistemi $\mathrm{AB} 0$ e $\mathrm{Rh}$ osservati ad Alia, analizzati con il metodo del $\chi^{2}$, sono stati confrontati con campioni provenienti dall'Italia meridionale, dalla Sicilia e da Palermo. È emersa una differenza statisticamente significativa per il sistema $\mathrm{AB} 0(\mathrm{P}<0,01)$ tra Alia e i campioni di controllo.

In particolare, Alia presenta un'elevata frequenza del gruppo sanguigno B $(23,5 \%)$ che in Sicilia generalmente non supera $1^{\prime} 11-12 \%$. D'altra parte il numero di individui con gruppo A è inferiore alla media dell'isola ( $35 \%$ circa) poiché la frequenza non va oltre il $24,5 \%$. I gruppi 0 e $A B$, invece, hanno frequenze, rispettivamente del $48 \%$ e $4 \%$, molto simili al resto della Sicilia.

Lo studio dei gruppi sanguigni è molto interessante dal punto di vista non solo genetico ma anche antropologico in quanto sono state evidenziate in diverse popolazioni umane delle associazioni con malattie di carattere epidemico. Tra queste è nota una chiara associazione tra il sistema $\mathrm{AB} 0$ e il colera. In particolare recenti studi in Bangladesh hanno evidenziato che i soggetti con gruppo san- 
guigno 0 sono affetti più gravemente da questa patologia. Tuttavia la popolazione di Alia, colpita da un'epidemia di colera nel secolo scorso, non sembra presentare frequenze del gruppo 0 inferiori ai campioni di controllo.

Per quanto riguarda la distribuzione del fattore $\mathrm{Rh}$, Alia non presenta differenze significative rispetto alla Sicilia e più in generale all'Italia meridionale.

\subsection{Risultati sulle immunoglobuline}

I fenotipi osservati del sistema Gm e Km risultano in accordo con la legge di Hardy- Weinberg, poiché il test del $\chi^{2}$ non è statisticamente significativo, evidenziando un buon equilibrio del campionamento dei gruppi testati. La legge di HardyWeinberg enuncia che l'andamento della variabilità in una popolazione non apporta modifiche sostanziali al quadro genetico generale, si tratta di un rimescolamento dei geni nell'ambito della stabilità collettiva. Infatti, in assenza di specifici fattori di perturbazione (quali le mutazioni genetiche, la selezione naturale, le migrazioni e molte altre) le frequenze geniche nella popolazione restano costanti di generazione in generazione.

Dal punto di vista genetico, Alia, presenta una differenza statisticamente significativa $(0.001<\mathrm{p}<$ 0.01 , nei confronti di Valledolmo. L'elevato isolamento fino al secolo scorso di questi centri potrebbe aver favorito l'insorgere di fenomeni microevolutivi, che potrebbero aver interessato in particolare le immunoglobuline, a causa soprattutto delle grandi epidemie storiche, come l'ultima di colera del 1837, che, oltre ad aver sottoposto queste comunità ad un'enorme pressione selettiva, hanno portato ad un ulteriore isolamento imposto dalle rigide regole di controllo sanitario.

D'altra parte, abbiamo osservato che le differenze nella struttura genetica tra Alia e Valledolmo sono causate principalmente dalla presenza nel primo comune di molti caratteri africani, non riscontrati in Valledolmo più vicina invece alle popolazioni continentali. Sin dalla fondazione, questi comuni potrebbero aver presentato una diversa struttura genetica, mantenutasi fino ai nostri giorni.

Tenendo presenti le limitazioni relative allo studio di Cerda, a causa soprattutto del campionamento di un ridotto numero di casi, sembrerebbe che tra questo comune e Alia non esistano differenze significative, indicando una stretta relazione genetica tra i due centri rurali.
I gruppi delle Madonie sono stati confrontati anche con il campione raccolto a Palermo, per valutare come questi comuni si differenziano geneticamente dall'area nord-occidentale della Sicilia. Alia e Cerda non presentano differenze significative, evidenziando una buona omogeneità con il resto dell'isola, mentre Valledolmo si differenzia notevolmente $(0.001<\mathrm{p}<0.01)$.

Nonostante sia emersa un'influenza africana sulla struttura genetica di questi gruppi, i risultati risultano compatibili con i dati classici e molecolari, presenti in letteratura sulle altre popolazioni mediterranee (Rickards et al., 1992; Vona et al., 1998; Calò et al., 1998; Simoni et al., 1999).

Infatti, in tutti i campioni analizzati sono stati individuati i caratteri genetici tipici del bacino mediterraneo (Dugoujon et al., 1989) con un'alta frequenza degli aplotipi $\mathrm{Gm}^{3 ; 23 ; 5^{*}} \mathrm{e} \mathrm{Gm}^{3 ; \ldots ; 5^{*}}$. Compare inoltre l'aplotipo $\mathrm{Gm}^{1,17 ; \ldots ; 21,28}$ con una frequenza intorno al $16 \%$, valore piuttosto elevato se confrontato con le altre aree meridionali. Questo aplotipo presenta un'ampia variabilità nelle diverse popolazioni del mondo, e mostra nella sua distribuzione un cline da sud-est a nord-ovest.

Di notevole rilevanza risulta anche la presenza del comune aplotipo africano $\mathrm{Gm}^{1,17, . . ; 5^{*}}$, dall'1.5 al $5.5 \%$, dove Alia mostra la maggiore frequenza di questa combinazione.

L'aplotipo $\mathrm{Gm}^{1,2}, 17 ; \ldots ; 21,28$ si presenta con un bassa frequenza, circa il 5\%, ma senza una differenza significativa rispetto l'Italia continentale al contrario della Sardegna dove questo carattere è molto raro (Piazza et al., 1976). Infine, nel comune di Alia, compare un aplotipo $\left(\mathrm{Gm}^{1,2,17 ; 23 ; 21,28}\right)$ che non è affatto comune nella popolazione umana, probabilmente esso rappresenta una nuova mutazione genetica.

Per quanto riguarda il sistema Km, Alia, Cerda, Valledolmo e Palermo presentano l'allotipo Km(1) con una frequenza rispettivamente del $13.10 \%$, $28.00 \%, 25.00 \%$ e $18.09 \%$. Questo carattere è presente negli europei con una frequenza media del 10-20\% (Fraser et al., 1974), negli africani con il 40-60\% (Loghem, 1986) e negli orientali con il 30-60 \% (De Lange et al., 1985). E' stata osservata inoltre un'alta frequenza dell'allele $\mathrm{Km}(3)$, tra il $72.00 \%$ e il $86.90 \%$, caratteristica in tutte le popolazioni europee.

In un precedente studio delle immunoglobuline in Sicilia, condotto da Walter (1997), sono state osservate frequenze elevate, fino al $40 \%$, di due aplotipi $\left(\mathrm{Gm}^{1,3 ; 5,, 26}\right.$ e $\left.\mathrm{Gm}^{1,17 ; 10,11,13,15,16}\right)$ molto co- 
muni nell'estremo oriente (Cina, Giappone) ma rarisimi nelle popolazioni mediterranee. L'ipotesi di un'influenza importante da parte di questi gruppi in Sicilia, risultò difficilmente sostenibile dal punto di vista storico e geografico e suscitò parecchie controversie anche tra $\mathrm{i}$ genetisti. Il nostro studio sembra escludere contatti tra l'estremo oriente e l'isola, poiché non sono stati osservati tali aplotipi. L'aplotipo $\mathrm{Gm}^{1,3 ; 5^{*}, 26}$, emerso in quell'indagine, potrebbe essere il risultato di un artefatto conseguente a un problema di tipizzazione dell'allotipo G1m (17), ed essere in realtà il comune aplotipo mediterraneo $\mathrm{Gm}^{1,17 ; 5^{*}}$.

\subsection{Stima dei rapporti genetici con altre popolazioni mediterranee}

Sfortunatamente le informazioni relative alla distribuzione degli aplotipi del sistema $\mathrm{Gm}$ nel bacino mediterraneo sono ancora frammentarie e spesso incomplete. Emerge talvolta una forte eterogeneità dei dati presenti in letteratura a causa dell'impiego di tecniche di tipizzazione non ancora uniformate e frequentemente a causa della caratterizzazione parziale degli allotipi.
In particolare, in molte indagini non viene testato l'allotipo G2m(23), nonostante la sua presenza o assenza rivesta una fondamentale importanza nello studio delle popolazioni mediterranee. Questo marcatore è caratterizzante più di altri ed è fortemente discriminante per l'aplotipo mediterraneo $\mathrm{Gm}^{3 ; 5^{*}}$. A tal riguardo, è stata osservata in Sardegna (Piazza et al., 1976) una significativa differenza nella distribuzione del G2m(23) tra aree poste a diversa altezza rispetto il livello del mare, come osservato per alcuni polimorfismi legati a una maggiore resistenza alla malaria..

Inoltre, il campionamento delle popolazioni è spesso discutibile o addirittura scorretto. Non è infrequente per esempio che i campioni di siero siano raccolti in centri trasfusionali senza indagini preliminari sull'origine dei donatori.

Tenendo conto di queste limitazioni sono stati selezionati dalla letteratura gli studi più significativi e, integrandoli con dati inediti del Dott. Jean Michel Dugoujon dell'Università di Toulouse (Francia), è stato creato un archivio su cui condurre analisi cladistiche e multivariate, al fine di valutare le distanze genetiche tra le popolazioni e dunque le relazioni che intercorrono tra di esse.

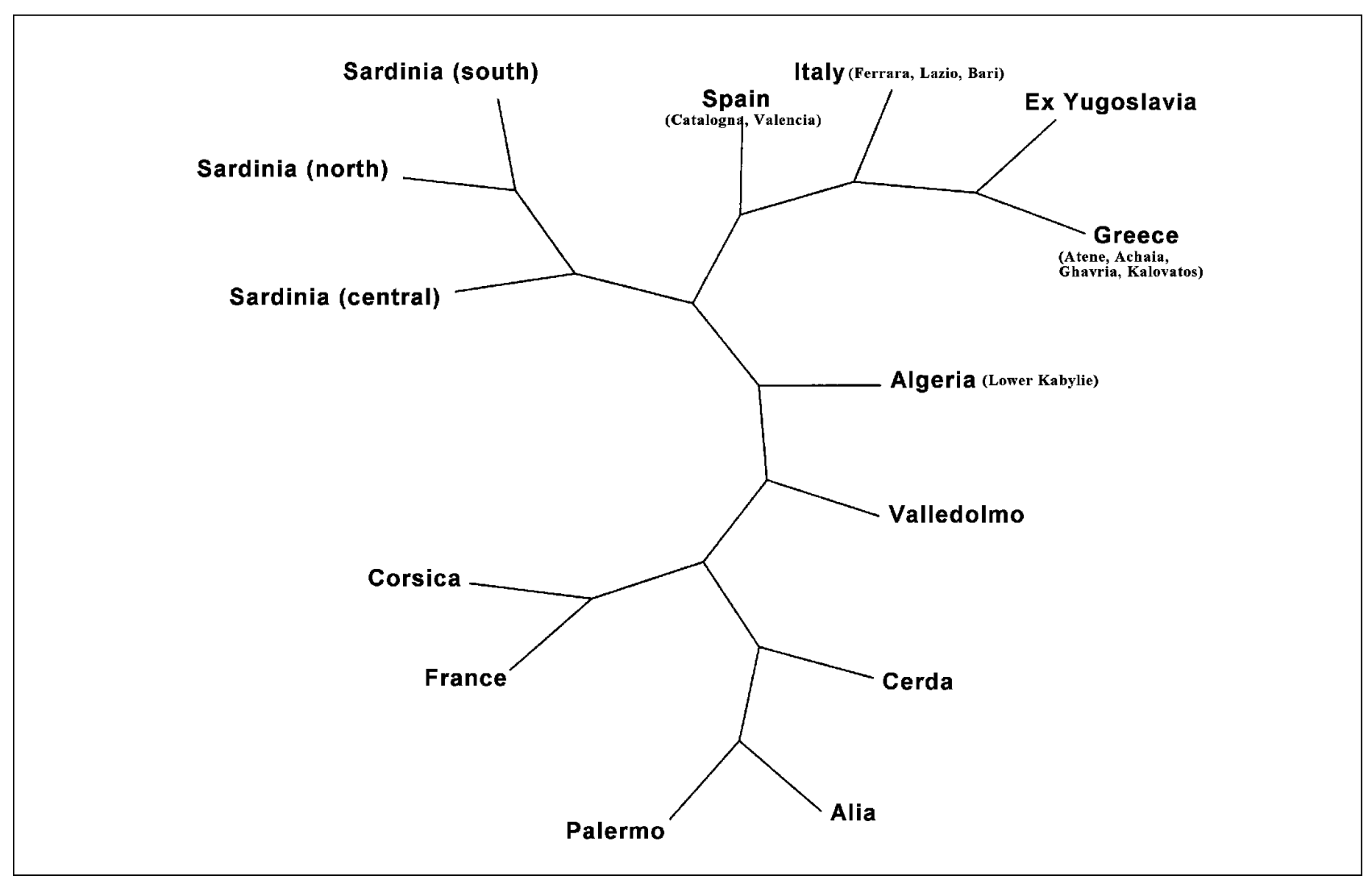

Fig. 1 - Dendrogramma ottenuto dalla matrice di distanza secondo Nei con il metodo del neighbor joining. 


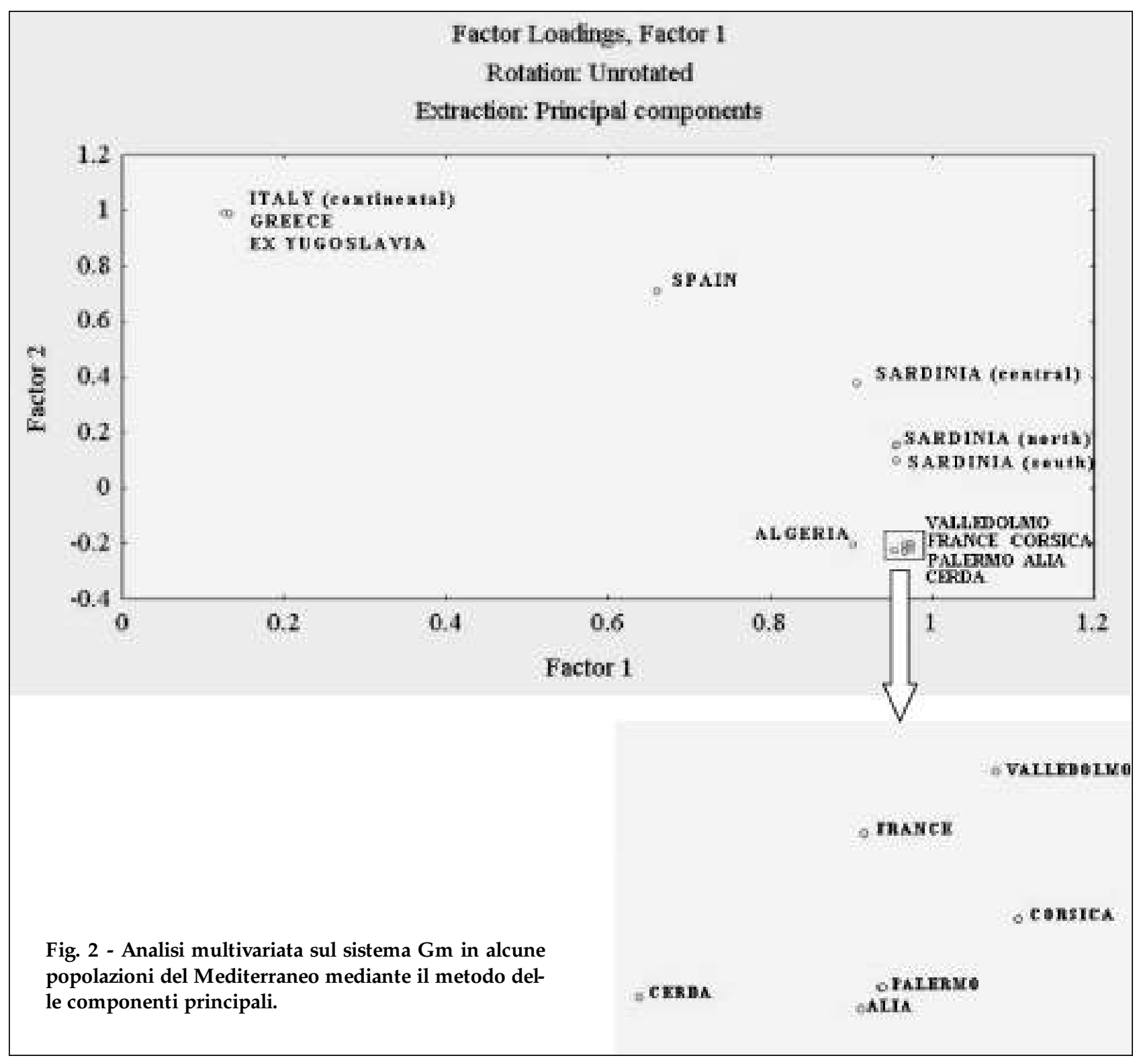

Dalle matrici di distanza sono stati costruiti i diagrammi ad albero, che hanno prodotto dei raggruppamenti delle popolazioni in base alle somiglianze della loro struttura genetica.

La scelta di seguire diversi principi e metodi di raggruppamento cladistici, ha reso possibile un confronto tra i diversi alberi e constatare una buona riproducibilità dei diversi cluster. In tutti gli alberi si riconoscono infatti sempre tre clusters principali (Fig. 1) dove il primo ramo raggruppa alcune popolazioni della penisola italiana (Ferrara, Lazio, Bari), della Grecia, dell'ex Yugoslavia e della Spagna. Il secondo comprende le aree nord, centro e sud della Sardegna (viste le sue particolari peculiarità genetiche, i gruppi si mantengono così suddivisi) infine il terzo comprende Alia, Palermo e Cerda, strettamente legati, seguiti dalla Francia e la Corsica, Valledolmo e l'Algeria (Kabilia).

Mediante l'analisi multivariata delle componenti principali sono state concentrate tutte le informazioni sulle frequenze aplotipiche per fornire un quadro sintetico del sistema Gm nelle diverse popolazioni del bacino mediterraneo (Fig. 2). Anche in questo caso le relazioni tra le diverse popolazioni sono state confermate dai risultati di queste analisi che, essendo di tipologia diversa dai metodi cladistici, hanno permesso di verificarne la loro riproducibilità.

In generale l'associazione delle popolazioni mostra una buona analogia con la loro posizione geografica, anche se si osserva qualche apparente discordanza ricorrente nel raggruppamento com- 
prendente Valledolmo e la Francia. Questo dato non è in realtà così inatteso, infatti, storicamente la Sicilia, in particolare l'area nord-occidentale dell'isola, è stata governata da Normanni, Svevi e Angioini. Le tracce di queste dominazioni evidentemente non sono solo storiche, come dimostra lo stesso stemma di Valledolmo fondato come $\mathrm{Ca}$ strum Northmandum, ma sono state lasciate anche nei geni della popolazione. La stretta somiglianza genetica fra il Nord Europa e l'estremità occidentale dell'isola era già stata evidenziata da Pavesi (1997) mediante l'analisi delle componenti principali costruite sulle frequenze dei gruppi sanguigni, delle aptoglobine e del sistema HLA.

Inoltre, in uno studio sulla Corsica, Calafell e Bertranpetit (1996) sottolineano l'esistenza di una grande affinità genetica tra Sicilia, Campania, Provenza e Corsica mentre la Sardegna e l'Italia centrale presentano differenze molto più marcate.

\subsection{Risultati sulle emoglobine}

Grazie all'indagine sulle emoglobine sono stati evidenziati 13 casi con anomalie fenotipiche, di questi 5 appartengono al comune di Cerda, 7 sono stati rilevati presso Palermo e un solo caso nel comune di Alia.
In base alle alterazioni morfometriche dei globuli rossi e alle variazioni qualitative o quantitative dell'emoglobina, i campioni ematici di tali soggetti sono stati sottoposti ad analisi specifiche al fine di identificare la mutazione genetica. Per facilitarne la lettura, i risultati vengono riportati qui di seguito suddivisi secondo le tipologie dei difetti emoglobinici.

\section{Varianti strutturali}

Le varianti emoglobiniche si presentano generalmente nel cromatogrammma (HPLC) come picchi anomali compresi nell'intervallo dei tempi di ritenzione delle emoglobine (Fig. 3). Nella nostra indagine sono stati osservati due casi, entrambi provenienti da Cerda, con dei picchi anomali nel tracciato HPLC, riferibili rispettivamente a $\mathrm{Hb} \mathrm{S}$ e Hb G-San Josè. Tali campioni sono stati sottoposti ad analisi più approfondite, di tipo elettroforetico e biochimico, al fine di accertare la presenza e il tipo di variante emoglobinica.

L'analisi elettroforetica sfrutta le proprietà elettriche delle molecole, come l'emoglobina e altre proteine del sangue, che poste su un supporto (in genere acetato di cellulosa o gel di agar) sottoposto a un campo elettrico migrano secondo la loro cari-

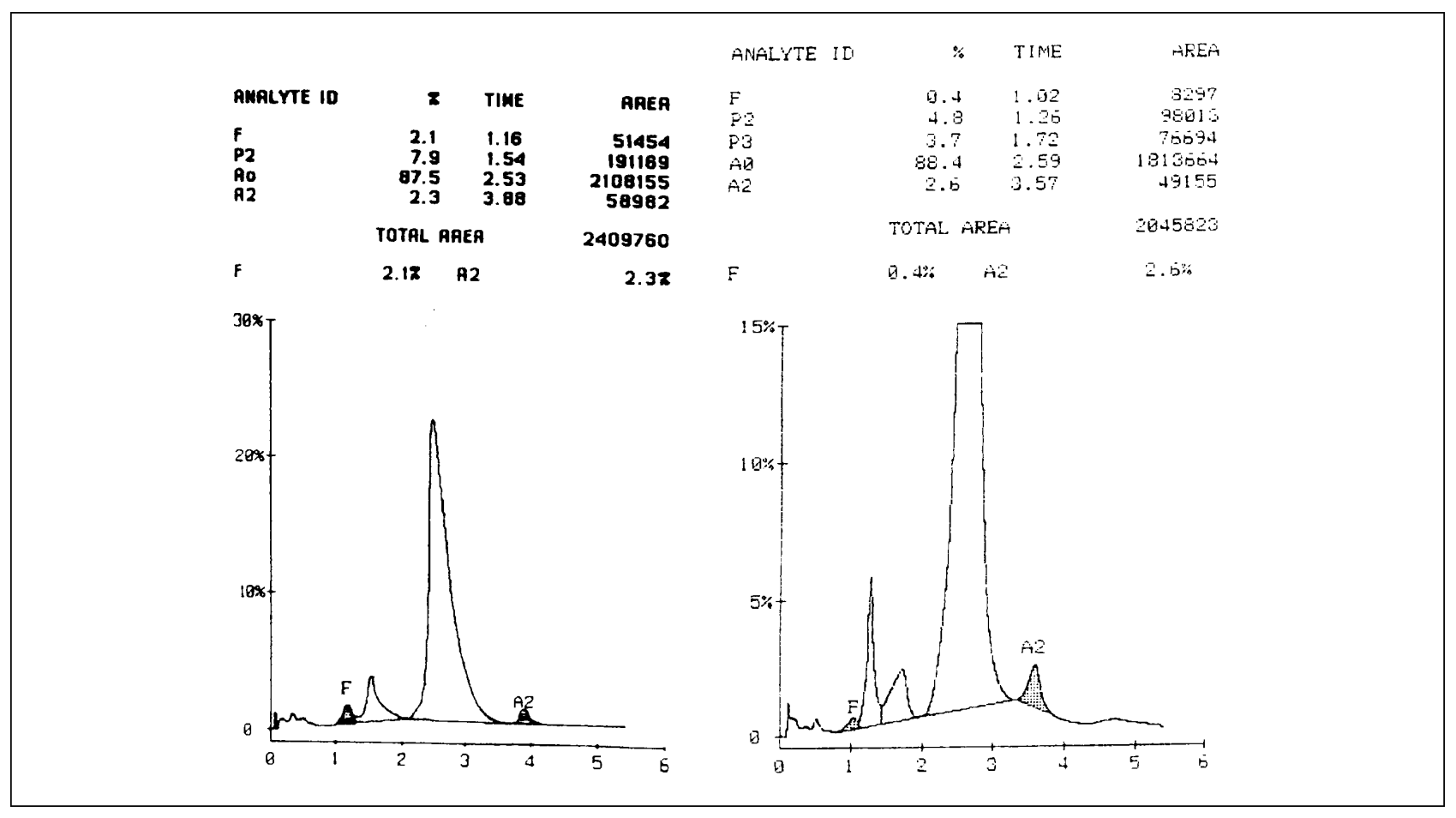

Fig. 3 - Cromatogrammi HPLC: a sinistra soggetto normale, a destra un caso con un picco anomalo nell'intervallo dei tempi di ritenzione delle emoglobine, riferibile a una variante strutturale dell'emoglobina. 
ca elettrica verso il polo opposto. Le emoglobine con struttura diversa da quella normale sono visibili nella corsa elettroforetica come bande anomale con velocità diversa dovuta al peso molecolare diverso (a causa della sostituzione di uno o più aminoacidi nelle catene polipeptiche che compongono la proteina). Mediante doppia elettroforesi a $\mathrm{pH}$ acido e alcalino (Fig. 4) è stata confermata la presenza di emoglobina $S$ ( $\beta 6$ glu $\Rightarrow$ val) e G-San Josè ( $\beta 7$ Glu $\Rightarrow$ Lys).

L'osservazione di emoglobina $S$ è stata effettuata anche mediante il test di falcizzazione dei globuli rossi, aggiungendo una goccia di sostanza riducente (soluzione di bisolfito di sodio $1 \mathrm{~g} / \mathrm{dl}$ ) nel sangue. Il fenomeno della falcizzazione, osservabile con la diminuzione della tensione di ossigeno, è causato dalla precipitazione in forma di cristalli dell'emoglobina S, che determina la tipica deformazione a falce del globulo rosso. Dal punto di vista clinico le emazie falcemiche, irrigidite e deformate, rallentano il flusso ematico causando trombosi vascolari con diversi disturbi circolatori e vengono eliminate dai macrofagi con conseguente anemia emolitica.

Dal punto di vista antropologico, il gene $\mathrm{Hb} \mathrm{S}$ presenta una frequenza media dell' $1.2 \%$ in Sicilia, con considerevole eterogeneità endemica. L'osservazione di tale mutazione in quest'area rappresenta un caso abbastanza raro. Infatti l'emoglobina $S$, contrariamente alle mutazioni $\beta$ talassemiche, non è uniformemente distribuita nell'isola, ma si presenta prevalentemente lungo la costa sudorientale secondo un gradiente nord-sud (Barrai et al., 1987). L'osservazione della mutazione $\beta^{\mathrm{s}}$ potrebbe essere interpretata come un fenomeno di "effetto fondatore" anche se risulta assai difficoltoso stabilirne l'origine. Di particolare interesse risulterebbe l'accertamento dell'origine mediante lo studio degli aplotipi mediante gli RFLP o del sito ipervariabile 2 (HS2) appartenente alla regione di controllo del locus. Infatti le indagini molecolari hanno mostrato un'associazione del gene falcemico ad aplotipi differenti in tre regioni dell'Africa (Benin - Nigeria, Repubblica centro-africana, Senegal) evidenziando la possibilità di un'origine multicentrica della falcemia (Pagnier, 1984).

L'aplotipo Benin si presenta prevalentemente nelle popolazioni mediterranee (greci, turchi, siriani, tunisini, arabi) e raggiunge frequenze molto elevate sulle coste orientali e meridionali della Sicilia (Schilirò et al., 1991). Se il caso portasse un nuovo aplotipo si potrebbe ipotizzare una muta-

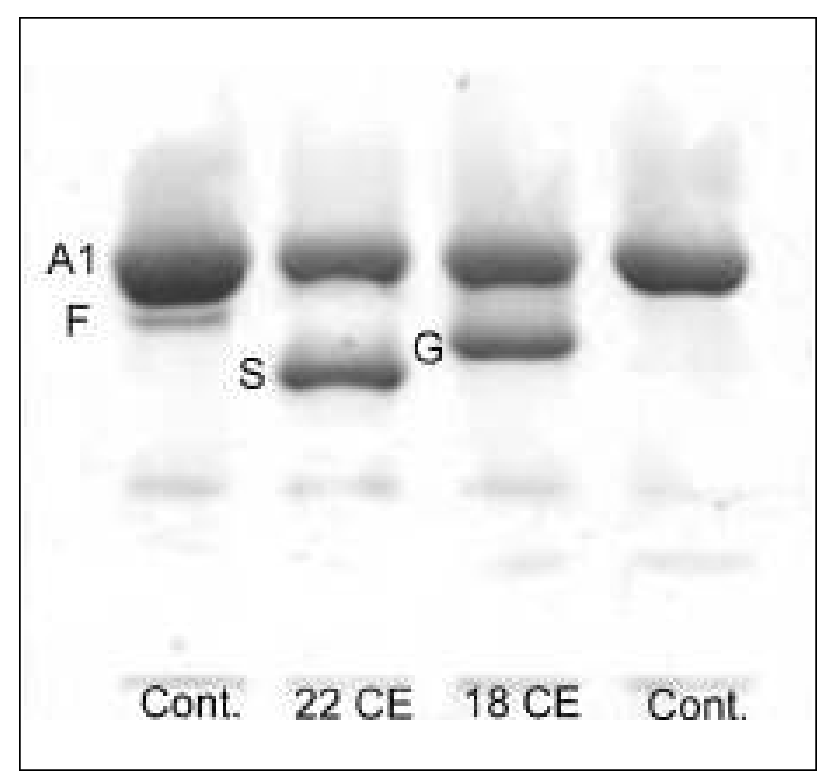

Fig. 4 - Elettroforesi dei due campioni sospetti portatori di una variante emoglobinica. Entrambi presentano infatti nella corsa elettroforetica una banda più lenta.

zione ex novo se invece più verosimilmente fosse associato all'aplotipo Benin l'allele falcemico, potrebbe essersi diffuso dalle aree occidentali a quelle settentrionali dell'Africa, attraverso le migrazioni dei popoli trans-sahariani, ed infine raggiungere la Sicilia direttamente dal nord Africa.

L'altra mutazione identificata, l'emoglobina GSan Josè, è una variante $\beta$ globinica generalmente rara, che tuttavia appare regolarmente in Sicilia (Schilirò et al., 1981), anche se con una distribuzione molto limitata (Schilirò et al., 1997). I casi scoperti finora, infatti, sembrerebbero provenire da famiglie residenti o originarie di un piccolo centro a $50 \mathrm{~km}$ da Catania, Grammichele. Gli eventi storici possono fornire un'interpretazione della peculiarità genetica di questo comune. Nel 1693 un terremoto devastante distrusse il villaggio, uccidendo gran parte degli abitanti. Dopo che il centro fu riedificato, seguì una politica di ripopolamento e con una legge emanata da Carlo II d'Austria fu trasformato in un rifugio per criminali. La comparsa di $\mathrm{Hb} \mathrm{G}-\mathrm{San}$ Josè in questo centro potrebbe essere interpretato come "effetto fondatore" e potrebbe essersi conservato successivamente grazie alla quasi totale assenza di immigrazione e il conseguente isolamento genetico della popolazione, che portarono a un'elevata frequenza di matrimoni tra consanguinei.

Presumibilmente questa emoglobina potrebbe essere il prodotto di un unico evento mutazionale associato all'aplotipo IV (Cremonesi et al., 1989). 
La presenza occasionale di emoglobina G-San Josè in altre aree, come nel caso di Cerda, potrebbe essere il risultato di migrazioni successive.

\section{Difetti $\alpha$ talassemici}

I casi sospetti di $\alpha$ talassemia (valori ridotti di $\mathrm{Hb} \mathrm{A}_{2}$ ) sono stati sottoposti a un'indagine molecolare volta a verificare la presenza della comune delezione $\alpha^{3.7}$, ma sono risultati negativi per tale mutazione. I dati emocromocitometrici non indicano la possibilità di difetti a talassemici più marcati e la presenza di un difetto $\delta$ appare poco plausibile, considerando la scarsa probabilità di trovare un difetto così raro. $\mathrm{L}^{\prime} \mathrm{HbA}_{2}$ ridotta potrebbe dipendere da una sottostima dovuta alla possibilità che i prelievi non fossero in condizioni ottimali oppure da patologie associate quali carenza marziale o di acido folico.

\section{Difetti $\beta$ talassemici}

Le mutazioni di tipo $\beta$ talassemico rappresentano in Sicilia i disordini più comuni dei geni globinici.

L'anomalia emoglobinica più interessante della nostra indagine è stata rilevata nel comune di Alia, dove è stato osservato un soggetto con una mutazione molto rara. I valori elevati di $\mathrm{HbA}_{2}$ osservati nel dosaggio HPLC e i risultati dell'emocromo (ipocromia-microcitosi degli eritrociti) depongono per la presenza di un difetto $\beta$ talassemico. Dalle analisi del DNA appare che questo soggetto non presenta alcuna delle mutazioni $\beta$ più comuni, che interessano circa il $90 \%$ delle mutazioni note nella popolazione italiana. È auspicabile un'ulteriore accertamento al fine di identificare tale mutazione, presumibilmente di tipo $\beta^{+}$, tramite sequenziamento nucleotidico diretto del gene $\beta$ globina.

Nel comune di Cerda sono emersi due casi eterozigoti per due mutazioni talassemiche piuttosto comuni in Sicilia: IVS-I-110 ( $\Rightarrow$ A) e IVS-I -6 $(\mathrm{T} \Rightarrow \mathrm{C})$.

La sostituzione IVS-I-110 è una mutazione molto frequente $(24 \%)$ e si presenta distribuita uniformemente in tutta l'isola a differenza degli altri paesi mediterranei, dove questa mutazione è caratteristica delle coste orientali del bacino (Perrin et al., 1998).

La sostituzione IVS-I-6 è la terza delle mutazioni più diffuse in Sicilia, dopo la CD 39 e la IVSI-110, con una frequenza media del 15.4\%. La fre- quenza di questa mutazione è molto elevata nelle zone orientali dell'isola (28.9\%), nella ex Yugoslavia $(29.1 \%)$ e in Turchia $(18.1 \%)$ mentre si riduce in Spagna (15\%), nei paesi mediterranei del sud quali l'Algeria (3.5\%), la Tunisia (3\%), il Libano $(8 \%)$ e Israele $(3.5 \%)$.

In un soggetto di Palermo è stato evidenziato invece un particolare caso di $\beta^{+}$talassemia eterozigote per la mutazione del secondo introne (IVS-II) in posizione $-745(C \Rightarrow G)$ associato a persistenza ereditaria di emoglobina fetale (HPFH).

Anche questa mutazione è caratteristica dell'area mediterranea, presenta una frequenza del 5\% circa in Sicilia (Giambona et al., 1995) e raggiunge frequenze più elevate in Grecia $(7 \%)$, Cipro $(5.5 \%)$, Tunisia $(7.5 \%)$, Egitto $(8.3 \%)$ e Bulgaria $(10.2 \%)$.

La persistenza di emoglobina fetale, rilevata nello stesso soggetto, è, come accennato, ereditaria. La persistenza della sintesi di catene $\gamma$ nell'adulto si verifica anche nella $\beta$ o $\delta$ talassemia per compensare la mancata o ridotta produzione di catene $\beta$ o $\delta$, ma in questi casi non è ereditaria. L'identificazione della mutazione è stata effettuata mediante digestione con l'enzima di restrizione XmnI. La persistenza ereditaria di emoglobina fetale di questo particolare caso è causata da una sostituzione nel promotore del gene $G_{g}$ in posizione -158 ( $\Rightarrow \mathrm{T})$. L'assenza di una quota elevata di $\mathrm{HbF}(2.3 \%)$ fa ritenere, in base ai dati disponibili in letteratura (Silvestroni, 1992), che la mutazione osservata in questo soggetto non sia particolarmente grave e dia luogo ad una maggiore produzione di catene $\gamma$ solo in condizioni di stress ematologico. Dal punto di vista antropologico, $l^{\prime} \mathrm{HPFH}$ è stata segnalata in diversi popoli mediterranei e in alcuni gruppi africani (Weatherall, 1990; Silvestroni et al., 1992).

I dati ottenuti confermano precedenti osservazioni, che evidenziano come i difetti emoglobinici non sono associati a poche e predominanti mutazioni ma sono molto eterogenei geneticamente.

I difetti emoglobinici, individuati nella presente indagine, sono caratteristici in aree geografiche diverse, mediterranee e continentali e possono essere interpretati in chiave storica. Costituiscono una prova dei contatti secolari delle Madonie con altri popoli, confermando come la Sicilia può essere considerata al tempo stesso centro di civiltà mediterranee, africane e medioorientali.

In base ai dati ottenuti e altri presenti in letteratura (Schilirò et al, 1997; Fichera et al., 1997) le 
aree di diffusione di alcune varianti strutturali emoglobiniche sembrerebbero riflettere la proiezione storica dell'area sudorientale dell'isola verso la penisola italiana e la Grecia e dell'area occidentale verso l'Africa e la Spagna.

\subsection{Conclusioni e prospettive}

La Sicilia grazie all'uniformità morfologica delle coste e, soprattutto alla sua posizione nel bacino Mediterraneo, per secoli è stata centro di incontro di numerosi popoli che hanno scambiato non solo merci e tradizioni ma anche i loro geni. In accordo con la lunga storia di dominazioni e colonizzazioni, recenti studi antropogenetici, anche se ancora piuttosto frammentari, avevano già evidenziato una complessa struttura genetica nella popolazione siciliana attuale, sia a livello delle immunoglobine e delle emoglobine che di altri polimorfismi classici prevalentemente eritrocitari e sieroproteici.

La nostra indagine ha evidenziato un'enorme variabilità genetica anche nella popolazione di Alia e negli altri comuni, confermando la grande eterogeneità dei siciliani più volte sottolineata nei lavori precedenti.

In generale, in questi gruppi sono presenti dei caratteri genetici principalmente di tipo mediterraneo anche se è emersa la presenza di marcatori tipicamente africani, in particolare nella struttura genetica del gruppo di Alia e di Cerda, evidenziando la possibilità di contatti nel passato con popoli provenienti dal nord Africa.

Potrebbe trattarsi di migrazioni di popolazioni molto antiche come i Sicani (di origine nord africana, secondo Caracè), che hanno dominato l'area montuosa delle Madonie per un lungo periodo, mentre il resto dell'isola era interessata da diverse e ricorrenti colonizzazioni.

L'introduzione di polimorfismi genetici africani in quest'area potrebbe essere riferibile più verosimilmente alla colonizzazione fenicia, testimoniata anche dalle iscrizioni ritrovate nelle grotte della Gurfa di Alia (Runfola, 1978) o ancora alla più recente conquista araba.

Per una migliore comprensione delle modalità di popolamento delle Madonie sarebbe auspicabile proseguire la ricerca ampliando sia la numerosità del campione sia il tipo di marcatori genetici.

In particolare, risulterebbe di grande interesse l'integrazione dei risultati ottenuti nel presente lavoro con lo studio di altri sistemi sietroproteici con funzioni biologiche diverse dalle immunoglo- buline per ottenere un quadro completo sulle proteine plasmatiche. Inoltre l'indagine sul sistema HLA (Human Leucocyte Antigen), un altro importante gruppo di geni altamente polimorfici, potrebbe procurare preziose informazioni sui geni e sull'adattamento alle malattie epidemiche che storicamente hanno colpito queste popolazioni. La difesa immunitaria contro le infezioni da agenti patogeni è garantita, infatti, da due meccanismi principali: la difesa ad ampio raggio di tipo anticorpale, svolta dalle immunoglobuline, e la difesa mediata dagli antigeni HLA ristretta alle cellule infettate del nostro organismo. Il sistema HLA è diventato molto importante per gli studi clinici e di genetica medica poiché è stato riportato un crescente numero di associazioni tra i suoi geni e certe malattie. In alcuni casi, esiste un'associazione combinata o interattiva che coinvolge sia il sistema $\mathrm{Gm}$ che l'HLA. Sono state riportate associazioni con il sistema $\mathrm{Gm}$ per sclerosi multipla, malattia della tiroide, lupus eritematoso sistemico, epatite cronica, malattia di Grave, miastemia grave, diabete giovanile, morbo di Alzheimer, enteropatia glutine sensibile, alcune forme di cancro, neuro blastoma, e molte altre (Dugoujon et al., 1996).

\section{Bibliografia}

Barrai I., Schilirò G., Beretta M., Mazzetti P., Russo A., Russo Mancuso G., 1987. Population structure of Sicily: beta talassemia and $\mathrm{Hb} \mathrm{S}$. Hum Genet., 75: 1.

Calafell F., Bertranpetit J., Rendine S., Cappello N., Mercier P., Amoros J.P., Piazza A., 1996. Population history of Corsica: a linguistic and genetic analysis. Annals of Human. Biol., 23 (3): 237.

Calò C.M., Autuori L., Di Gaetano C., Latini V., Mameli G.E., Memmi M., Varesi L., Vona G., (1998). The polymorphism of the APOB3' VNTR in the populations of the three largest islands of the western Mediterranean. Anthropologischer Anzeiger, 56 (3): 227.

Cremonesi L., Travi M., Li Volti S., Testa R., Schilirò G., Ferrari M., 1989. Evidence for the single origin of the Hb G-San Josè in Sicily. Hemoglobin, 13: 579.

De Lange G., Fa Ming Z., Henke J., Feng Z., 1985. Immunoglobulin allotypes:in a chinese population: comparison of haplotype frequencies with other asian groups. J. Immunogenet., 12: 191.

Dugoujon J.M., Borot N., Chaventre A., Rudan P., 1989. $\mathrm{Gm}$ and $\mathrm{Km}$ immunoglobulins allotypes in Olib and Silba Islands (Northern Dalmatia) .Coll. Anthropol., 13 (2): 291

Dugoujon J.M., Cambon-Thomsen A., 1996. Immunoglobulin allotypes ( $\mathrm{Gm}$ and $\mathrm{Km}$ ) and their interactions with HLA antigen in autoimmune diseases: a review. Autoimmunity, 22: 245. 
Edwards A.W.F., 1984. Likelihood. Cambridge University Press, Cambridge.

Felsenstein J., 1985. Confidence limits on phylogenies: an approach using the bootstrap. Evolution, 39: 783.

Felsenstein J., 1989. PHYLIP Phylogeny inference package v 3.2. Cladistics, 5: 164.

Fichera M., Spalletta A., Fiorenza F., Lombardo T., Schilirò G., Tamouza R., Lapouméroulie C., Labie D., Ragusa A., 1997. Molecular basis of $\alpha$ thalassemia in Sicily. Hum Genet., 99: 381.

Fitch W.M., Margoliash E., 1967. Construction of phylogenetic trees. Science, 155: 279.

Fraser G., Volkers W., Bernini L., Loghem E., Meera P., 1974. Gene frequencies in a dutch population. Hum. Hered., 24:435.

Giambona A., Lo Gioco P., Marino M., Abate I., Di Marzo R., Maggio A., 1995. The great heterogeneity of thalassemia molecular defects in Sicily. Hum. Genet., 95: 526.

Loghem E. van, 1986. Immunoglobulin markers. In: Cavalli Sforza, African pygmies, 14: 201-218 (Academic Press, New York).

Pagnier J., Mears J., Dunda O., Schaafer K., 1984. Evidence for the multicentric origin of the sickle cell hemoglobin gene in Africa. Proc. Natl. Acad. Sci USA, 81:1771.

Pavesi A., Siri E., Conterio F., 1997 Analisi della distribuzione dei cognomi in Sicilia. Antrop. Contemp., 20 (12-3): 189.

Perrin P., Bouhassa R., Mselli L., Garguier N., Nigon V.M., Bennani C., Labie D., Trabuchet G., 1998. Diversity of sequence haplotypes associated with beta thalaessemia mutations in Algeria: implications for their origin. Gene, 213 (1-2):169.

Piazza A., Loghem E. van, De Lange G., Curtoni S., Ulizzi L., Terrenato L., 1976. Immunoglobulin allotypes in Sardinia. Am. J. Hum. Genet., 28: 77.
Porter R.R., 1973. Structural studies of immunoglobulins. Science, 180: 713.

Raymond M., Rousset F., 1995. Genepop: population genetics software for exact tests and ecumenicism. J. Heredity, 86:248.

Rickards O., Biondi G. F., De Stefano G. F., Vecchi F., Walter H., 1992. Genetic structure of the population of Sicily. Am. J. Physic. Anthrop., 87: 395.

Runfola M., 1978. Le grotte della Gurfa fra mito e realtà. Novalia, CITTA?.

Schilirò G., Li Volti S., Musumeci S., Mollica F., Marinucci M., Mavilio L., Tentori L., 1981. Sicily a cluster of Hb G-San Josè. Hemoglobin, 5: 725.

Schilirò G., Gangarosa S., 1991. Sicily: a melting pot of races and civilizations. Sphere 15, Publication of the Comprehensive Sickle Cell Center Augusta, Georgia, Canada.

Schilirò G., Mirabile E., Testa R., Russo Mancuso, Dibenedetto S., 1997. Presence of hemoglobinopathies in Sicily. Am. J. Med. Gen., 69: 200.

Silvestroni E., Bianco I., 1992. Microcitemie e anemia mediterranea. Therapeutic Bases Today, 18, 2.

Simoni L., Gueresi P., Pettener D., Barbujani G., 1999. Patterns of gene flow inferred from genetic distances in the Mediterranean region. Hum. Biol., 71, 3: 399.

Vona G., Calò C M., Autuori L., Mameli G. E., Lixi M. F., Ghiani M. E., Di Gaetano C., 1998. Genetic structure of western Sicily. Int. J. Anthrop., 13, 2: 137.

Walter H., Matsumoto H., Danker Hopfe H., De Stefano G. F., Rickards O., 1997. GM and KM allotypes in nine population samples of Sicily. Ann. Hum. Biol., 24 (5): 419 .

Weatherall D.J., 1990. Genetica e pratica clinica. Zanichelli, Bologna.

Weir B.S., 1990. Genetic Data Analysis. Sinauer Associates, Sunderland, Mass. 


\title{
IL COLERA E LA FIBROSI CIST ICA: COSA ACCOMUNA DUE PATOLOGIE COSİ DIVERSE?
}

\author{
SINEO L. \\ Dip. Biologia Animale, Università degli Studi di Palermo \\ E-mail: lsineo@unipa.it
}

\subsection{Il colera, malattia infettiva}

Il Colera è una malattia acuta ed altamente infettiva che si manifesta con diarrea continua a cui segue vomito incoercibile. Questa situazione determina uno stato di disidratazione parossistica con perdita di liquidi e sali di Calcio e Potassio. L'individuo colpito manifesta una crescente ipotensione e tachicardia, anuria e impossibilità di assumere cibi liquidi e solidi. Se non interviene una adeguata terapia farmacologica e una intensa reidratazione l'individuo entra in coma irreversibile.

Non sempre il quadro clinico è così intenso: si descrivono infatti forme cosiddette "attenuate" che risultano non letali per gli adulti in buone condizioni fisiche ma comunque pericolose nei bambini dove l'equilibrio idrico e salino è molto facilmente alterabile.

Il colera è determinato dalla infezione delle cellule dell'intestino tenue da parte di un microorganismo, il batterio Vibrio cholerae. I vibrioni sono una categoria piuttosto ampia di microorganismi: l'agente eziologico del colera è infatti classificabile in diversi biotipi, sierogruppi e sierotipi. Il vibrione maggiormente coinvolto nella malattia umana è il $V$. cholerae detto Et Tor N16961 (biotipo), del sierogruppo 01, sierotipo Ogawa, anche se nel 1992 è stato descritto un nuovo sierogruppo eziologico (0139). Il vibrione, entrato nell'organismo, colonizza rapidamente le cellule intestinali e inizia la secrezione della tossina che stimola un'intensa secrezione acquosa; questo innesca il meccanismo perverso che porta alla disidratazione dell'individuo.

Il colera affligge l'uomo e ne modella la sua storia agendo drasticamente sulle popolazioni da circa duemila anni. In epoca storica, fino al XIX secolo la malattia era confinata al subcontinente indiano dove presumibilmente assumeva già stato endemico
(Waldor e RayChaudhuri, 2000). A cominciare dal 1817 lo stato di epidemia cronica indiana si è trasformato in pandemia con l'esportazione del vibrione (Tagarelli et al., 2000).

La malattia, al suo arrivo in Europa, con le estese e terribili epidemie che si verificarono tra il 1817 e il 1855, venne studiata in modo esemplare da John Snow, un medico ostetrico inglese. I suoi studi sulle due principali epidemie londinesi del 1848 e del 1854, sintetizzati nel lavoro "On the mode of communication of Cholera" (i lavori di Snow sono stati recentemente ripubblicati integralmente dalla University of California, Los Angeles, School of Public Health Department) sono tuttora considerati un classico nella storia dell'epidemiologia per l'acume delle osservazioni e la modernità metodologica.

L'agente eziologico del colera venne identificato per la prima volta da Pacini nel 1854 e fu ottenuto in coltura da Koch solo nel 1892, in Egitto.

Le pandemie fino ad oggi registrate sono state sette. L'ultima pandemia è iniziata in Indonesia nel $1961 \mathrm{e}$, gradualmente ha interessato l'Asia, l'Africa negli anni settanta, quindi l'Europa e l'America latina. In Africa e in America latina l'infezione ha assunto dimensioni tali da farla considerare endemica.

I paesi attualmente più colpiti da questo flagello sono quelli del terzo mondo, dove è più facile che le elementari norme igieniche siano assenti. L'Organizzazione mondiale della sanità (OMS) segue attentamente l'andamento delle epidemie nei vari continenti. Il maggior numero di casi di colera si riscontra nel continente africano, che registra anche il maggior numero di decessi, seguito dal subcontinente latino-americano, dall'Asia, dall'Europa (dove il 99\% dei casi risulta attualmente "importato") e dall'Oceania.

L'endemismo e la diffusione della malattia sono influenzate da vari parametri, quali il biotipo bat- 
terico, la sensibilità individuale alla tossina, il gruppo sanguigno dell'individuo stesso (Glass et al., 1985), l'intensità del contatto infettante; il vibrione sopravvive per anni nelle acque stagnanti che funzionano quindi da reservoir di infezione, invisibile alle correnti metodologie di indagine batteriologica (Torres Codeço, 2001; Colwell e Huq, 1994). L'esplosione dei fenomeni epidemici in situazione di endemismo è generalmente in relazione ad eventi climatici quali il passaggio dalla stagione arida a quella umida (Africa), eventi catastrofici quali El Niño, o periodi post-monsonici (America latina e Bangladesh); molto importante appare l'associazione nelle acque temperate, con zooplancton, crostacei e altri organismi acquatici (Torres Codeço, 2001).

Da circa un decennio il colera è nuovamente una grande emergenza sanitaria. La problematica coinvolge lo studio dell'uomo moderno ed il suo posto negli ecosistemi attuali (Epstein, 1993, Islam et al., 1994, Faruque et al., 1998). Il colera è quindi un problema medico e sociale ma soprattutto antropologico. Il tasso di riproduzione e mantenimento del colera nelle comunità umane è definito dal prodotto di fattori sociali ed ambientali, dalla mancata diffusione delle norme di prevenzione ma soprattutto dalle mutate situazioni demografiche conseguenti alla crescita della popolazione, all'abbandono dei modelli comportamentali che regolano il rapporto uomo e ambiente ed ai fenomeni di inurbamento incontrollato.

Oggi conosciamo molto della organizzazione molecolare del microorganismo oltre alla sequenza completa del suo DNA. La cosa più particolare che caratterizza la biologia del vibrione è l'organizzazione del genoma in due cromosomi circolari, uno "grande" con 2.96 megabasi (milioni di coppie di basi) ed uno "piccolo" con 1.07 megabasi. Il cromosoma "grande" contiene una cosiddetta "area o isola di patogenicità", con le informazioni per le principali funzioni cellulari del batterio (replicazione del DNA, sintesi proteica, divisione cellulare, sintesi della parete) dei rapporti con la cellula ospite e del comportamento patogeno (affinità recettoriale e determinanti per la tossina). Il cromosoma "piccolo" porta informazioni circa alcuni processi metabolici ed energetici e i processi di trasduzione del segnale. La relazione filogenetica dei due cromosomi sembra antica (Heidelberg et al., 2000) ma molte sono le ipotesi proponibili.

A dispetto delle notevoli conoscenze e della lunga frequentazione con questo ospite maligno, l'uo- mo ha una crescente difficoltà ad elaborare un efficace controllo ed un vaccino adeguato. Il controllo e la prevenzione sono spesso vanificati dalle situazioni di degrado connessi a flussi migratori grandi o piccoli, mentre la variabilità biologica del vibrione pone problemi alla produzione di un vaccino universalmente efficace o privo di notevoli effetti collaterali.

\subsection{La Fibrosi cistica, malattia ereditaria}

La fibrosi cistica, nota anche come mucoviscidosi, è una patologia ereditaria autosomica recessiva a notevole diffusione nella popolazione "caucasica" (per caucasica si intende la popolazione bianca occidentale). La malattia è causata da un' alterata idratazione delle mucose, intestinali, respiratorie, dei dotti pancreatici e spermatici, con conseguente ristagno delle secrezioni. Questo quadro, seguito dalla sovrapposizione di infezioni batteriche recidivanti è invalidante. Prima della scoperta di adeguate terapie antibiotiche l'individuo affetto era condannato a morte certa nei primi anni di vita. Attualmente l'aspettativa di vita si è notevolmente allungata ma la patologia resta comunque letale.

Il gene coinvolto, localizzato sul cromosoma 7 e clonato da Ryordan nel 1989, codifica per una proteina di membrana di 1480 aminoacidi detta CFTR (Cystic Fibrosys Transmembrane Regulator). La proteina, costituita da due domini transmembrana (TDM), da due domini citoplasmatici $(\mathrm{NBF})$ e da un dominio globulare $\mathrm{R}$, viene sintetizzata nel reticolo endoplasmatico e, veicola ta dal Golgi, migra verso la parte apicale degli epiteli dove svolge funzione di "pompa del Cloro" regolando il trasporto degli ioni a livello della membrana plasmatica

Il quadro clinico è più o meno grave a seconda della mutazione o delle mutazioni intervenute nel gene. Da un punto di vista molecolare l'alterazione del gene per mutazione (sono state descritte circa 900 diverse mutazioni del gene ma solo una minima parte di esse è patogenetica o assume rilevanza nell'epidemiologia a livello di popolazione) determina la sintesi di una proteina di membrana anomala e quindi malfunzionante.

L'incidenza del deficit nella popolazione è di un individuo affetto ogni 2500 (1/2500) nati, in media, con un individuo "portatore", eterozigote, ogni 25 individui $(1 / 25)$.

Abbiamo detto che la Fibrosi cistica è una delle patologie ereditarie a maggiore diffusione nella 
popolazione. Studiando la distribuzione delle mutazioni nelle varie popolazioni si è scoperto che esse presentano frequenze diverse a seconda della popolazione considerata. In Italia, che ha un quadro molto eterogeneo di mutazioni, frutto dei molti flussi migratori e delle molte popolazioni susseguitesi in epoca protostorica e storica, vi è una mutazione dominante, la cosiddetta Delta F 508, che, peraltro, non è così frequente come nel nord europa, e mutazioni locali, "sarde", "trentine", "liguri", chiaro risultato di fenomeni di flusso genico e di deriva genetica.

Relativamente alla storia del gene, non è così facile seguire le varie mutazioni nelle popolazioni europee alla ricerca del genotipo ancestrale. Sappiamo comunque che la mutazione più frequente, la già citata Delta F 508, è comparsa presumibilmente 50.000 anni fa in una popolazione geneticamente distinta da ogni popolazione europea attuale, e si è diffusa attraverso flussi consecutivi (Morral et al., 1994).

\subsection{Colera e fibrosi cistica: un'ipotesi di lavoro}

Le frequenze dei geni sono correlate alla storia bio-demografica della popolazione regolate da fenomeni di mutazione, di selezione naturale e di deriva genetica. I geni malattia sono ancor più soggetti a queste regole, data la tendenza della selezione naturale a ridurre il numero degli affetti.

La Fibrosi cistica, malgrado sia una patologia estremamente invalidante, non viene efficacemente selezionata e la sua diffusione nella popolazione occidentale, mostra invece una chiara tendenza alla stabilità, assicurata dalle altre frequenze di eterozigoti (abbiamo detto che un individuo su venticinque è un portatore con una discreta probabilità di incontrare un partner ugualmente portatore e di generare figli affetti, oltre che sani o portatori secondo le probabilità stabilite dalle Leggi di Mendel).

Esempi di patologie ereditarie molto diffuse e non adeguatamente selezionate, a causa di un vantaggio degli eterozigoti in particolari situazioni ambientali come nel caso della Talassemia o del deficit della G6PD in ambiente malarico (vedi Cerutti e Rabino Massa in questo volume) hanno fatto ipotizzare a Romeo et al. (1987) chel'alta incidenza della Fibrosi cistica nelle popolazioni caucasiche possa essere spiegata efficacemente con analogo modello. Secondo Romeo esiste una relazione tra l'alta frequenza di eterozigoti per la fi- brosi cistica e la resistenza a patologie da disidratazioni parossistiche quali il Colera. L'ipotesi, testata sperimentalmente, è risultata plausibile ed è stata successivamente ripresa da Betranpetit e Calafell (1996).

Effettivamente ambedue le patologie, Colera e Fibrosi cistica, agiscono sull'equilibrio idro-salino della cellula, una aumentando (il colera) la perdita di liquidi mediante l'azione della tossina, l'altra (la fibrosi cistica) alterando lo scambio del cloro, trattenendo i liquidi e provocando l'aumento di viscosità a livello delle mucose ed il ristagno.

L' ipotesi, che viene proposta e preliminarmente testata nel lavoro presentato da Barbara Bramanti (vedi capitolo 8 in questo volume), utilizzando un campione subfossile della collezione scheletrica di Alia, prevede che individui eterozigoti per la fibrosi cistica, con un danno funzionale sub-clinico, abbiano una protezione nel caso di infezione da Vibrio cholerae che determina disidratazione parossistica.

\section{Bibliografia}

Bertranpetit J e Clafell F., 1996. Genetic and Geographic variability in Cystic Fibrosis: evolutionary considerations. Ciba Foundation Symposium, Jhon Wiley \&Son 197: $97-118$

Colwell R., 1996. Global climate and infectious disease; the Cholera paradigm. Science 274: 2025

Epstein PR, 1993. Algal blooms in the spread and persistence of Cholera. Biosystem 31: 209-221

Faruque SM et al, 1998. Epidemiology, Genetics and Ecology of Toxigenic Vibrio cholerae. Microbiology and Molecular Biology reviews, 62: 1301.1314.

Heidelberg JF et al., 2000. Nature, 477-483

Glass RI et al., 1985. Preedisposition of Cholera of individuals with $\mathrm{O}$ group. Possible evolutionary significance.Am. J. Epidemiology 121: 791-796.

Islam MS et al., 1994. Probable role of blue-green algae in maintaining endemicity and seasonality of cholera in Bangladesh: a hypothesis. J. Diarrhoela disease Res. 12: 245-256.

Morral N et al., 1994. The origin of the major Cystic Fibrosis mutation (delta F508)in european populations. Nature genetics 8(3): 216-218.

Romeo G et al., 1987. Why is the Cystic fibrosis so frequent? Human genetics 84 (1); 1-5.

Riordan JR et al., 1989. Identification of the Cystic Fibrosis gene. Science 245: 1066-1073.

Tagarelli A., et al., 2000. The Cholera: the Epidemics and their social-demographic features in Southern Italy. Int. J. Anthropol. 15 (3): 241-253.

Torres Codeço C., 2001. Endemic and Epidemic dynamics of Cholera: the role of the aquatic reservoir. BMC Infectious disease 2001 (13) - Elechtronic pubbl. 



\title{
ANALISI GENETICA DI POPOLAZIONI STORICHE: IL CASO DI EPIDEMIA COLERICA AD ALIA
}

\author{
BRAMANTI B. \\ Laboratori di Antropologia - Dipartimento di Biologia Animale e Genetica, Università di Firenze \\ E-mail: antropos@unifi.it
}

\subsection{Il ruolo delle patologie genetiche nella storia della nostra specie}

Nella storia evolutiva della nostra specie un posto particolare è riservato alle patologie genetiche e, fra queste, a tutti quei casi detti di polimorfismo bilanciato, secondo i quali un gene svantaggiato dalla selezione naturale in omozigosi rimane comunque con alte frequenze in alcune popolazioni perché in eterozigosi offre un vantaggio verso alcuni stress ambientali. Esempio classico è la resistenza alla malaria offerta dal fenotipo eterozigote per l'anemia falciforme: rispetto agli omozigoti normali i portatori di anemia sopravvivono all'attacco più virulento del plasmodio.

In tempi recenti una teoria molto simile a quella per l'anemia è stata formulata per spiegare l'alta frequenza ( $1 / 25$ individui caucasici) dei portatori di mutazioni del gene per la fibrosi cistica (CF) che negli omozigoti causa una malattia gravemente invalidante. Poiché la proteina codificata dal gene è implicata nell'omeostasi idricosalina a diversi livelli, è stato suggerito che un vantaggio selettivo del gene mutato possa consistere in un'alta resistenza alle patologie che causano disidratazione parossistica. Alcuni autori hanno proposto in particolare che possa proteggere dall'exitus per colera.

Ad Alia nel 1996 è stato recuperato un intero collettivo di individui deceduti a causa dell'epidemia di colera del 1837. Questo ritrovamento apre la strada per la prima volta ad una verifica diretta dell'ipotesi di relazione fra le due patologie.

\subsubsection{Studi di genetica di popolazione}

Le mutazioni del gene della CF sono distribuite in maniera diversa nelle diverse popolazioni. Dalla frequenza degli omozigoti affetti è stato sti- mato che la frequenza dei portatori sia del $4 \%$ fra i caucasici non ispanici, del 2,2\% fra gli ispanici, dell' $1,7 \%$ fra i gli africani e gli afro-americani e dello $0,7 \%$ fra gli asiatici.

Dai dati riportati dal Cystic Fibrosis Genetic Analysis Consortium la frequenza relativa della mutazione DeltaF508 fra i caucasici è di circa il 66\%, con una frequenza relativa dell' $80 \%$ nell'Europa del Nord (87\% fra i danesi) e di circa il $50 \%$ nel Sud dell'Europa. Nelle regioni mediterranee sono quindi più presenti altri tipi di mutazioni: per la Sicilia sono state calcolate le frequenze relative delle maggiori mutazioni: DeltaF508 52\%, G542X 7\%, N1303K 3\%, W1282X 3\%, R553X 3\%, 2183AA->G 2\%, R347P 2\% (Rendine et al. 1997). Le mutazioni N1303K e 2183AA- $>$ G sono, fra l'altro, rappresentate in Italia con la maggior frequenza relativa rispetto alle altre popolazioni caucasiche. La ragione delle differenze delle frequenze relative delle varie mutazioni risiede, probabilmente, nella diversa storia demografica dei paesi europei e nelle diverse dimensioni delle popolazioni (Bertranpetit \& Calafell 1996). Ciò non spiega, tuttavia, l'alta incidenza delle mutazioni della CF fra i caucasici.

\subsubsection{Ipotesi sull'alta incidenza delle mutazioni della $\mathrm{CF}$}

Sebbene la frequenza della CF non sia uniforme fra le popolazioni caucasiche, si stima comunemente che la sua incidenza sia di uno su 2.500 nati vivi. Sulla base del modello di eredità autosomica recessiva si calcola che la frequenza degli alleli mutanti sia del $2 \%$. Per spiegare un'incidenza così alta sono stati proposti diversi meccanismi, come l'alto tasso di mutazione del gene CFTR (Cystic Fibrosys Tranomembrane Regulator), un vantaggio degli eterozigoti, fenomeni di deriva ge- 
netica, presenza di loci multipli e aumento della fertilità negli individui portatori (Kerem et al. 1989).

Smentite all'ipotesi di deriva genetica come causa primaria sono state proposte prima da Wright e Morton (1968) e poi da Morral et al. (1994). Bertranpetit e Calafell (1996) fanno notare che dopo la contrazione della popolazione europea avvenuta circa 18.000 anni fa durante l'ultima glaciazione, le dimensioni della popolazione europea non sono mai state tali da permettere un aumento significativo della frequenza di un allele recessivo letale (in fondo all'articolo è riportata una interes santissima discussione al proposito).

Un incremento della fertilità negli eterozigoti era stato descritto da Knudson et al. (1967), con una evidenza quasi incredibile che è stata successivamente smentita da uno studio dettagliato sulle famiglie degli affetti (Jorde e Lathrop 1988).

Per quanto riguarda l'ipotesi del vantaggio degli eterozigoti, è stato proposto che questi siano protetti rispetto a diverse patologie ad eziologia microbica o virale, fra le quali la tubercolosi polmonare (Meindl 1987) e l'influenza (Shier 1979).

Nel 1988 Hansson propose (ma l'ipotesi era già comparsa in Quinton 1982) che gli individui eterozigoti per le mutazioni del gene della $\mathrm{CF}$ fossero protetti dalle infezioni intestinali che causano diarrea parossistica, principalmente dovute ad Escheri chia coli e Vibrio cholerae. Sia la tossina Escherichia coli LT che la tossina del colera mediano l'apertur ra dei canali ionici ed elevata secrezione di ioni cloro, in particolare nelle cellule delle ghiandole tubolari. L'aumento della secrezione ionica determinata dal colera potrebbe essere contrastato dalle cellule che hanno canali del cloro difettosi negli affetti da CF. Probabilmente, gli eterozigoti per le mutazioni CF esprimono solo nel 50\% delle cellule le proteine canale alterate, come avviene per altre patologie genetiche recessive. Perciò in occasione di una diarrea la perdita parossistica di liquidi che è spesso causa di exitum potrebbe risultare notevolmente ridotta. Questo potrebbe aver procurato agli eterozigoti un vantaggio selettivo durante le epidemie che colpirono l'Europa e aver così favorito il mantenimento di alte frequenze delle mutazioni del gene CFTR nelle popolazioni caucasiche. La resistenza ad esprimere un aumento della secrezione in risposta all'esposizione a tossine derivate da E. coli e da V. cholerae è stata successivamente dimostrata in individui affetti (Baxter et al. 1988).
L'ipotesi fisiologica ha trovato ulteriore conferma in un modello murino appositamente creato (Gabriel et al. 1994): sotto lo stimolo della tossina colerica la quantità di secreto e il suo contenuto di ioni cloro diminuiscono proporzionalmente alla presenza di alleli mutanti nei topi.

Una critica fondata all'ipotesi di un vantaggio degli eterozigoti CF rispetto al colera consiste nell'osservazione che negli altri casi in cui tale vantaggio è stato dimostrato - come, ad esempio, per l'anemia mediterranea e la malaria - la distribuzione geografica delle due patologie risultava sovrapposta (Fontelo 1995). Gabriel (1995) risponde all'osservazione confermando che la tossina colerica non rappresenta che un modello di tutte le enterotossine batteriche (incluse le E. coli Sta e LT) che causano diarrea, e auspica che vengano fatti ancora studi epidemiologici ad ampio raggio sulle popolazioni umane per confermare l'ipotesi.

Del resto, il colera non può essere considerato l'unico agente che ha determinato l'attuale incidenza della mutazione anche in ragione della sua recente introduzione in Europa (XIX secolo). Considerando che la frequenza originale della mutazione fosse intorno allo 0,002 (cioè vicina alla frequenza attuale nelle popolazioni asiatiche e africane), è stato calcolato che sono necessarie almeno 23 generazioni (circa 450 anni) perché il vantaggio selettivo possa esprimersi negli eterozigoti con l'incidenza attuale media del 2\% (Knudson et al. 1967). Assumendo un equilibrio fra la perdita totale degli affetti da CF e la perdita parziale di quelli protetti contro il colera Bertranpetit e Calafell (1996) osservano che: se la CF ha raggiunto allora l'equilibrio, ci devono essere volute 670 generazioni (più o meno 13.400 anni) perché una mutazione raggiungesse dalla frequenza iniziale di $10^{-6}$ (mutazione singola in una popolazione) il livello attuale di mutazioni che causano la CF. Se il colera fosse stato l'unico agente selettivo, considerando le 5 generazioni durante le quali imperversò in Europa, si calcola che il 68\% di tutti gli individui in età riproduttiva sarebbe dovuto morire di colera ad ogni generazione. E questo non è il caso. Perciò, nonostante i risultati di Gabriel et al. (1994) questa malattia non può essere stato il solo agente selettivo che ha permesso di raggiungere alle $\mathrm{CF}$ la frequenza attuale in Europa.

Il fatto che il vantaggio evolutivo si sia verificato nella sola Europa - pur essendo le forme di diarrea da E. coli diffuse in tutto il mondo - può essere giustificato dalla scoperta di Quinton (1982) 
relativa alla perdita salina aumentata con il sudore: in climi caldi la perdita eccessiva di sale può aver sfavorito i portatori della mutazione, ad esempio in un'epoca in cui la caccia richiedeva lunghe corse, il che può aver costituito una forma di resistenza rispetto all'ipotizzata pressione selettiva subita soprattutto nel nord dell'Europa in presenza della stessa diffusione degli agenti che causano diarrea parossistica.

\subsubsection{Alia e l'epidemia di colera (1837)}

Alia fu raggiunta dalla prima epidemia nel luglio del 1837. Alla pagina 482 del Registro parrocchiale dei morti si legge: "Incipit cholera morbus die sep tima juli millesimo octincentesimo trigesimo septimo 1837". Da luglio fino a novembre furono ufficialmente registrate 306 vittime del "cholera morbus". "Il morbo che, per la sua provenienza, venne anche de nominato 'colera asiatico' si presentava con violente scariche di diarrea [... ] vomito, crampi muscolari, ar resto della secrezione urinaria e collasso. La febbre non sempre era una componente costante, ma, se modera ta, era sintomo di possibile guarigione, mentre, se alta, diventava causa di una serie di complicazioni che, normalmente, conducevano alla morte. [...] Alia, come quasi tutti $i$ comuni della Sicilia, non era in grado di affrontare adeguatamente un'epidemia di quella gravità. Il paese mancava di fognature, di rete idrica, di strade e di tutti quegli accorgimenti indi spensabili per bloccare o, quanto meno, ridurre le fu neste conseguenze della più banale epidemia. Il fatto che desta maggiore stupore non è tanto il pesante nu mero dei morti, quanto il gran numero di superstiti che riuscirono a salvarsi malgrado la totale carenza igienica dell'ambiente" (E. Guccione 1991). Questa osservazione rende particolarmente interessante il campione in esame per la verifica dell'ipotesi suddetta. Nello stesso testo si registra inoltre come una seconda ondata del contagio negli anni successivi abbia provocato solo poche decine di decessi, quasi la popolazione sopravvissuta al primo contagio fosse in gran parte "immune".

I morti del 1837 furono portati in "una grotta naturale, ampliata ai lati, che era stata adibita, per l'occasione, a fossa comune [... ] chiusa con un muro nuovo fatto di calce e grossi macigni, al di sopra con due buchi coverti da laminati ferrei portelli" che successivamente fu denominata Camposanto Vecchio. "I cadaveri, ammucchiati nella grotta, venivano trat tati con getti di secchi di calce viva nel tentativo di disinfettare l'ambiente".

\subsection{Ispezione del sito di raccolta}

Il Camposanto Vecchio, riaperto nel 1996, per recuperare gli scheletri ivi presenti, presenta pareti prive di segni di umidità e muffe. Si può presupporre che l'apertura superiore lasciasse percolare acqua piovana, ma questa doveva essere naturalmente canalizzata verso l'esterno perché anche sul pavimento non permangono tracce di acqua stagnante. Nonostante il clima caldo e asciutto della zona, la temperatura interna alla grotta non deve aver mai raggiunto temperature troppo elevate proprio per la sua esposizione. L'ambiente in cui sono state conservate le ossa, sia per la costituzione chimica della roccia, sia per la presenza della calce viva, presumibilmente era piuttosto basico che acido. Tutte caratteristiche che, in base alla nostra esperienza (Burger et al. 1999), consentono normalmente una buona conservazione della struttura del DNA.

\subsubsection{Studi precedenti sul materiale scheletrico}

I campioni di Alia consistono di crani e postcraniali non in connessione anatomica. Sono stati perciò raccolti e classificati per tipo di elemento scheletrico con distinzione bilaterale per le ossa pari. Le ossa sono conservate in grosse scatole di cartone chiuse ma non sigillate e immagazzinate al primo piano dell'Archivio Comunale di Alia, sito in via Galilei.

Le ossa sono state precedentemente contate per calcolare il Numero Minimo e il Numero Massimo di Individui (per la consistenza e tipologia del materiale esaminato si rimanda alla tabella I del capitolo 2 di questo volume). I calvari sono stati oggetto di una indagine osteologica per i caratteri epigenetici e di uno studio sui denti (Bigazzi et al. 1997).

\subsubsection{Analisi molecolare del materiale osteologico}

La possibilità di analizzare porzioni di osso che datano di più di due secoli se da un lato apre spazio alla verifica di ipotesi fino a qualche tempo fa insondabili, dall'altro pone svariati problemi "tecnici" non sempre facilmente superabili.

La rarità del "pezzo" da analizzare impone una serie di accorgimenti che permettano l'ottimizzazione del processo con la minore perdita di campione possibile. Quest'ultimo, d'altro canto, non sempre è utilizzabile ai fini di un'analisi molecolare perché molto spesso le modalità di conservazione ne hanno degradato il DNA, riducendo così il materiale di studio. La degradazione del DNA im- 
plica una frammentazione delle molecole che altrimenti si trovano sotto forma di lunghe catene super-spiralizzate. Il risultato di tali rotture è naturalmente la perdita di porzioni di materiale genetico. Il campione così degradato non risulterà quindi positivo all'analisi della particolare sequenza cercata, se questa è andata perduta. D'altro canto un risultato positivo può essere anche prodotto da agenti contaminanti, ossia DNA eterologo moderno e integro che si è sostituito al DNA antico assente o degradato durante una delle fasi di sperimentazione alterando così l'analisi. Di conseguen$\mathrm{za}$, anche in condizioni chimico-fisiche eccellenti il cosiddetto DNA antico, proprio per la sua caratteristica "non integrità", richiede nelle diverse fasi un ambiente di lavoro sterile ossia esente da contaminazioni di DNA eterologo.

In questo caso il prelievo del materiale da analizzare è stato fatto negli stessi locali di via Galilei (in Alia) in cui si trova in giacenza il materiale osteologico, ove è stato allestito un laboratorio "da campo". L'ambiente, opportunamente ripulito, era dotato di un unico tavolo sul quale sono stati effettuati i prelievi con la massima attenzione ad evitare contaminazioni.

I prelievi di materiale osseo sono stati effettuati sui femori per non danneggiare la collezione che potrebbe essere sottoposta ad altre indagini antropologiche. Si è scelto di prelevare campioni dai femori destri. Per ogni osso sono stati raccolti due campioni, uno nella porzione distale e uno nella porzione prossimale.

Successivamente il materiale è stato portato in contenitori sterili nei laboratori dell'Istituto di Antropologia dell'Università di Göttingen (Germania) specializzati in studi sul DNA antico. Qui si è provveduto all'estrazione del DNA contenuto nei campioni e alla sua amplificazione, al fine di ritrovare la mutazione per la $\mathrm{CF}$.

Il primo passo della ricerca consiste nella valutazione dello stato del DNA antico. La scelta dei campioni da sottoporre all'analisi per la fibrosi cistica è stata compiuta in base ai risultati dell'indagine su microsatelliti autosomici, ottimi indicatori dello stato di conservazione del materiale antico. Solo quei campioni che contengono DNA in buono stato di conservazione sono sottoposti ai test successivi. I risultati di un'indagine condotta in doppio su 50 campioni di Alia mostrano che è possibile effettuare un'analisi sui campioni antichi ottenendo profili genetici individuali riproducibili. Dei 50 campioni analizzati per circa il 48\% (24 in- dividui) si è ottenuto un profilo allelico quasi completo; per altri 11 individui ( $22 \%$ ) si sono ottenuti risultati riproducibili solo per un ridotto numero di loci, il che indica la presenza di DNA amplificabile nel campione seppure in condizione di forte degradazione. Solo 15 campioni $(30 \%)$ non hanno reagito all'amplificazione.

Poiché, secondo l'ipotesi di lavoro, nel campione di Alia costituito da deceduti per colera non dovrebbero essere presenti mutazioni CF analizzabili, si è proceduto al calcolo del numero minimo di individui necessario per provare una reale assenza di mutazioni per la CF. In questo caso il numero minimo di individui da analizzare è risultato pari a 75 , questo per ottenere un livello di confidenza del 95\%. Dagli studi finora condotti, sullo stato di conservazione del DNA ci si aspetta che mediamente 146 individui contengano DNA in buono stato di conservazione. $\mathrm{Ci}$ sono perciò ottime probabilità che l'indagine condotta sul DNA antico ci fornisca gli elementi necessari per la comparazione con le frequenze della popolazione moderna.

Un primo tentativo di isolare il frammento che porta l'eventuale mutazione $C F$ ha infatti dato ottimi risultati su alcuni dei campioni antichi in esame. Il frammento è stato ottenuto con successo nella sua forma non mutata in tutti i campioni che avevano dimostrato uno stato di conservazione ottimale.

\subsection{Prospettive}

Le analisi fin qui sommariamente discusse saranno naturalmente approfondite per verificare l'effettiva presenza della mutazione in esame. La procedura è lunga e alquanto complessa, ma risulta indispensabile per un'effettiva risposta positiva all'ipotesi di base. Confrontare i risultati ottenuti da materiale antico, con quello proveniente dai discendenti dei sopravvissuti all'epidemia inoltre permetterà di verificare se è effettivamente osservabile un vantaggio evolutivo per i portatori delle mutazioni CF rispetto al colera.

Un ulteriore conforto ai risultati ottenuti dal materiale scheletrico verrà dalla ricerca per via genetica del Vibrio cholera che potrebbe essere ancora presente nei vasi sanguigni delle ossa se prima della morte si è verificata una setticemia (Herrmann \& Hummel 1998a e b). Quest'ultima analisi, oltre a confermare la causa della morte, potrebbe apportare un contributo non indifferente allo studio dell'evoluzione del vibrione. 


\section{Bibliografia}

Baxter P.S., Goldhill J., H ardcastle J., H ardcastle P.T., Taylor, C.J., 1988. Accounting for cystic fibrosis. (Letter) Nature, 335:21 1.

Bertranpetit J., Calafell, F., 1996. Genetic and geographical variability in cystic fibrosis: evolutionary considerations. In: Variation in the human genome. Ciba Foundation Symposium 1997, Wiley, Chichester, pp. 97-118.

Bigazzi R., Crisafulli R., Lazzerini L., Valletta A., Tartarelli G., 1997. Le vittime dell'epidemia di colera del 1837 ad Alia (PA). Studio antropologico e paleontologico degli inumati della Grotta del Camposanto Vecchio. Antropologia Contemporanea, 20 (1-3): 27-3 0.

Bramanti B., Pacciani E., 1999. Norme per il recupero di resti umani nello scavo archeologico in funzione dell'analisi del DNA. In: Il DNA nello studio dei resti umani antichi: principi, metodi, applicazioni. Medical Book, Palermo, pp. 19-29.

Bramanti B., Hummel S., Schultes T., Herrmann B., 2000. STRs Allelic Frequencies in a German Skeleton Collection. Anthrop. Anz., 58: 45-49.

Burger J., Hummel S., Herrmann B., Henke W., 1999. DNA preservation: a microsatellite-DNA study on ancient skeletal remains. Electrophoresis, 20, 17221728 .

Cheng S.H., Gregory R.J., Marshall J. et al., 1990. Defective intracellular transport and processing is the molecular basis of most cystic fibrosis. Cell 63: 827-834.

Collins F.S., 1992. Cystic Fibrosis: Molecular Biology and Therapeutic Implications. Science, 256: 774-779.

Cuthbert A.W., Halstead J., Ratcliff R., Colledge W.H., Evans M.J., 1995. The genetic advantage hypothesis in cystic fibrosis heterozygotes: a murine study. Joumal of Physiology, 482 (2):449-454.

Estivill X., Farrall M., Scambler, P. J., Bell G. M., Hawley K. M. F., Lench N. J., Bates G. P., Kruyer H.C., Frederick P. A., Stanier P., Watson E. K., Williamson R., Wainwright B. J., 1987. A candidate for the cystic fibrosis locus isolated by selection for methylation-free islands. Nature, 326: 840-845.

Fontelo P., 1995. Protection against Cholera. Science 267:71.

Gabriel S.E., Brigman K.N., Koller B.H., Boucher R.C., Stutts M.J., 1994. Cystic Fibrosis Heretozygote Resistance to Cholera Toxin in the Cystic Fibrosis Mouse Model. Science, 266: 107-109.

Gabriel S., 1995. Protection against Cholera (Response to Fontelo). Science, 267:7 I.

Guccione E., 1991. Storia di Alia 1615-1860. Salvatore Sciascia, Caltanissetta-Roma, pp. 304-313.

Hansson G.C., 1988. Cystic fibrosis and chloride-secreting diarrhoea. Nature, 333: $71 \mathrm{I}$.

Harris H., Hopkinson A., Robson E.B., 1974. The incidence of rare alleles determining electrophoretic variants: data on 43 enzyme loci in man. Ann. Hum. Genet., 37: 237-253.
Herrmann B., Hummel S. 1988a. Ancient DNA can Identify Disease Elements. In: Digging for Pathogens (C.L.Greeblatt editor), Balaban Publishers, Rehovot, Philadelphia.

Herrmann B., Hummel S., 1998b. Paleoepidemiology of infectious diseases using ADNA analyses: Pros and Cons. Bull. et Mém. de la Société d'Anthropologie de Paris, n.s., 10 (1-2): 195-200.

Hummel S., Schultes T., Bramanti B., Herrmann B., 1999. Ancient DNA profiling by megaplex amplifications. Electrophoresis, 20:1717-1721.

Kerem B., Rommens J.M., Buchanan J.A., Markiewicz D., Cox T.K., Chakravarti A., Buchwald M., Tsui L., 1989. Identification of the Cystic Fibrosis Gene: Genetic Analysis. Science, 245:1073-1080.

Knudson A.G., Wayne L., Hallett W.Y., 1967. On the selective advantage of cystic fibrosis beterozygotes. Am. J. Hum.Genet., 19:388-392.

Jorde L.B., Lathrop G.M., 1988. A test of the heterozygoteadvantage hypothesis in cystic fibrosis carriers. Am.J. Hum. Genet., 42: 808-815.

Meindl R.S., 1987. Hypothesis: a selective advantage for cystic fibrosis heterozygotes. Am. J. Phys. Anthropol., 74:39-45.

Morral N., Bertranpetit J., Estivill X., et al., 1994. The origin of the major cystic fibrosis mutation (AF508) in European populations. Nat. Genet., 7: 169-175.

QuintonP.M. 1982 In: Fluid and Electrolyte Abnormalities in Exocrine Glands in Cystic Fibrosis (Quinton, P.M., Martinez, R.J., Hopfer, U., eds.), San Francisco Press, San Francisco: 53-76.

Rendine S., Calafell F., Cappello N., Gagliardini R., Caramia G., Rigillo N., Silvetti M., Zanda M., Miano A., Battistini F., Marianelli L., Taccetti G., Diana M.C., Romano C., Giunta A., Padoan R., Pianaroli A., Raia V., De Ritis G., Battistin A., Grzincich G., Japichino L., Pardo F., Antonelli M., Quattrucci S., Lucidi V., Castro M., Santini B., Castello M., Guanti G., Leoni G.B. Cao A., Toffoli C., Lucci E., Vullo C., Torricelli F., Sbemini F., Romeo G., Ronchetto P., Seia M., Rossi A., Ferrari M., Cremonesi L., Salvatore F., Castaldo G., D'Alcamo E., Maggio A., Sangiuolo F., Dallapiccola B., Maceratesi P., Bisceglia L., Gasparini P., Carbonara A., Bonizzato A., Cabrini G., Bombieri C., Pignatti P.F., Borgo G., Castellani C., Villani A., Arduino C., Salvatore D., Mastella G., Piazza A., 1997. Genetic history of cystic fibrosis mutations in Italy. I. Regional distribution, Ann. Hum. Genet. 61:411-424.

Riordan J.R., Rommens J.M., Kerem B., Alon N., Rozmahel R., Grzelczak Z., Zielenski J., Lok S., Plavsic N., Chou J., Drumm M.L., lannuzzi M.C., Collins F.S., Tsui L., 1989. Identification of the Cystic Fibrosis Gene: Cloning and Characterization of Complementary DNA. Science, 245: 1066-1072.

Rommens J.M., lannuzzi M.C., Kerem B., Drumm M.L., Melmer G., Dean M., Rozmahel R., Cole J.L., Kennedy D., Hidaka N., Zsiga M., Buchwald M., Riordan J.R., Tsui L.-C., Collins F.S., 1989. Identification of the Cy- 
stic Fibrosis Gene: Chromosome Walking and Jumping. Science, 245: 1059-1065.

Schmidt T., Hummel S., Herrmann B., 1995. Evidence of contamination in PCR-laboratory disposables. Naturwissenschaften, 82:423-43 I.

Shier W.T., 1979. Increased resistance to influenza as a possible source of heterozygote advantage in cystic fibrosis. Med. Hypotheses, 5:661-667.
Vogel F., Motulsky A.G., 1979. Human genetics. Problems and Approaches. Springer-Verlag, Berlin-

Heidelberg-New York, p. 377.

Welsh M.J., Smith A.E., 1993. Molecular mechanisms of CFTR chloride channel dysfunction in cystic fibrosis. Cell, 73:1251-1254.

Wright S.W., Morton N.E., 1968. Genetic studies on cystic fibrosis in Hawaii. Am.J.Hum.Genet., 20:157162. 


\title{
Capitolo 9
}

\section{IL MUSEO ETNOANTROPOLOGICO DI ALIA}

\author{
CEDRINI R.
}

Università degli Studi di Palermo

\begin{abstract}
"Può venire il giorno in cui tutto l'oro del mondo non basterà

a darci l'immagine del tempo suanito". (Artur Hazelius, fondatore del museo

Skansen di Stoccolma 1891)
\end{abstract}

Alle soglie del terzo millennio nuovi parametri di riferimento condizionano la vita e l'esistere di intere comunità. Si è sempre più chiamati a vivere e convivere in un villaggio globale dove sono caduti gli sbarramenti delle frontiere in nome di un più ampio rapporto dialogico tra i popoli.

A questo appuntamento con la storia, gli uomini devono presentarsi con i propri modelli di vita e, dunque, la propria diversità, la propria storia etnica e sociale che coincide con quell' identità unica e irripetibile che accomuna e distingue culturalmente un popolo dall'altro e, proprio per questo, rende ognuno di essi indispensabile nel grande palcoscenico che le diverse tessere del mosaico umano disegnano.

L'omologazione a modelli che non appartengono ha come conseguenza sbandamento e crisi di identità destinati a ripercuotersi sulle sorti delle nuove generazioni, determinandone spesso situazioni irreversibili.

La cultura tradizionale ha svolto da sempre un ruolo determinante nella trasmissione del retaggio del passato, proponendosi come forza coibente di valori senza i quali s'annullano, in ogni comunità, le ragioni del proprio esistere. E non solo valori. L'identità, infatti, è racchiusa in ogni cosa che l'uomo pensa e realizza, in ogni gesto che ripete, in tutto ciò che senza rendercene conto esprime con forza l'appartenenza.

Le res che circondano la vita di ogni uomo, vanno al di là della materia che le racchiude e della forma che le definisce. Sono segni e simboli di un ampio universo di rimando.
Anche la fabrilità non è soltanto un processo manuale legato al fare: è espressione di quella wel tanchauung, visione della vita e del mondo, che connota ogni popolo, è abilità che ha consentito a ognuno di essi di attraversare i tempi e gli spazi della storia.

Le attività tecnico economiche, infatti, sono sempre il risultato di processi produttivi legati a conoscenze che gli uomini, nel corso del loro cammino, si sono tramessi attraverso un iter assimilativo e cumulativo, in una coralità lavorativa che ha determinato regole, rapporti, ruoli. Le tracce, pur se esili, consentono spesso di ricucire gli strappi di secoli silenti e leggere il passato.

Alia, come altri centri dell'Isola, conserva ancora oggi tratti forti della propria storia, storia che coincide con quella sociale e economica della comunità che li ha perpetuati.

Tutto il suo territorio è disseminato di tracce e racconta storie da cui trapelano l'alternarsi di vicende, la successione di eventi. Storie segnate nelle pietre che, se pur possenti, si piegano all'inesorabile scorrere del tempo, sottomesse all'insìpida ignavia degli uomini.

Se nel monumento ogni comunità ha preservato la memoria di fatti, avvenimenti o personaggi, è alla trasmissione orale che ha affidato l'antico sapere, un sapere forgiato attraverso generazioni, fatto di storie e di fabrilità, di riti e di tecniche, di cerimonialità e consuetudini alimentari. In altri termini quell'universo che contribuisce a ricostruire la storia anche attraverso microstorie collettive e individuali.

La storia, si sa, non consente salti, ma passaggi e i tempi lunghi a volte - segno apparente di società immobili - non sono che il necessario arco temporale per consentire a idee e abitudini di sedimentarsi, e, alla fine del processo assimilativo, divenire retaggio su cui costruire il nuovo, su cui 
operare i cambiamenti, ma in rapporto armonico con i tratti determinanti della tradizione.

Gli oggetti, estensioni dell'io collettivo, sono anch'essi testimoni. Apparentemente silenti, in realtà, raccontano di lunghi percorsi, di incontri di popoli, di necessità economiche e di risposte culturali che ogni comunità si è data. Oggetti plasmati nel corso del tempo che pur tuttavia mantengono l'essenzialità dei tratti, indispensabile a ricostruirne il cammino a ritroso. Ogni oggetto ha sempre una causalità che gli ha consentito di trasmettersi nel tempo e un peso che inciso anche nei rapporti di produzione.

Nella cultura tradizionale non c'e stato mai spazio per il superfluo. Ogni oggetto poteva essere reso più o meno aggraziato, abbellito nelle forme $\mathrm{e}$ nei decori, ma in ogni caso era sempre espressione di una funzionalità finalizzata.

La comunità di Alia, avviata anch'essa a inesorabili cambiamenti, ha sentito l'esigenza di guardare alla propria storia, di riflettere sulle proprie radici per guardare al futuro. Da qui la raccolta di tante "storie" che addensano un teatro di memorie in una magica enciclopedia di messaggi. Queste le ragioni che spiegano la nascita di un museo dei beni etnoantropologici.

Il meseo prende l'avvio da una raccolta di oggetti, ordinati con cura amatoriale da Rosario Di Vitale, a cui va il riconoscimento di averli preservati dalla dispersione. La sua sensibilità ha consentito che giungesse fino a noi un patrimonio di cultura materiale, di oggetti di vita quotidiana, di curiosità sacre e profane destinate all'oblìo della memoria.

Dai comportamenti alle abitudini, infatti, tutto ciò che ci circonda sembra precipitare verso 1'"ormai superato": un'obsolescenza destinata al più a divenire flebile traccia da cui leggere un passato che sembra computato in secoli, tanto è forte il distacco che si è venuto via via a determinare.Testimonianze della cultura di una società che sembrano avviate a non lasciar traccia.

In passato la realizzazione di musei - creati dall'Illuminismo come istituzione pubblica per la conservazione e l'educazione - aveva avviato una visione elitaria e gerarchica della cultura. L'insegnamento della scuola francese delle Annales ha spezzato i vecchi schemi: ogni traccia è utile alla ricostruzione storica e pertanto tutto ciò che fa parte del vissuto è segno: dagli oggetti sacri e profani, ai processi produttivi, alle tecniche, ai modelli di comportamento, alla gestualità che accompagna il fare, alle fogge del vestire, alla memoria orale, ogni tratto costituisce reperto di una storia che non c'è più. Il museo diventa allora mezzo attraverso il quale ogni comunità rappresenta il rapporto con la la propria storia e si traassforma in "emozione storica" da regalare alle generazioni, perché comprendano il lungo cammino che ha segnato la vita di coloro che li hanno preceduti nel tempo.

La realizzazione del museo ha comportato una programmazione di fasi di cui l'allestimento non è stato che il risultato ultimo.

La ricerca e la catalogazione su schede, regolamentate dalle direttive ministeriali e regionali, compilate secondo gli attuali criteri metodologici e scientifici, hanno delineato mestieri, attività o cicli produttivi. Il corredo cromatico, che accompagna ogni scheda, rimanda l'appartenenza dello stesso a una attività, mentre l'immagine fotografica, nel visualizzare la specificità dell'utilizzo, ne chiarisce anche la tipologia. Gli oggetti, infatti, consentono di ricostruire non solo i cicli lavorativi della terra, ma anche i percorsi di vita quotidiana che dalla fucina del fabbro guida alla bottega del ciabattino, del sarto, del barbiere. Strumenti di un sapere antico che è stato patrimonio di generazioni.

Anche se così diversi l'uno dall'altro, i mestieri e le attività sono complementari a una vita sociale ed economica, in un rapporto inscindibile di interazione. È impensabile una comunità basata su attività agraria che non abbia la presenza del fabbro o del falegname.

L'allestimento ha cercato, nell'eseguità degli spazi, di ricostruire ambienti in cui ricreare i tratti di un sapere antico e di sapienti manualità cadute in disuso. Dall'antica arte di forgiare i metalli il percorso guida il visitatore a seguire, nell'alternanza delle stagioni, il lavoro dei campi, nel mito dell'eterno ritorno delle messi, nelle zolle che danno solo se i rituali della fatica umana si ripetono uguali, carichi di una stessa speranza, nei gesti millenari.

Spesso la terra e la pastorizia hanno segnato i confini tra la vita e la morte di intere generazioni. Gli oggetti da lavoro ne narrano la storia: ma per chi quella storia non l'ha conosciuta il significato può essere colto appieno soltanto attraverso il contesto espressivo della forza delle immagini del passato che affiancano l'oggetto disvelandone un racconto. Immagini che svolgono il ruolo preciso e prezioso di documentazione storica, di strumento di conservazione della memoria collettiva. 
Gli oggetti, segni di una gestualità che legava l'uomo agli animali e alla terra, illustrano il lavoro faticoso che le condizioni strutturali e ambientali hanno imposto agli uomini.

Coltelli di diverse forme e grandezze, accanto alla ruota dell'arrotino allineati nell'attesa del loro turno, rimandano nella tipologia alle attività in cui erano impiegati. Nella cucina a maidda con $u$ sbir rione ricorda che il pane e la pasta si faceva una volta alla settimana, $u$ smilature che l'impiego del miele era più diffuso di quello dello zucchero (la presenza romana!), che le lucerne, anche le più umili, aggraziate nelle forme, hanno allietato il buio con luce diversa a seconda dei tempi.

La sequenza tipologica dei ferri degli animali nella bottega del fabbro richiama l'indispensabile fatica animale accanto a quella umana, consumata in silenzi; i misuratori delle tre culture mediterranee per eccellenza, la vita, l'ulivo e il grano rimandano all'economia del territorio. Accanto, disteso in tutta la sua ampiezza, il vecchio scapularu, il mantello del contadino. Compagno inseparabile durante l'inclemenza del tempo invernale, il mantello rappresenta l'abbigliamento tradizionale maschile di primaria importanza, La sua ampiezza a ruota, con cappuccio e colletto alto fino quasi a coprire tutto il volto, era riparo per l'uomo e la sua bestia.

La ricostruzione di spazi con oggetti della vita quotidiana disegnano un universo fatto di essenzialità, aggraziato seppure modesto ma non per questo meno armonico nell'organizzazione: dal letto con la naca (la culla) all'angolo cottura, ai bummuli (contenitori) per l'acqua al telaio. La presenza del telaio lascia intendere il contributo femminile all'economia della casa, contributo non indifferente che l'adagio popolare ricorda nel detto che $u$ tilaru è zapponi, per sottolinearne la fatica e l'introito economico, pari a quello di uno jur natari (un lavoratore a giornata) in campagna.

Spesso il telaio costituiva la dote che la donna portava all'atto del matrimonio, dote arricchita dal corredo che la stessa aveva prima tessuto e poi impreziosito con l'arte del ricamo. Ma il telaio non assolve solo la produzione di stoffe per il corredo: con il telaio si realizzano i tappeti - utili anche durante la barchiatura delle oliveo, in ogni caso nella attività di raccolta - tessuti spesso con la stoffa dei vestiti dimessi. In un mondo dove l'economia era basilare alla sua sussistenza lanche la tessitura lascia leggere il retaggio del passato. Le diverse zone di produzione della Sicilia si differenziano l'una dal- l'altra per caratteristiche proprie. I colori, le tipologie, i disegni, nonché il gioco degli abbinamenti cromatici, infatti, rimandano a mspecificità che nel corso della storia le singole comunità hanno perpetuato. Si pensi, oltre ad Alia, ad esempio, ad Erice, in provincia di Trapani, ad Alcara Li Fusi, in provincia di Messina, dove le losanghe, le strisce, i colori, nell'armonico e ingenuo interrelarsi, marchiano un'identità.

L'universo femminile contadino ha sempre legato la propria attività alla filatura e alla produzione di quanto necessario al fabbisogno familiare. Ecco la ragione per cui fusi, conocchie e navette, nella leggerezza dei disegni e delle forme, trovano spazio nel museo: parlano della capacità di mani callose ad alternare la fatica dei campi con la realizzazione di trine e merletti, spesso destinate ad altre spose.

Le testimonianze dell'impiego delle prime macchine per affiancare la fatica di uomini e donne, lascia intendere il dialogo che tradizione e innovazione hanno avviato anche in centri per certi versi ai margini dei grandi circuiti di comunicazione. Le macchine ormai da tempo costituiscono anch'esse testimonianza per la ricomposizione storica di vicende economiche e sociali. La loro presenza e obsolescenza documentano anch'esse la vita e la storia di una comunità: segnano qui come altrove il cambiamento che passa anche attraverso i primi passi della industrializzazione: documenti di archeologia industriale che segnano il cambiamento, il desiderio di adeguare le tecniche al tempo che passa.

Il Museo non è e non vuole essere contenitore di una raccolta di oggetti ormai caduti in disuso, patinati dal tempo, nè un monumento al lavoro dell'uomo, ma testimonianza della storia di una comunità, di quella comunità, che è passata attraverso quei reperti, materiali segnati da microstorie apparentemente personali. Testimonianze di una cultura senza le cui tracce non si affronta, né si persegue il futuro.

"Quando un popolo non ha il senso vitale del suo passato, si spegne - scriveva Cesare Pavese. La vitalità creatrice è fatta di una riserva di passato. $\mathrm{Si}$ diventa creatori anche noi quando si ha un passato."

I segni del lavoro e della fatica sono parte della identità di ciascuna comunità. Impressi non solo sulle mani, sul viso e sul corpo di intere generazione essi sono documenti su cui costruire anche i grafici sociali dell'andamento della nostra economia. Sono tratti di un tempo che non è passato in- 
vano, nè il vissuto di una storia che si perimetra lontana da noi. La conoscenza e il saper passano anche attraverso quelle vicende. Per molto tempo di quella storia non si è sentito parlare, non valeva la pena parlarne. La vergogna tendeva ad escludere quella che Oscal Lewis definiva "la voglia di cancellare la cultura della povertà". Era una cultura di stenti, di fatica, di povere cose che però davano il senso alla vita.

Un museo, sia che lo si chiami dell'identità o della cultura tradizionale o ancora dei beni etnantropoligici, non disegna mai solo il cerchio precario di una comunità con un'economia essenziale. Se è vero che ogni cosa che appartiene all'uomo finisce sempre per raccontare una storia - non importa quanto grande, non importa quanto semplice - quegli oggetti sussurrano di una cultura, semplice forse, ma tuttavia capace di incidere sulle umane vicende, scandendo i tempi della storia su un vissuto apparentemente sempre uguale.

Il museo etnoantropologico di Alia aveva tra gli obiettivi che si era prefisso quello di corredare gli oggetti in sito con proiezioni a circuito chiuso da cui evincere la fruizione e il contesto lavoratvo degli stessi. Un museo, infatti, dovrebbe avvalersi di tale materiale, perché la conservazione imposta dai rapidi mutamenti suggerisce i criteri di un'antropo logia urgente: preservare non soltanto gli strumenti del passato, gli attrezzi, ogni cosa che valga la pensa musealizzare, ma anche tutto il loro corredo fatto di consequenzialità dei gesti, di posture, di canti, di organizzazione lavorativa.

È questo un intento che proponevano gli studiosi già nei primi anni del secolo scorso, perché era già chiaro, da quei prodromi, il ritmo accelerato che il mutamento avrebbe preso di lì a poco. Un suggerimento che la scuola di Gottingen avrebbe messo in opera verso gli anni Cinquanta, realizzando L'enciclopedia con unità enciclopediche, dove ogni attività umana, nei vari paesi del mondo era stata regolarmente ripresa e sintetizzata in tre minuti: quanto bastava a correlare ogni oggetto esposto nel museo alla sua funzione.

In paesi come il nostro, dove sulla cultura si investe quanto basta per non dimenticare, l'esempio di Alia dovrebbe richiamare altre comunità a fare i conti con la propria storia, non per evidenziare il ritrovamento e la musealizzazione del trecentesimo aratro a chiodo, ma per scoprire le peculiarità locali che nel corso della storia hanno connotato una comunità piuttosto che un'altra. Si pensi ai ricami (Santa Caterina Villermosa, Comiso) o alla lavorazione della ceramica (Bugio, Sciacca, Santo Stefano - Galtagirone lo ha già allestito) o alla realizzazione di campane (Bugio), o ancora alla specificità delle sedie (Bivona con le sedie anche per le ricamatrici), o alla lavorazione della seta (la provincia di Messina).

Anche i primi passi verso l'industrializzazione andrebbero preservati. Si pensi a un'antica cartiera sorta a Borgo Molara vicino Monreale, o a un'altra cartiera realizzata dai baroni Turrisi nei pressi di Castelbuono, Tracce a volte ancora disseminate sul territorio, tal'altra irrimediabilmente fagocitate dalla speculazione edilizia.

La salvaguardia delle identità locali passa anche attraverso un rapporto di interdisciplinarietà tra $\mathrm{i}$ vari interessi culturali che pertengono il territorio.

Un tratto culturale, come ad esempio quello legato alla tessitura di Alia, potrebbe costituire momento di riflessione per la storia e le tecniche di questa antica arte, finalizzata non solo ad un uso didattico, ma anche di comunicazione tra i diversi musei, con una lettura che dalla storia dell'arte abbraccia la storia delle arti minori, la storia economica, l'antropologia.

La produzione differenziata, attuata attraverso modalità e tecniche che segnano le peculiarità di ogni retaggio tradizionale, esita, infatti, in tipologie legate alle diverse lavorazioni: dal feltro, alla tessitura a telaio, nonchè ai capi realizzati a uncinetto o a ferri.

Lo studio comparato e lo scambio di informazioni sulla storia e sulle tecniche di sviluppo della produzione dei tessuti, a seconda delle diverse tradizioni delle zone di produzione, potrebbe costituire prezioso materiale di confronto.

Il progetto - a partire dalla fase di ricerca fino alla diffusione dei risultati ottenuti - nella misura in cui potrebbe essere attivato lo scambio di informazioni, di materiale fotografico e d'archivio attraverso incontri conferenze, dibattiti, produzioni di film e scambi di oggetti e manufatti tra loro interrelati, potrebbe sensibilizzare altri centri.

Dalla realizzazione del progetto potrebbero scaturire esperienze e conoscenze tali da rendere lo stesso progetto "esperimento pilota", pattern del settore per altri musei interessati a questa peculiarità di ricerca. L'interscambio potrebbe avvenire attraverso azioni dimostrative attuate nelle differenti sedi dei patners.

I risultati del progetto potrebbero andare a costituire materiale cartaceo e non CD Room - di- 
dattico e tecnico - video cassette, interscambi con computer vere.

Un'altra storia che andrebbe la pena poter scri-

"Gli oggetti del quotidiano che accompagnano la vita di ogni uomo, pur se umili ricordano la dignità di una storia troppo a lungo considerata minore". (Fernand Braudell)

\section{Bibliografia essenziale}

AA.VV., 1980. Museo e società, Atti del XVII convegno nazionale, Palermo.

AA.VV., Oggetti della civiltà contadina. Per un mu seo laboratorio, Corato s.d.

Wilson D.M. et Alii, 1993. Scienza e crisi del mu seo, (cura di Barbiani L. - Perego F.), Liguori, Napoli.

Eco U. et Alii, 1988. Le isole del tesoro, Electa, Milano. 



\title{
"LE COSE IMPORTANTI DELLA MIA CITT À" UN ESPERIMENTO FOTOGRAFICO PER LA POPOLAZIONE GIOVANILE DEL TERRITORIO DI ALIA
}

\author{
Chiarelli C., TARTARELli G. \\ Museo di Antropologia ed Etnologia. Università degli Studi di Firenze \\ Laboratori di Antropologia - Dipartimento di Biologia animale e Genetica. Università degli Studi di Firenze
}

E-mail: antropos@unifi.it

Nel corso dei laboratori e dell'attività di ricerca e di didattica multidisciplinare che ha visto coinvolta la città di Alia e il suo territorio a partire dal 1996 e i cui risultati sono pubblicati in questo volume, la presenza partecipe e curiosa dei bambini del luogo è stata sempre un elemento costante. Lungi dall'essere un fattore di intralcio o di disturbo, i piccoli gruppi di bambini e di ragazzi che seguivano i ricercatori impegnati nelle loro attività, si sono rivelati anzi un felice e utilissimo veicolo di interazione con la popolazione locale. Per questo motivo, nei coordinatori del progetto scientifico ad un certo momento è sorta quasi spontanea l'esigenza di favorire un maggiore e più diretto coinvolgimento della popolazione giovanile nelle attività di ricerca.

$\mathrm{Si}$ è dunque pensato di proporre una sorta di esperimento visuale, che ha preso la forma di un concorso fotografico sul tema della auto-rappresentazione, dal titolo "Le cose importanti della mia vita. Autoritratto per immagini".

La finalità dell'esperimento era duplice: da una parte quella di ancorare la ricerca al territorio, contribuendo a sensibilizzare e responsabilizzare la popolazione nei confronti del progetto ponendo le basi per la prosecuzione di un dialogo; dall'altra quella di arricchire i dati della ricerca di una documentazione "dall'interno", altrimenti difficilmente reperibile.

È necessario precisare che fin dal momento della stesura del regolamento si è optato per una impostazione metodologica libera e non rigorosa. Le uniche indicazioni riguardavano i limiti di età (615 anni), e la strumentazione, consistente in una macchina "usa e getta" con rullino a colori di 24 pose, fornita direttamente dai proponenti del concorso al momento dell'iscrizione e ritirata dagli stessi al termine della realizzazione del lavoro, e comunque prima che il rullino venisse sviluppato e stampato.

La scelta della macchina usa è getta è stata determinata, oltre che dalla volontà di offrire uno strumento identico per tutti i partecipanti, dalle caratteristiche specifiche del mezzo, che permette di valutare il risultato nella sua sequenza originaria, senza manipolazioni o selezione preventiva da parte degli stessi autori.

Il tema è stato invece lasciato di proposito in termini generici. La speranza degli organizzatori era infatti quella di raccogliere una documentazione più vasta possibile di soggetti e situazioni diverse, una sorta di catalogo visivo degli stimoli cultur rali e sociali della popolazione giovanile di Alia.

Coordinato dalla locale Biblioteca Comunale, il concorso ha riscosso un notevole interesse del quale è solo parzialmente indicativo il numero dei rullini sviluppati e stampati (16), in quanto i partecipanti si sono spesso riuniti in coppia o in piccoli gruppi.

Le immagini riprodotte nelle pagine seguenti rappresentano una selezione del materiale pervenuto. Appare superfluo sottolineare che il criterio adottato per la selezione non ha tenuto conto dell'aspetto estetico-formale quanto della valenza significativa.

Una prima riflessione, che traspare solo parzialmente dalla selezione presentata, è la serietà, pur nella dimensione del gioco, con la quale i partecipanti hanno svolto il tema del concorso. Sebbene nella maggior parte dei casi il medesimo apparecchio sia stato utilizzato da più partecipanti, oppure più gruppi di bambini abbiano percorso insieme i medesimi luoghi e situazioni e quindi non sia possibile attribuire i risultati a personalità individuali, il risultato complessivo risponde pienamente agli obiettivi proposti, offrendo uno sguardo tutt'altro che banale e monocorde, e anzi molto ben articolato della realtà aliese.

Questa impressione è confermata anche a livello dei singoli rullini. Nella sequenza originale degli scatti, ogni lavoro comprende una progressione calcolata di soggetti, che risponde all'insieme dei 
luoghi, delle persone e delle situazioni importanti della vita e del contesto sociale dei partecipanti. E se in alcuni casi vi è una maggiore insistenza su di un singolo soggetto, come nel caso dell'allevamento di bestiame o di quello degli struzzi, oppure nella sequenza sul mercato (Tavola VII), questo fatto appare piuttosto il risultato di una scelta ponderata e consapevole, una sorta di "reportage" di documentazione su alcuni aspetti che hanno particolarmente incuriosito gli autori.

Venendo ora ai soggetti più frequenti, nella tavole che seguono essi sono stati accorpati entro alcune categorie tipologiche.

Nella quasi totalità dei casi, i partecipanti hanno ritenuto di documentare il territorio. Le immagini aventi per soggetto vedute o dettagli di un luogo o un edificio sono in totale 216 . Tra di esse prevalgono le vedute della città (121; cfr. Tavola I), rappresentata nei suoi luoghi salienti (monumenti, piazze), come pure in semplici scorci stradali o angoli privati. E' possibile notare inoltre un'attenzione particolare per gli arredi e gli abbellimenti urbanistici recenti, segnale di un generale apprezzamento estetico. Generalmente però manca in queste riprese uno sguardo selettivo. Fa eccezione un partecipante, che utilizza l'intero rullino per effettuare una campionatura "sistematica" del patrimonio artistico locale urbano ma anche rurale, andando a cercare anche luoghi apparentemente abbandonati.

La campagna è altrettanto rappresentata (95; cfr. Tavola II), anche se quasi sempre in vedute panoramiche che comprendono la città. Solo quando la campagna diventa il soggetto privilegiato del partecipante si hanno rappresentazioni più vissute, nelle quali, oltre alla documentazione dello spazio fisico è presente una attenzione per le attività contadine e produttive.

Gli interni delle abitazioni sono invece estremamente rari (Tavola V). Le sole tre immagini nelle quali gli ambienti domestici siano soggetto principale e non solo di contesto per una ambientazione familiare (ritratti di genitori o parenti), rappresentano una cucina (apparentemente nuova) con una televisione accesa, un locale non identificato con un crocifisso, un deposito con un lettino accanto a un trattore. Naturalmente parte di questa carenza è dovuta a limiti tecnici (il funzionamento del flash), ma non è da escludere un certo pudore dei partecipanti nel rappresentare una dimensione così privata.

Le fotografie che ritraggono persone (autoritratti, parenti, amici, per un totale di 32 scatti; Ta- vole III e IV), pur non molto numerose, sono quelle nelle quali si coglie un coinvolgimento più profondo che si riflette sugli esiti spesso felici anche da un punto di vista estetico-formale.

A questa categoria di immagini appartengono gli auto-ritratti dei protagonisti. Da soli o in piccoli gruppi, i partecipanti indulgono volentieri nella auto-rappresentazione, facendosi ritrarre in un contesto domestico, oppure cittadino. In proposito è interessante notare la sequenza riprodotta nella Tavola III, nella quale gli stessi protagonisti prima si fanno fotografare in gruppo e poi ciascuno per sé, sottolineando nelle pose e nelle espressioni una dimensione al contempo ludica e rigorosa.

La tavola IV riproduce alcuni ritratti di componenti del nucleo familiare. Da un punto di vista quantitativo, sebbene in questo caso le informazioni sul grado di parentela possono risultare inesatte, è interessante notare la netta prevalenza di immagini di coetanei (fratelli, cugini, etc.); all'opposto è da segnalare la pressoché totale assenza di ritratti paterni; le madri sono un po' più rappresentate, mentre con maggiore frequenza sono ritratti i componenti anziani.

Come si è già detto, solo in alcuni casi è possibile evidenziare un percorso individuale focalizzato su di un tema specifico di approfondimento. Tra questi ci è sembrato utile proporre tre esempi (Tavola VII), dei quali il primo è particolarmente significativo in quanto documenta, attraverso immagini realizzate in un mercato e in diversi nego$\mathrm{zi}$, la dimensione del commercio, che viene addirittura sottolineata da una insolita inquadratura di un mazzo di banconote.

$$
* * *
$$

Al di là del valore e della consistenza numerica del materiale, il risultato dell'esperimento appare stimolante per ulteriori approfondimenti. Quello che nasceva come un saggio collaterale alle ricerche in corso si delinea ora come una direttiva di ricerca ben caratterizzata ed estremamente promettente. Il materiale raccolto si presta a rappresentare il primo nucleo di un ipotetico archivio visivo del territorio aliese. D'altra parte, una auspicabile riproposizione periodica della medesima iniziativa e il suo allargamento ad altri comuni della regione siciliana, permetterà di "monitorare" su scala temporale e territoriale, i riflessi sulla comunità giovanile dei cambiamenti socioculturali in atto. Finalità che il costituendo "Museo Archivio per la Fotografia della Sicilia e del Mediterraneo" della città di Alia dovrebbe porre come prioritaria della sua attività istituzionale. 


\section{TAVOLE}

I. Il territorio: la città

II. Il territorio: la campagna

III. L'uomo: autoritratti

IV. L'uomo: il nucleo familiare

V. Interni domestici

VI. Aspetti del lavoro

VII. Approfondimenti (il commercio, l'allevamento di struzzi, l'allevamento tradizionale)

Nota:

Data la natura collettiva del progetto le singole immagini non riportano il nome degli autori. Si è ritenuto invece doveroso trascrivere qui di seguito l'elenco completo dei partecipanti:

Davide Calà, Antonino Cannata, Orazio Cannata, Simone Cimento, Vincenzo Cimò, Giuseppe Colletto, Mario Faro, Paola Faro, Matteo Ferrara, Angelo Fricano, Anthony Gabiino, Mario Gangi, Salvatore Inguaggiato, Grazia Mezzatesta, Roberto Minnuto, Salvatore Pagnotta, Luigi Pinnisi, Salvatore Porretto, Antonino Riili, Luciano Sangiorgi, Carmelo Scaccia, Giulia Siragusa, Alessandro Valenza, Antonino Valenza, Emanuela Vicari, Giuseppe Vicari. 
Tavola I - Il territorio: la città
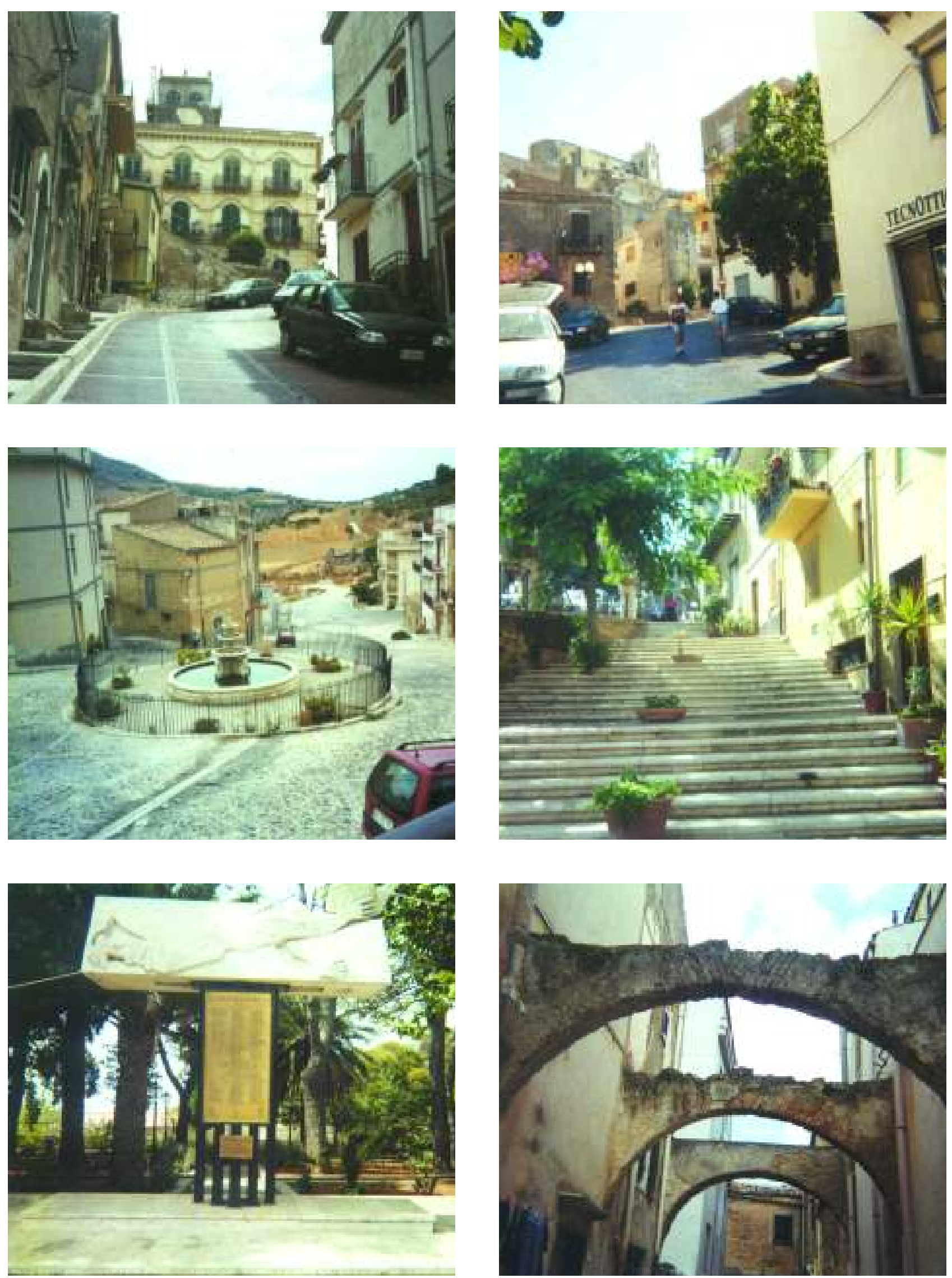
Tavola II - Il territorio: la campagna
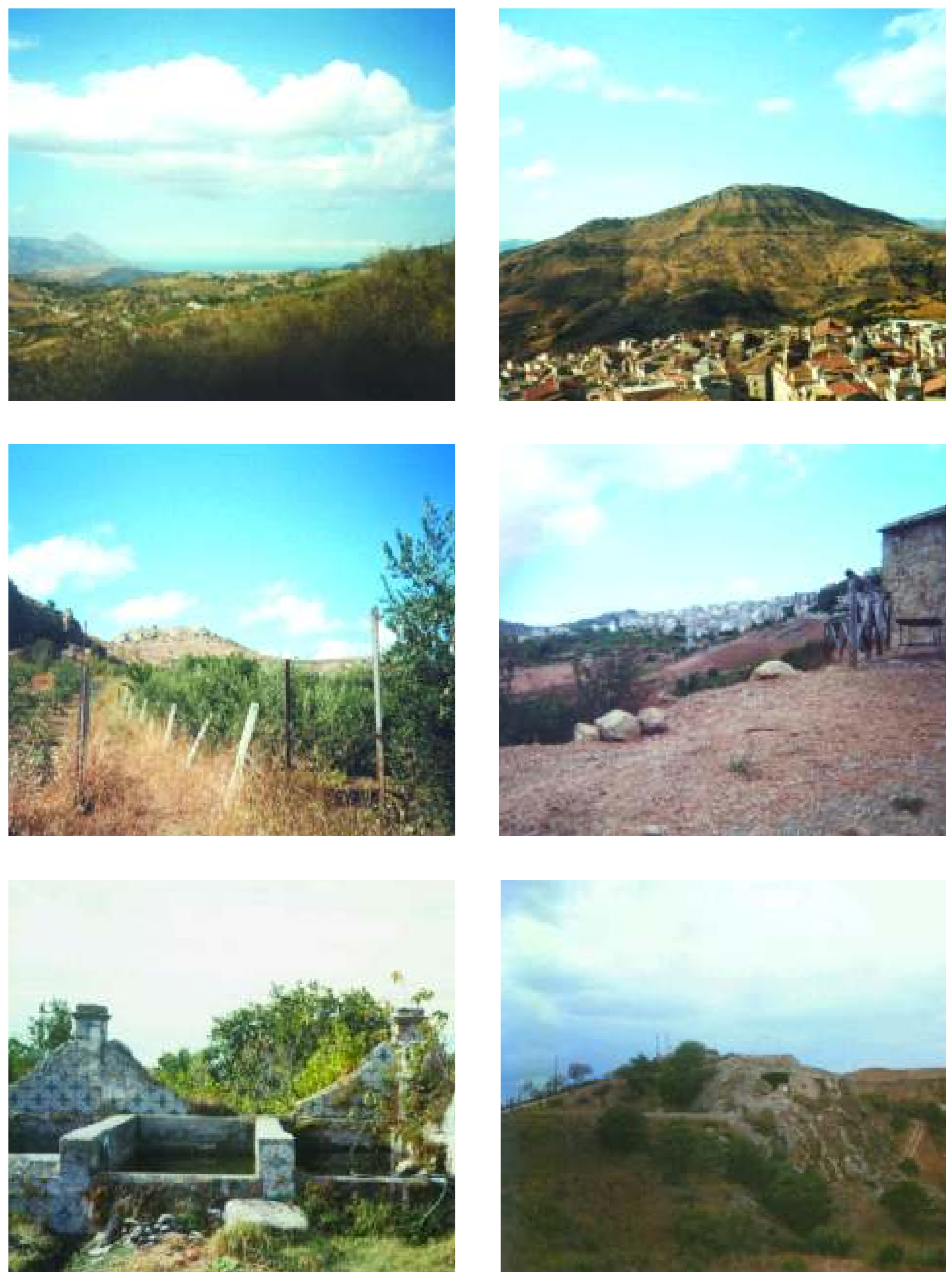
Tavola III - L'uomo: autoritratti
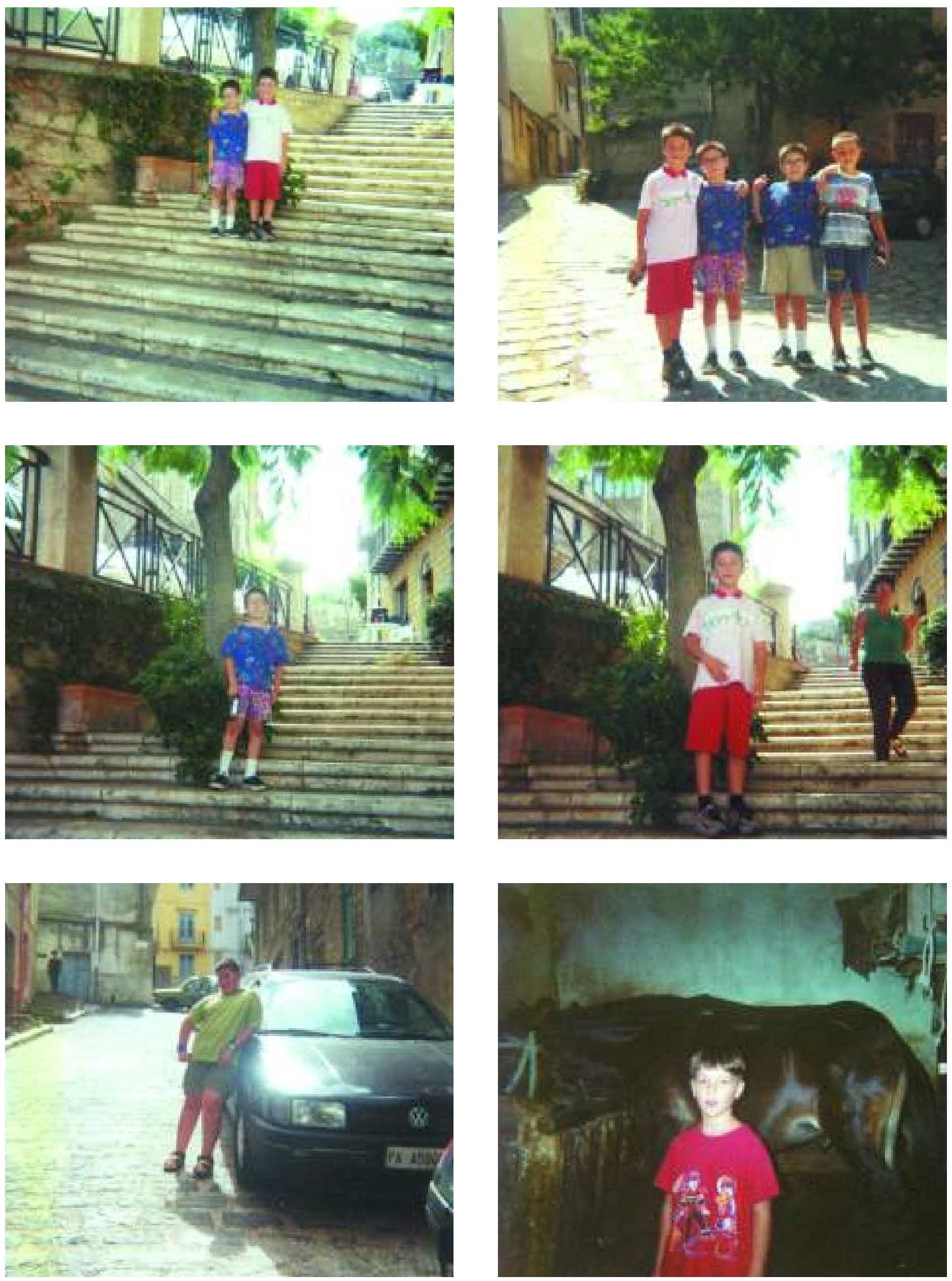
Tavola IV - L'uomo: il nucleo familiare
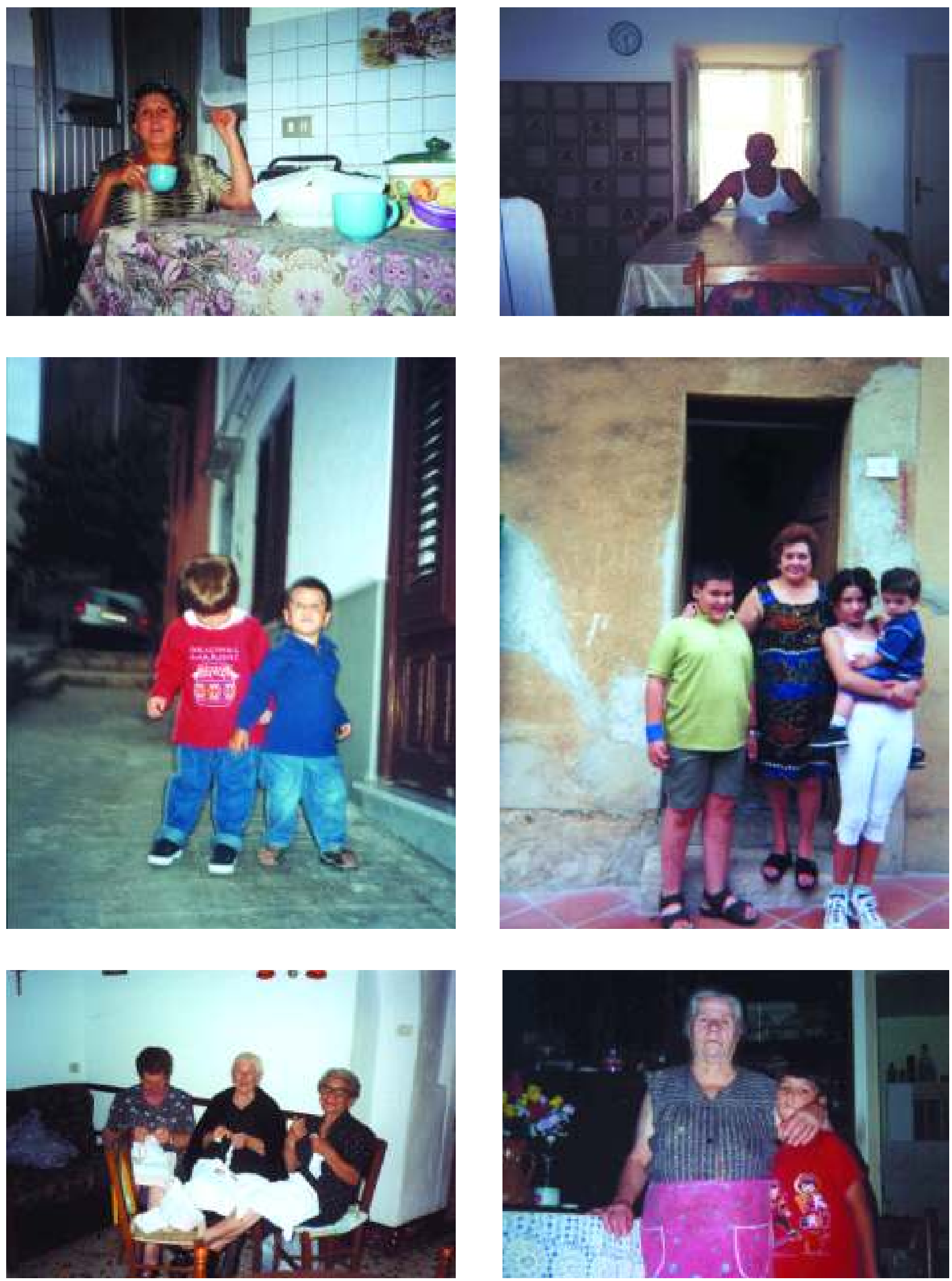
Tavola V - Interni domestici
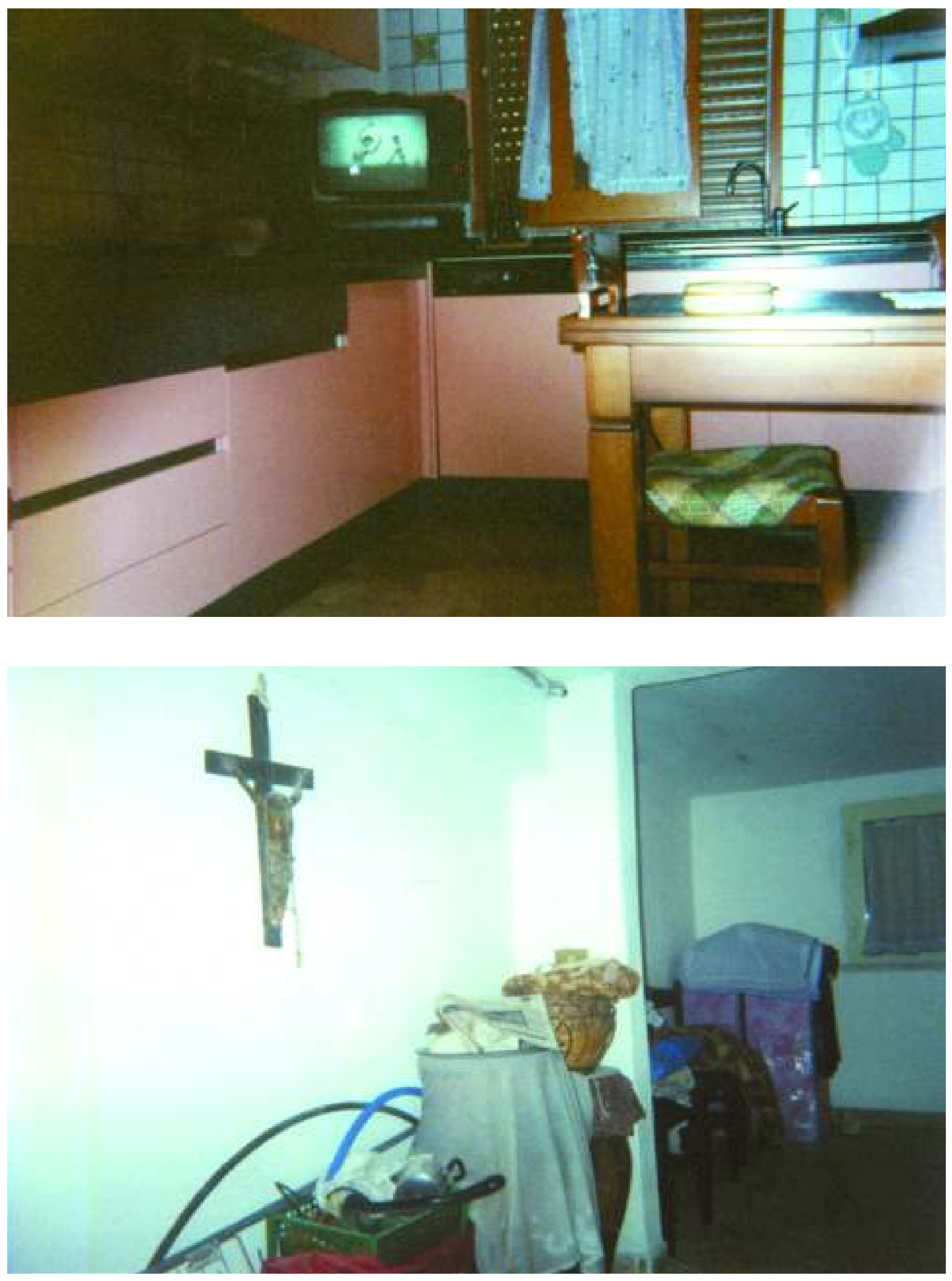
Tavola VI - Aspetti del lavoro
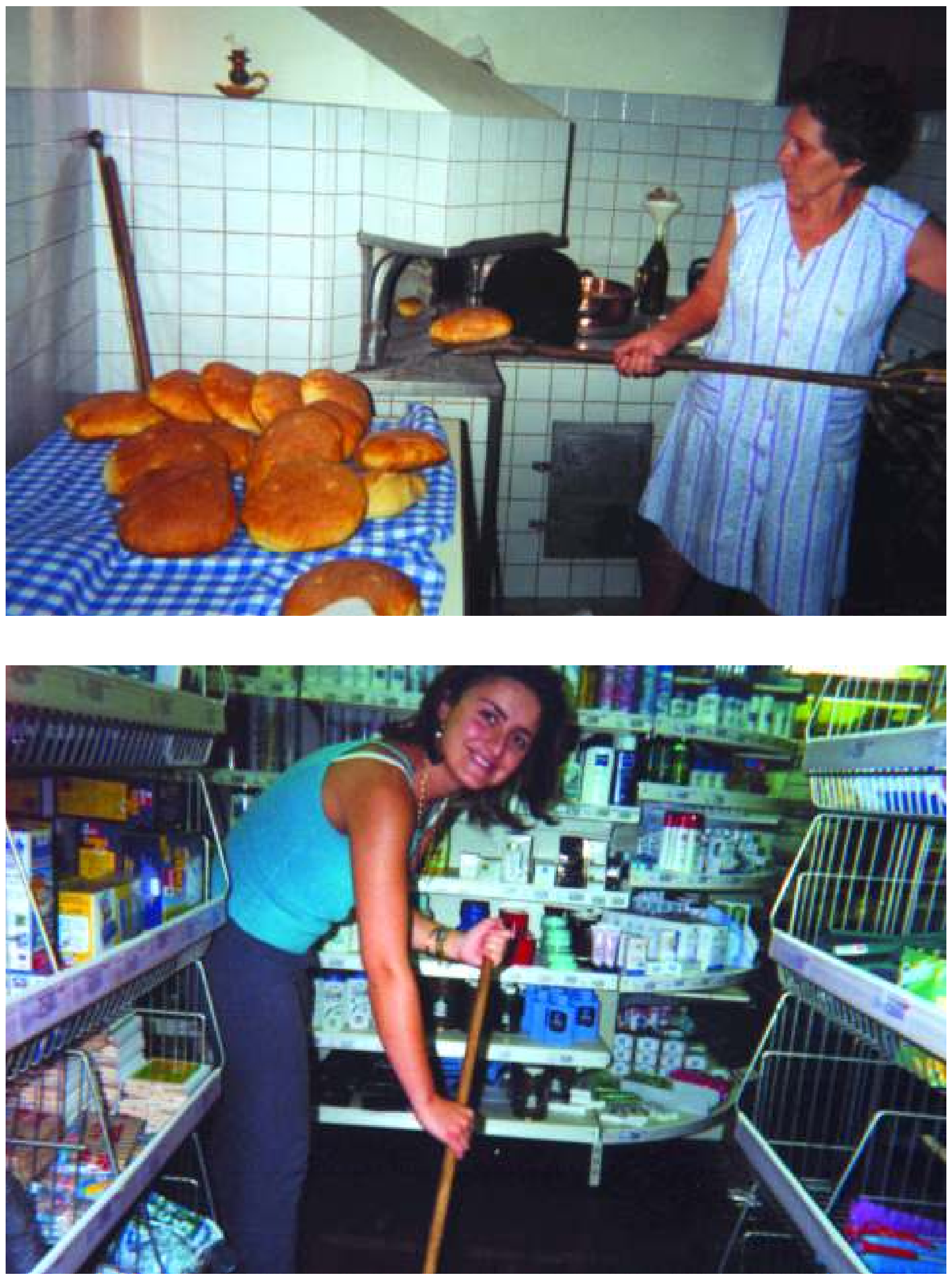
Tavola VII - Approfondimenti (1)
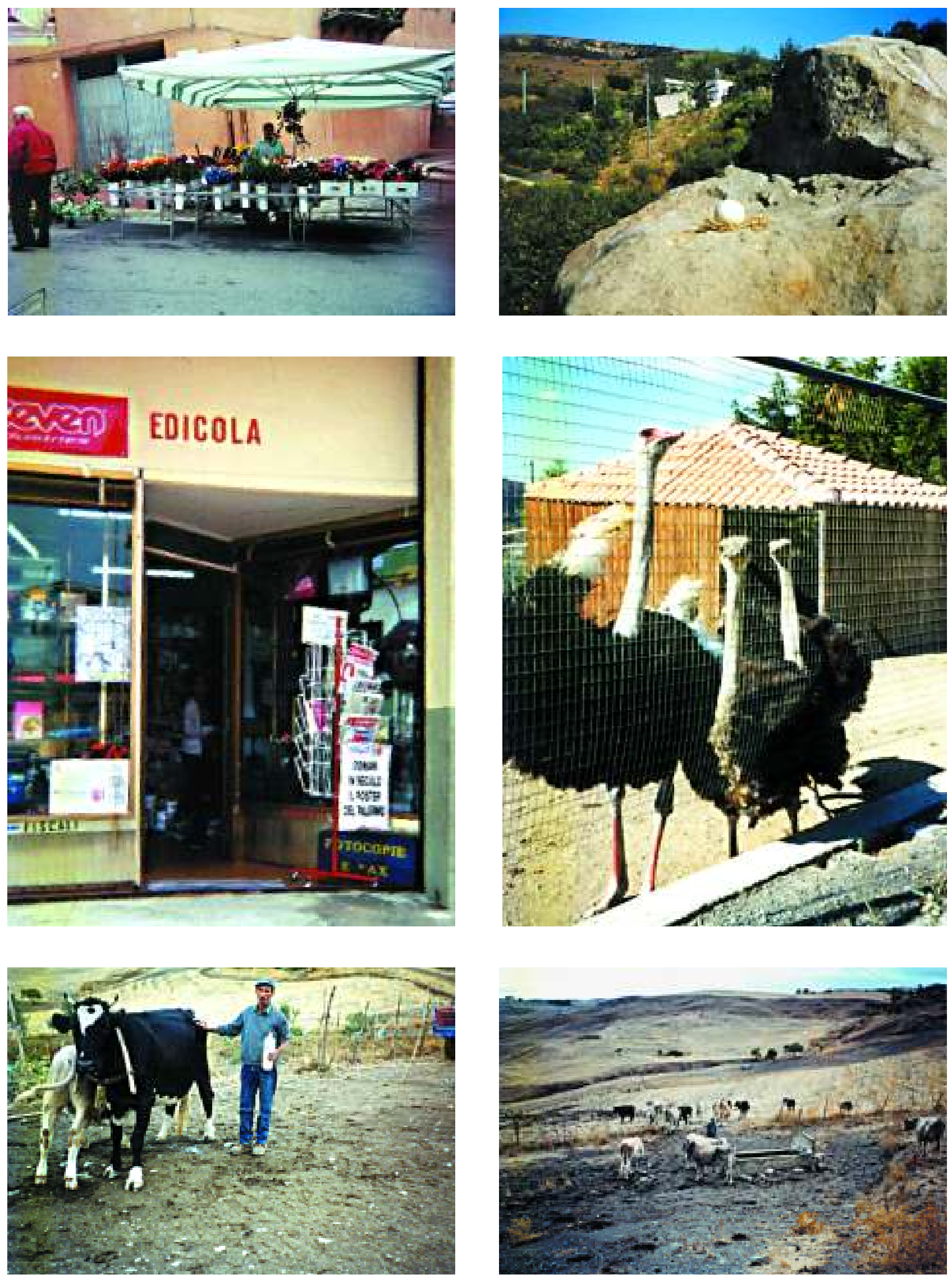
Tavola VII - Approfondimenti (2)
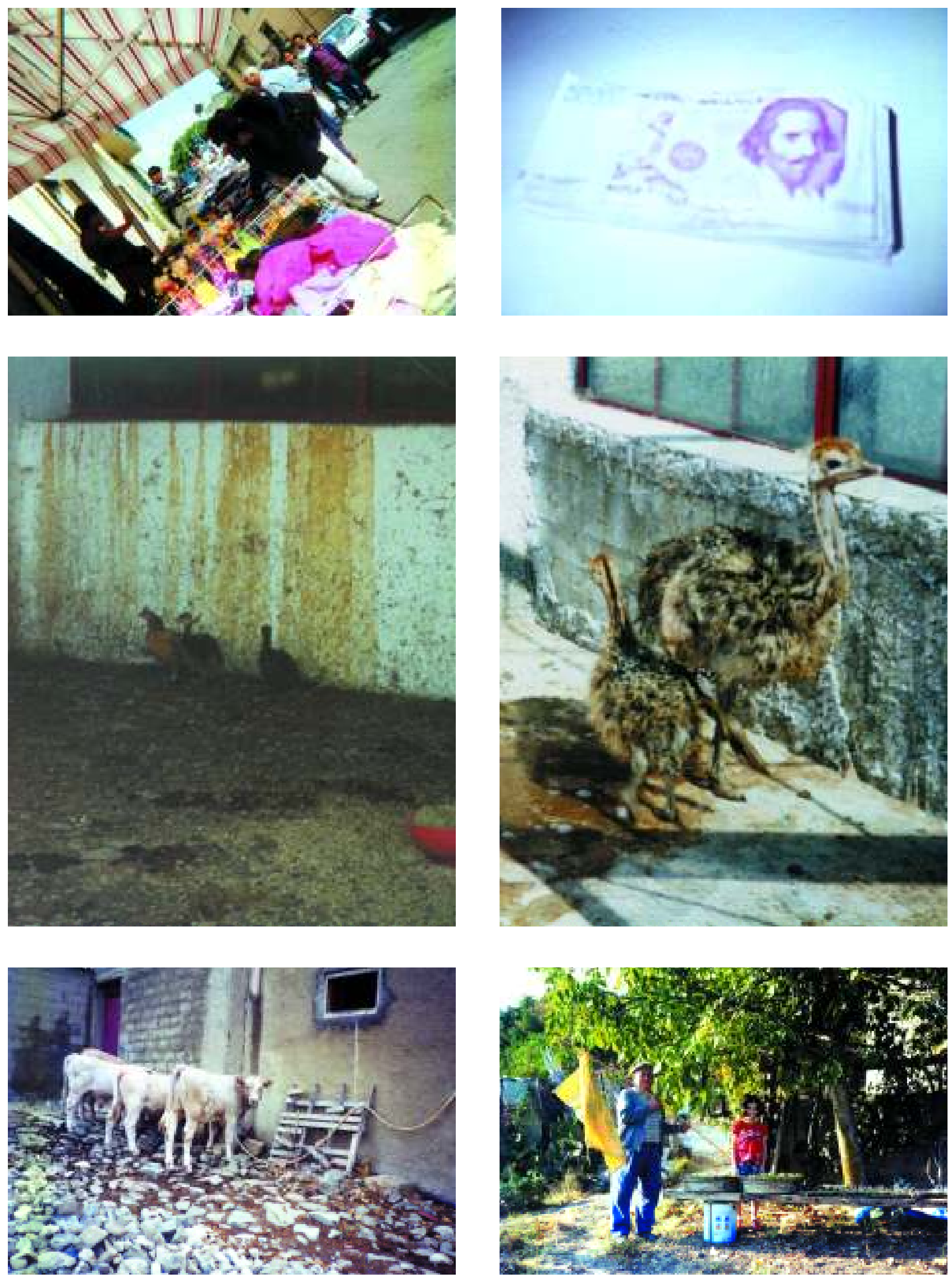



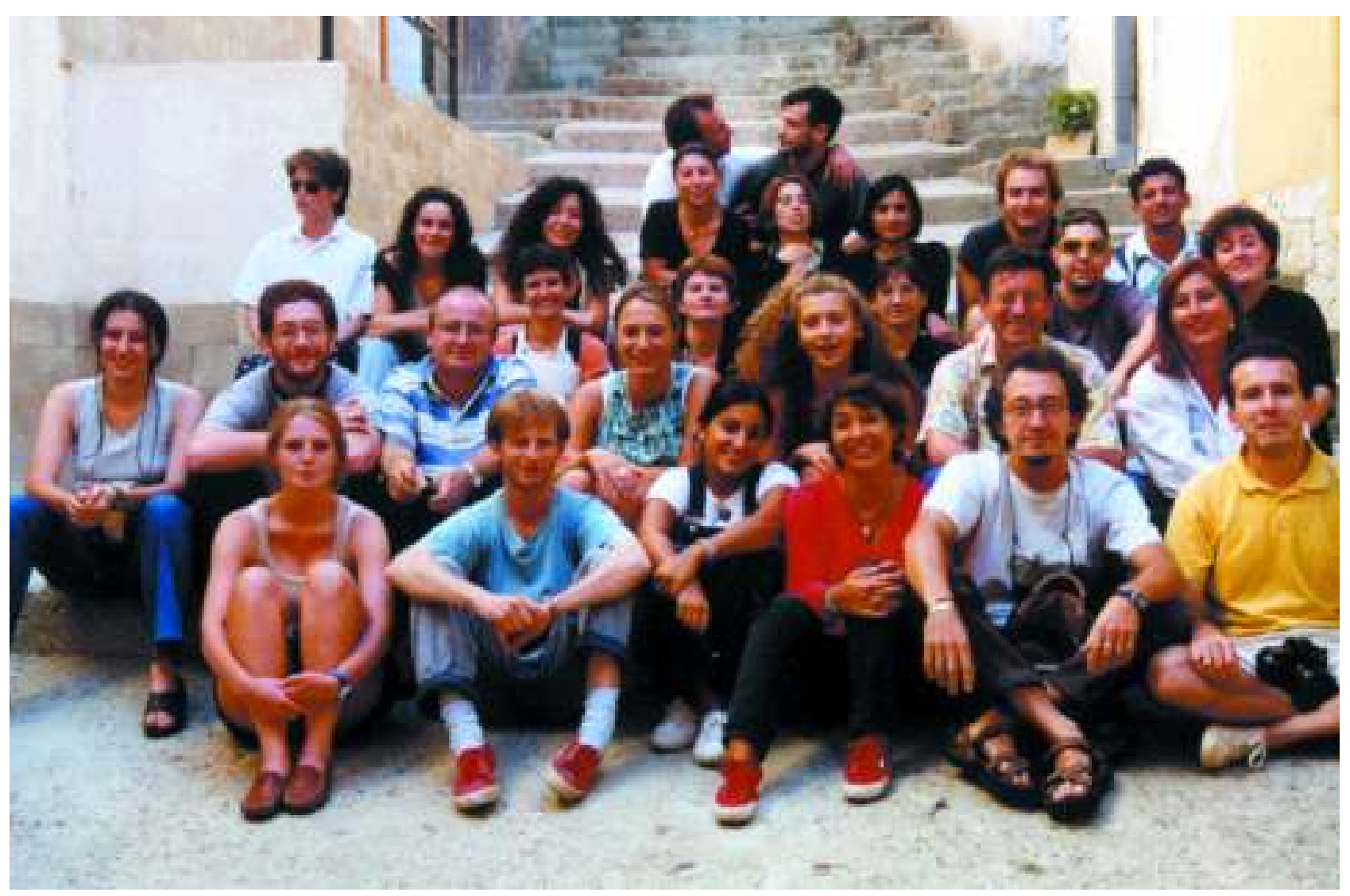

I partecipanti ad una sessione del Campo Scuola di Alia (1997). 



\section{DOCENTI DEI CAMPI SCUOLA DI ALIA \\ (1996-2000)}

Agnesi Valerio - Università di Palermo

Becker Marshall J. - Università della Pennsylvania

Bigazzi Renzo - Università di Firenze

Bove Annalisa - Università di Pisa

Bramanti Barbara - Università di Firenze

Cedrini Rita - Università di Palermo

Cerutti Nicoletta - Università di Torino

Chiarelli Brunetto - Università di Firenze

Cognetti Goffredo - Università di Palermo

Crisafulli Rachel - Università di Firenze

D'Amore Giuseppe - Università di Firenze

De Iasio Sergio - Università di Parma

Francalacci Paolo - Università di Sassari

Herrmann Bernd - Università di Göttingen

Iandelli Francesca - Università di Firenze

Lazzerini Luca - Università di Firenze

Lucchetti Enzo - Università di Parma

Masseti Marco - Università di Firenze

Meaglia Donatella - Università di Torino

Porcella Paola - Università di Cagliari

Rabino Massa Emma - Università di Torino

Raimondo Francesco Maria - Università di Palermo

Sarà Maurizio -- Università di Palermo

Scalfari Francesco - Università di Torino

Sineo Luca - Università di Palermo

Tartarelli Giandonato - Università di Firenze

Vernesi Cristiano - Università di Firenze

Vona Giuseppe - Università di Cagliari 



\section{EVENTI CORRELATI CON LE RICERCHE ANTROPOLOGICHE IN CORSO AD ALIA}

1995

- Sopralluogo del dott. G. D'Amore alla Grotta del "Cimitero Vecchio" e primo inventario del materiale osteologico umano ivi rinvenuto (settembre).

1996

- Inizio dello studio del materiale da parte dei dottori R. Bigazzi, R. Crisafulli, F. Iandelli, L.V. Lazzerini e G. Tartarelli (10 - 18 giugno, 22 luglio - 4 agosto);

- Campo Scuola di Antropologia ad Alia (22 luglio - 4 agosto), coordinato dalla dott. C. Di Gaetano;

- Conferenze estive in Piazza Garibaldi dei seguenti relatori: V. Agnesi, B. Chiarelli, R. Cedrini, G. Cognetti, F. M. Raimondo, M. Sarà;

- Riordino dell'Archivio Storico comunale di Alia, coordinato dal dott. R. Bigazzi;

- Mostra "Antropologia ad Alia: uno studio multidisciplinare", curata dal dott. R. Bigazzi, presso 1'Orto Botanico di Palermo (15 dicembre 1996 - 12 gennaio 1997) e quindi a Firenze presso l'Istituto di Antropologia.

1997

- Campo Scuola di Antropologia (15 luglio - 8 settembre), coordinato dal dott. R. Bigazzi;

- Conferenze estive in Piazza Garibaldi dei seguenti relatori: B. Chiarelli, R. Cedrini, L. Sineo;

- Realizzazione del Museo Didattico di Antropologia e del Giardino Botanico di specie endemiche, allestiti da G. Saladino, L. Zanca e M. Sarà, curata per la parte archeologica e antropologica da R. Bigazzi, A. Bove, L. V. Lazzerini, , G. Tartarelli, presso la Grotta del "Cimitero Vecchio";

- Realizzazione del Museo Etno-Antropologico, curata dalla prof. R. Cedrini.

- XII Congresso degli Antropologi Italiani (Palermo, Alia, 16-20 settembre).

\section{8}

- Campo Scuola di Antropologia (24 agosto - 6 settembre), coordinato dal dott. R. Bigazzi.

\section{9}

- Conferenze estive in Piazza Garibaldi dei seguenti relatori: M. J. Becker, B. Bramanti, B. Chiarelli, G. D'Amore, M. Ernandez, B. Herrmann, E. Lucchetti, M. Masseti, L. Sineo, G. Vona.

2000

- Campo Scuola di Antropologia, coordinato dalla dott. S. Tulumello. 
Pubblicato nell'anno 2002 